UNIVERSIDADE DE SÃO PAULO

FACULDADE DE FILOSOFIA, CIÊNCIAS E LETRAS DE RIBEIRÃO PRETO

DEPARTAMENTO DE PSICOLOGIA E EDUCAÇÃO

PROGRAMA DE PÓS-GRADUAÇÃO EM PSICOBIOLOGIA

\title{
Avaliação da atividade neuroprotetora da Parawixina 11 isolada da peçonha da aranha Parawixia bistriata (Araneae, Araneidae), em ratos Wistar submetidos a um modelo de glaucoma agudo.
}

\section{Marcela Nunes Rosa}

Dissertação apresentada à Faculdade de Filosofia, Ciências e Letras de Ribeirão Preto, da Universidade de São Paulo, como parte das exigências para a obtenção do título de Mestre em

Ciências. Área de concentração: Psicobiologia 


$$
\text { UNIVERSIDADE DE SÃO PAULO }
$$

FACULDADE DE FILOSOFIA, CIÊNCIAS E LETRAS DE RIBEIRÃO PRETO DEPARTAMENTO DE PSICOLOGIA E EDUCAÇÃO PROGRAMA DE PÓS-GRADUAÇÃO EM PSICOBIOLOGIA

\section{Avaliação da atividade neuroprotetora da Parawixina 11 isolada da peçonha da aranha Parawixia bistriata (Araneae, Araneidae), em ratos Wistar submetidos a um modelo de glaucoma agudo.}

Marcela Nunes Rosa

Dissertação apresentada à Faculdade de Filosofia, Ciências e Letras de Ribeirão Preto, da Universidade de São Paulo, como parte das exigências para a obtenção do título de Mestre em Ciências. Área de concentração: Psicobiologia 


$$
\text { UNIVERSIDADE DE SÃO PAULO }
$$

FACULDADE DE FILOSOFIA, CIÊNCIAS E LETRAS DE RIBEIRÃO PRETO DEPARTAMENTO DE PSICOLOGIA E EDUCAÇÃO PROGRAMA DE PÓS-GRADUAÇÃO EM PSICOBIOLOGIA

\title{
Avaliação da atividade neuroprotetora da Parawixina 11 isolada da peçonha da aranha Parawixia bistriata (Araneae, Araneidae), em ratos Wistar submetidos a um modelo de glaucoma agudo.
}

\author{
Versão corrigida
}

Marcela Nunes Rosa

Dissertação apresentada à Faculdade de Filosofia, Ciências e Letras de Ribeirão Preto, da Universidade de São Paulo, como parte das exigências para a obtenção do título de Mestre em Ciências. Área de concentração: Psicobiologia

Orientador: Prof. Dr. Wagner Ferreira dos Santos -

Departamento de Biologia 


\section{Ficha Catalográfica}

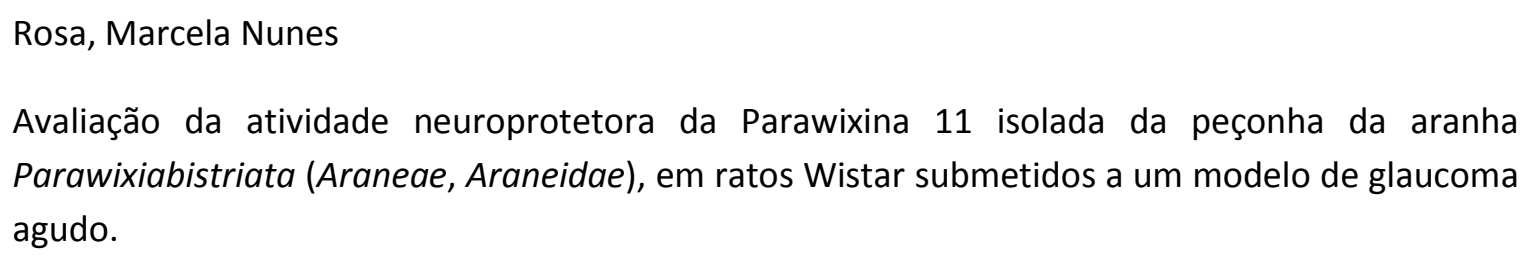
agudo.

Ribeirão Preto, 2012.

106p. : $30 \mathrm{~cm}$

Dissertação de Mestrado apresentada à Faculdade de Filosofia, Ciências e Letras de Ribeirão Preto da Universidade de São Paulo.

Orientador: dos Santos, Wagner Ferreira.

1-Isquemia; 2-Reperfusão; 3-Parawixia bistriata; 4- Neuroproteção; 5-Retina; 6- Glaucoma experimental 
Dedicatória

À minha mãe Isabel Aparecida Nunes pelo exemplo de vida, superação, serenidade e amor. 


\section{AGRADECIMENTOS}

Ao Prof. Dr. Wagner Ferreira dos Santos (Departamento de Biologia, FFCLRPUSP) pela disposição com que me recebeu e com que recebe os alunos que entram em contato com o laboratório. Não me esquecerei que um simples e-mail, perguntando se era possível eu realizar um estágio no laboratório, fez com que um mundo de possibilidades, descobertas e desafios se abrisse para mim, através da oportunidade que você me proporcionou. Agradeço por sua orientação.

Ao Prof. Dr. Renato Guizzo pelo ensinamento sobre a realização de imunofluorescência em retinas de coelho, atividade esta que me levou a optar pelo trabalho com retinas. Também agradeço pelos ensinamentos de algumas etapas metodológicas do glaucoma experimental agudo em ratos.

À Prof. ${ }^{a}$ M. ${ }^{\text {a }}$ Juliana Rosa Tostes, pelos ensinamentos sobre a metodologia do glaucoma experimental agudo.

Ao Sr. Amaury R. Pinhal pelo auxílio técnico em histologia.

Ao meu assessor Prof. Dr. Marcelo Cairrão Araujo Rodrigues (Departamento de Fisiologia e Farmacologia, Centro de Ciências Biológicas - UFPE), pelas excelentes observações e importantes sugestões durante as correções dos relatórios.

Aos Profs. Drs. Rodrigo Jorge (FMRP-USP) e Rubens Camargo Siqueira (FMRP-USP) pela oportunidade de estabelecer colaboração no projeto de descolamento de retina em coelhos, aperfeiçoando minha técnica histológica.

À Prof. ${ }^{a}$ Dr. ${ }^{a}$ Márcia Renata Mortari (UnB) e aos Profs. Drs. da FCFRP-USP, Leonardo Gobbo Neto e Norberto Peporine Lopes pelo fornecimento e isolamento das frações da Parawixina 11.

Ao Prof. Dr. Antônio Haddad e à técnica Sra. Vani Maria Alves Corrêa (Departamento de Biologia Celular e Molecular e Bioagentes Patogênicos, FMRPUSP), pelo esclarecimento de dúvidas sobre histologia e processamento de material.

Aos coordenadores do Programa de Pós-Graduação da Psicobiologia, Profs. Drs. Marcus Lira Brandão e José Lino Oliveira Bueno (atual).

À secretária do Programa Sra. Renata Beatriz Vicentini Del Moro pelos avisos sobre datas, documentações e entregas de relatório.

Aos funcionários do Biotério Central (PCARP-USP) e à bioterista Sra. Thalita A. R. P. Gonçalves, pelo cuidado e tratamento dos animais utilizados nesta pesquisa. 
Aos colegas que estão ou já passaram pelo Laboratório de Neurobiologia e Peçonhas (Depto. de Biologia, FFCLRP-USP): Lucas, Thalita, Lívea, Ricardo (Pseudo), Juzinha, Karina e André pelas conversas e por momentos de descontração. À Adriana, Zé, Matheus e Helene por conversas sobre assuntos teóricos e práticos, esclarecimentos e sugestões e, em especial, à Marcelí, Adriana, Helene e Bruninha pela amizade no "lab nosso de cada dia".

À CAPES/PROEX pela bolsa de mestrado e apoio financeiro e à FAPESP, também pelo apoio financeiro.

Aos professores e demais funcionários com quem tive contato e que, de alguma forma, contribuíram para este trabalho.

Aos meus amigos e familiares (incluindo a família Malanga e Wilson!) que não me deixam esquecer daquilo que realmente importa na vida.

Aos meus pais Isabel Aparecida Nunes e Paulo Roberto Rosa, aos meus irmãos Igor Nunes Rosa e Juliana Nunes Rosa e ao meu namorado Paulo Wilson Gomes da Silva Jr. pelo apoio, ombro amigo, carinho e torcida, mesmo que, às vezes, de longe.

A Deus, que sempre me guarda, tanto nas conquistas quanto nos momentos difíceis.

Aos animais utilizados neste trabalho, sem os quais não teríamos os avanços científicos atuais e futuros. 
"Cada um de nós é, na realidade, uma idéia, uma idéia ilimitada de liberdade. Você tem a liberdade de ser você mesmo, de ser o seu próprio eu, aqui e agora, e não há nada que possa interpor-se no seu caminho."

Richard Bach (do livro Fernão Capelo Gaivota).

"Às vezes é um erro subir, mas é sempre um erro nunca tentar. Se você não subir, não vai cair,a verdade é essa; mas será tão ruim assim fracassar? Tão duro cair? Às vezes, você desperta... outras, sim,você morre; mas há uma terceira alternativa: você voa!"

Neil Gaiman (das histórias de Sandman). 


\section{ÍNDICE}

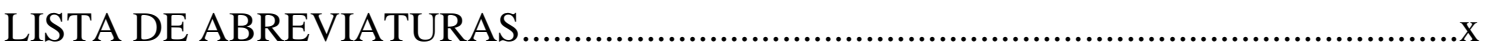

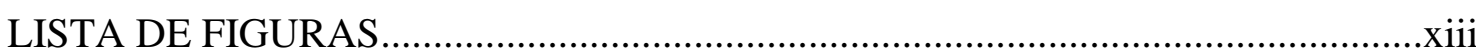

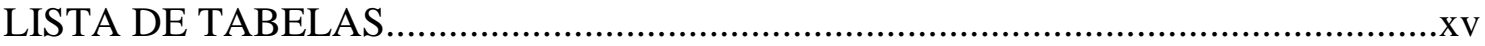

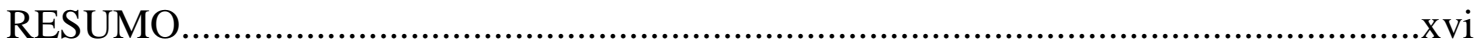

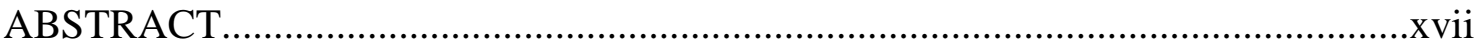

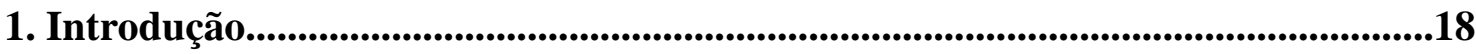

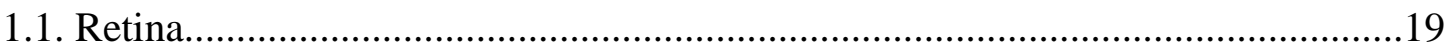

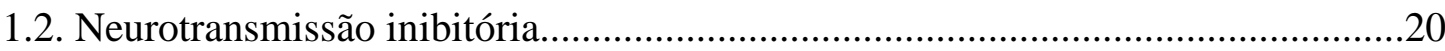

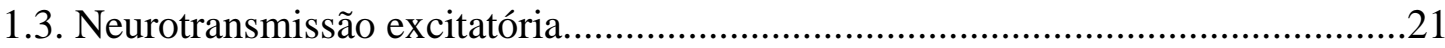

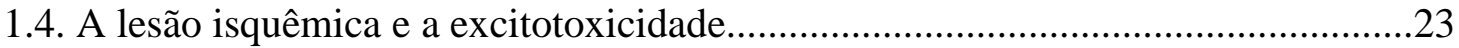

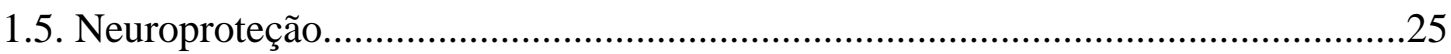

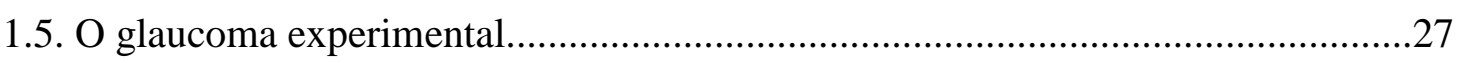

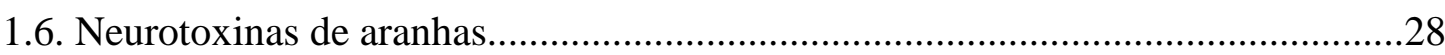

1.7. A aranha Prawixia bistriata (Araneae: Araneidae).............................................29

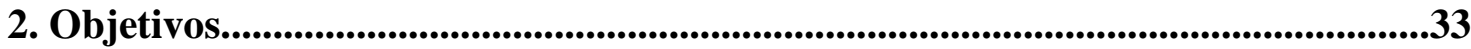

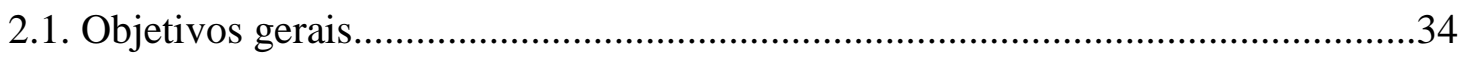

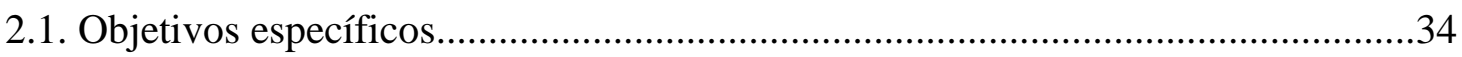

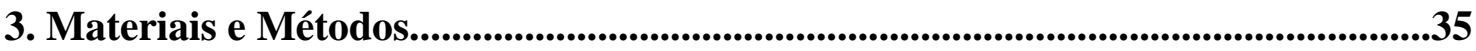

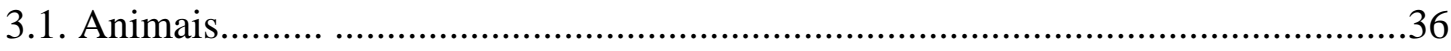

3.2. Coleta das aranhas e extração das glândulas..........................................................36

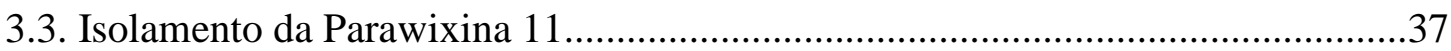

3.4. Cirurgia: glaucoma experimental agudo - isquemia/reperfusão............................38

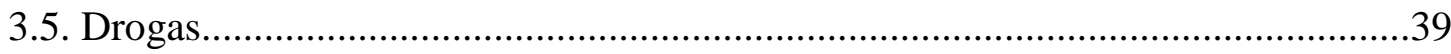




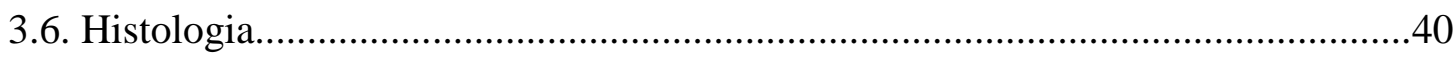

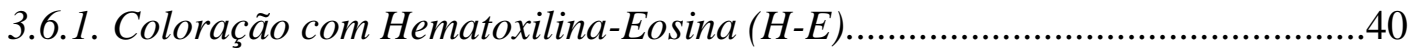

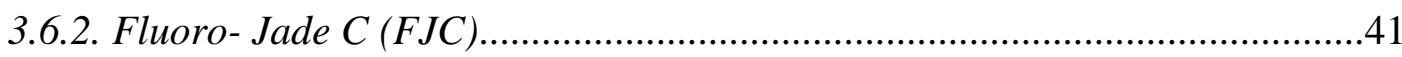

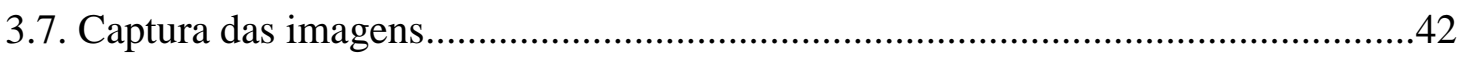

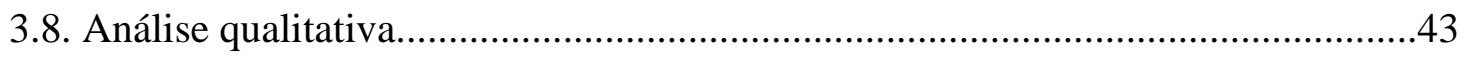

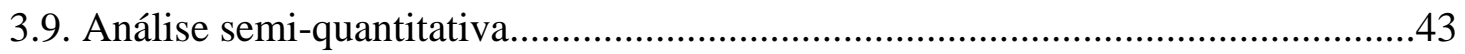

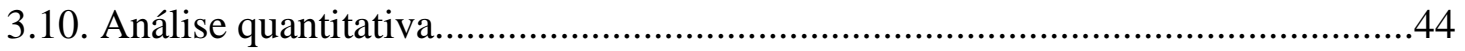

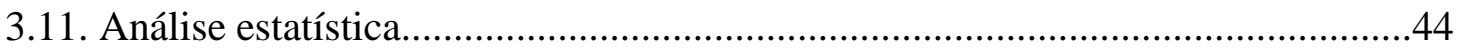

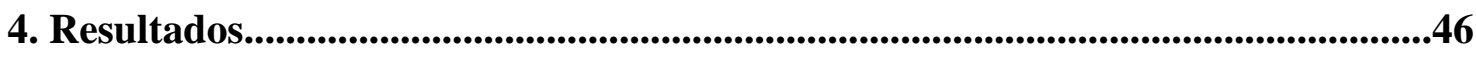

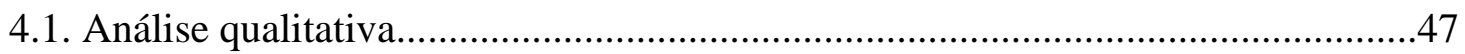

4.1.1. Retinas submetidas à ISQ e ISQ/REP após injeção de veículos....................47

4.1.2. Retinas tratadas submetidas à isquemia e isquemia/reperfusão....................48

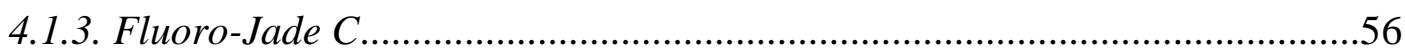

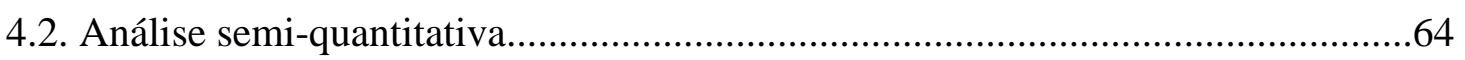

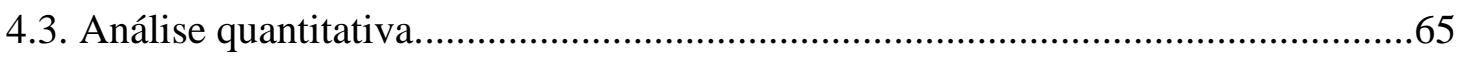

4.3.1. Retinas submetidas à isquemia...................................................................65

4.3.2. Retinas submetidas à isquemia/reperfusão.................................................71

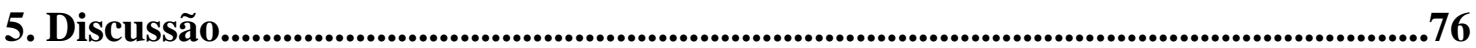

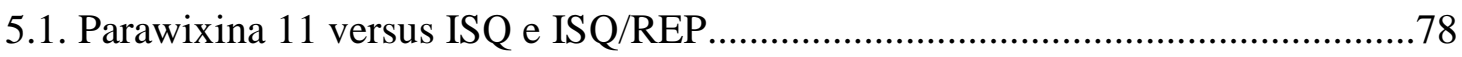

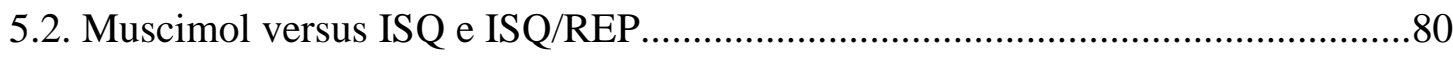

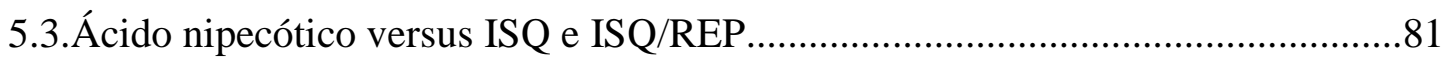

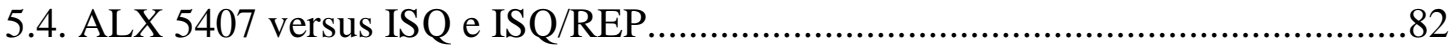

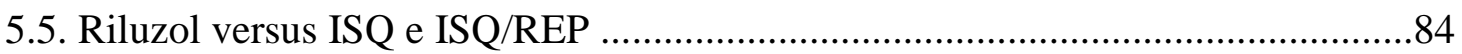

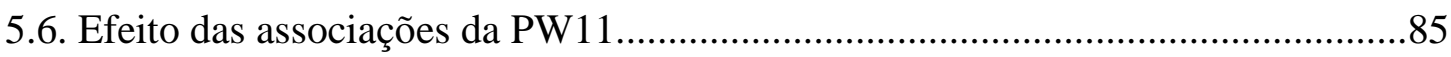

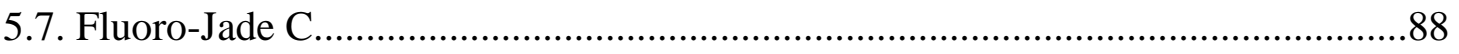




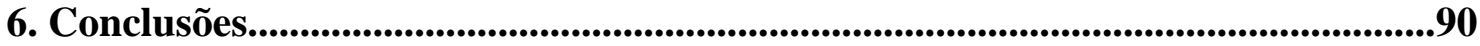

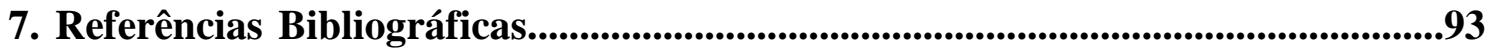




\section{LISTA DE ABREVIATURAS E SIGLAS}

$\left[{ }^{3} \mathrm{H}\right] \mathrm{GABA}: \mathrm{GABA}$ radioativo

$\left[{ }^{3} \mathrm{H}\right]$ glicina: glicina radioativa

ALX 5407: (r)-(n-[3-(4'-fluorofenil)-3-(4'-fenilfeenoxi) propil])sarcosina

AMPA : receptor ionotrópico de L-glutamato do subtipo ácido $\alpha$-amino-3-hidróxi-5-

metil-4-propriônico isoxazol

ATP: adenosina trifosfato

AVE: acidente vascular encefálico

Bax: proteína pró-apoptótica da familia Bcl-2

Bcl-xl: proteína antiapoptótica da familia Bcl-2

BGT1: transportador de GABA do tipo betaína

CCG: camada de células ganglionares

CFN: camada de fibras do nervo óptico

CNE: camada nuclear externa

CNI: camada nuclear interna

COS-7: linhagem celular derivada do rim do macaco verde africano

CPE: camada plexiforme externa

CPI: camada plexiforme inerna

DMSO: dimetilsulfóxido

DNA: ácido desoxirribonucleico

EAAC1: carreador de aminoácido excitatório 1

EAAT: transportador de aminoácido excitatório

ELA: esclerose lateral amiotrófica

eNOS ,iNOS e nNOS: isoformas da óxido nítrico sintetase 
EPR: epitélio pigmentar da retina

FJC: Fluoro-Jade C

GABA: ácido gama-amino butírico

$\mathrm{GABA}_{\mathrm{A}}$ : Receptor gabaérgico do tipo A

$\mathrm{GABA}_{\mathrm{B}}$ : Receptor gabaérgico do tipo $\mathrm{B}$

GABA $_{C}$ : Receptor gabaérgico do tipo $\mathrm{C}$

GAT1: Transportador de GABA do tipo 1

GAT2: Transportador de GABA do tipo 2

GLAST: transportador de glutamato e aspartato

GLT-1: tranportador de glutamato 1

H-E: hematoxilina-eosina

ISQ/REP: isquemia/reperfusão

ISQ: isquemia

L-GLU: L-glutamato

L- $\left[{ }^{3} \mathrm{H}\right]$ glutamato: L-glutamato radioativo

mGluR: receptor metabotrópico de L-glutamato

MLE: membrana limitante externa

MLI: membrana limitante interna

NAD: nicotinamida adenina dinucleotídeo

NCX: um tipo de proteína de membrana

NMDA: receptor ionotrópico de L-glutamato do subtipo N-metil-D-aspartato

NO: óxido nítrico

NOS: óxido nítrico sintetase

$\mathrm{ONOO}^{-}$: peroxinitrito

PARP: poli(ADP-ribose)polimerase 
PIO: pressão intra-ocular

PTZ: pentilenotetrazol

PW11: Parawixina 11

ROS: espécie reativa de oxigênio

SCCR: sinaptossomas cerebro-corticais de ratos

SNC: sistema nervoso central

THIP: tetrahidroisoxazolopiridina

Tx3-3 e Tx3-4: toxinas isoladas da peçonha da aranha Phoneutria nigriventer V/V: volume por volume 


\section{LISTA DE FIGURAS}

Figira 1. Esquema da cascata isquêmica. .25

Figura 2. Fluxograma ilustrando as etapas experimentais 42

Figura 3. Fotos representativas de algumas células normais e lesionadas da retina isquêmica. .48

Figura 4. Imagens de lâminas coradas com H-E. Grupos NAÏVE, SHAM, VE1 e DMSO .49

Figura 5. Imagens de lâminas coradas com H-E. Grupos PW1, PW2 e PW3.................51

Figura 6 Imagens de lâminas coradas com H-E. Grupos MUS, e PW2 + MUS.............52

Figura 7. Imagens de lâminas coradas com H-E. Grupos NIP e PW2 + NIP..................53

Figura 8. Imagens de lâminas coradas com H-E. Grupos ALX e PW2 + ALX..............54

Figura 9. Imagens de lâminas coradas com H-E. Grupos RIL e PW2 + RIL...................55

Figura 10. Imagens de lâminas coradas com FJC. Grupos NAÏVE, SHAM, VE1 e DMSO.....

Figura 11. Imagens de lâminas coradas com FJC. Grupos PW1, PW2 e PW3 ...............59

Figura 12. Imagens de lâminas coradas com FJC. Grupos MUS, e PW2 + MUS..........60

Figura 13. Imagens de lâminas coradas com FJC. Grupos NIP e PW2 + NIP...............61

Figura 14. Imagens de lâminas coradas com FJC. Grupos ALX e PW2 + ALX............62

Figura 15. Imagens de lâminas coradas com FJC. Grupos RIL e PW2 + RIL................63

Figura 16. Gráfico da média da densidade celular na CCG das retinas de ratos Wistar submetidos à isquemia por $45 \mathrm{~min}$

Figura 17. Gráfico da média da densidade celular na CNI das retinas de ratos Wistar submetidos à isquemia por $45 \mathrm{~min}$. .69 
Figura 18. Gráfico da média da densidade celular na CNE das retinas de ratos Wistar submetidos à isquemia por $45 \mathrm{~min} .$. .70 Figura 19. Gráfico da média da densidade celular na CCG das retinas de ratos Wistar submetidos à isquemia por $45 \mathrm{~min}+15 \mathrm{~min}$ de reperfusão. .72 Figura 20. Gráfico da média da densidade celular na CNI das retinas de ratos Wistar submetidos à isquemia por $45 \mathrm{~min}+15$ min de reperfusão .74

Figura 21. Gráfico da média da densidade celular na CNE das retinas de ratos Wistar submetidos à isquemia por $45 \mathrm{~min}+15$ min de reperfusão .75 


\section{LISTA DE TABELAS}

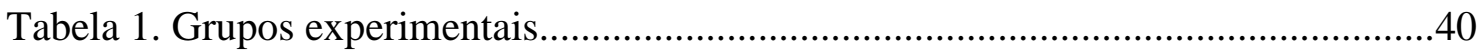

Tabela 2. Intensidade de células FJC-positivas na CCG e CNI...................................65

Tabela 3. Efeitos da associação de $0,01 \mu \mathrm{g} / \mu \mathrm{L}$ de Parawixina $11 \mathrm{com}$ as demais drogas

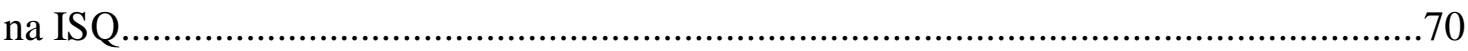

Tabela 4. . Efeitos da associação de $0,01 \mu \mathrm{g} / \mu \mathrm{L}$ de Parawixina $11 \mathrm{com}$ as demais drogas na ISQ/REP. 


\begin{abstract}
RESUMO
Rosa, M. N. Avaliação da atividade neuroprotetora da Parawixina 11 isolada da peçonha da aranha Parawixia bistriata (Araneae, Araneidae), em ratos Wistar submetidos a um modelo de glaucoma agudo. 104p. Dissertação de mestrado - Faculdade de Filosofia, Ciências e Letras de Ribeirão Preto, Universidade de São Paulo, Ribeirão Preto, 2012.
\end{abstract}

O glaucoma é definido como uma típica neuropatia óptica caracterizada por perda de células ganglionares e consequente lesão no nervo óptico, resultando em uma gradual redução do campo visual, podendo causar cegueira. Considerando que os compostos presentes nas peçonhas de aranhas representam uma fonte importante de moléculas bioativas, o estudo dos possíveis efeitos neuroprotetores destas substâncias, em modelos experimentais de glaucoma, é uma etapa indispensável para o desenvolvimento de novos fármacos para o tratamento desta neuropatologia. Neste contexto, nosso grupo de pesquisa tem investigado compostos neuroativos isolados da peçonha da aranha Parawixia bistriata. Até o momento três moléculas isoladas, a PbTx1.2.3 (Parawixina 1), a FrPbAII (Parawixina 2) e a Parawixina 10 mostraram efeitos anticonvulsivantes e neuroprotetores, devido à suas ações na facilitação da recaptação de L-GLU (Parawixinas 1 e 10) ou na inibição da recaptação de GABA (Parawixina 2). Além destes compostos também isolamos a Parawixina 11 (PW11). Os resultados obtidos até agora demonstraram que a Parawixina 11 possui efeito anticonvulsivante em ratos submetidos à indução de crises por vários convulsivantes e foi neuroprotetora após indução de Status epilepticus por pilocarpina. Sendo assim, o presente estudo consistiu em verificar se a PW11 também seria neuroprotetora em um modelo de glaucoma agudo e tentar inferir seu mecanismo de ação, comparando-a e asssociando-a ao muscimol, ao ácido nipecótico, ao ALX 5407 e ao riluzol. Para isso, o modelo utilizado foi o de aumento da pressão intra-ocular (PIO), interrompendo o fluxo sanguíneo na retina e causando isquemia. Foi utilizado um sistema com pressão de ar, constituído por uma agulha de punção venosa de $27 \mathrm{G}$, conectada a um reservatório de ar acoplado a um manômetro. Ratos Wistar $(200-250 \mathrm{~g})$ foram anestesiados e cada grupo $(\mathrm{n}=4)$ recebeu uma injeção intravítrea (volume de $1,2 \mu \mathrm{L}$ ) no olho esquerdo, de uma

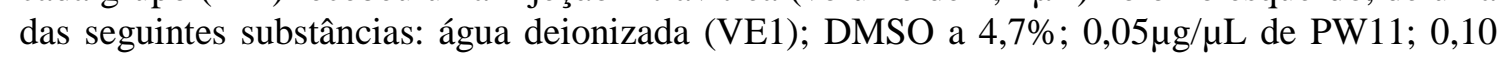
$\mu \mathrm{g} / \mu \mathrm{L}$ de PW11; $0,20 \mu \mathrm{g} / \mu \mathrm{L}$ de PW11; $5 \mu \mathrm{g} / \mu \mathrm{L}$ de muscimol; $3 \mu \mathrm{g} / \mu \mathrm{L}$ de ácido nipecótico; $0,30 \mu \mathrm{g} / \mu \mathrm{L}$ de ALX 5407; $23,45 \mu \mathrm{g} / \mu \mathrm{L}$ riluzol. Outros grupos receberam uma injeção (volume de $2,4 \mu \mathrm{L}$ ) com uma das seguintes associações: $0,10 \mu \mathrm{g} / \mu \mathrm{L}$ PW1 + muscimol; $0,10 \mu \mathrm{g} / \mu \mathrm{L}$ de PW11 + ácido nipecótico; $0,10 \mu \mathrm{g} / \mu \mathrm{L}$ de PW11 + ALX 5407 e $0,10 \mu \mathrm{g} / \mu \mathrm{L}$ de PW11 + riluzol. Quinze minutos após a injeção, foi aplicada uma pressão de $120 \mathrm{mmHg}$, por $45 \mathrm{~min}$, causando isquemia retiniana. Alguns animais, que faziam parte do grupo isquemia (ISQ), foram sacrificados logo após esse tempo. Já os do grupo isquemia/reperfusão (ISQ/REP) tiveram a PIO normalizada durante $15 \mathrm{~min}$, após a isquemia, permitindo o retorno do fluxo sanguíneo na retina, e só então foram sacrificados. Em seguida, os olhos foram removidos e fixados em solução ALFAC. As retinas isquêmicas com e sem reperfusão apresentaram núcleos picnóticos, vacuolização citoplasmática, edema e desorganização das camadas, característicos deste tipo de lesão. Após ISQ, os tratamentos com 0,10 e $0,20 \mu \mathrm{g} / \mu \mathrm{L}$ de PW11 preservaram, respectivamente, 17,51 e $37,45 \%$ de células na CNI, se comparados com o grupo VE1. Na CCG, quando a PW11 foi associada ao agonista do receptor $\mathrm{GABA}_{\mathrm{A}}$, o muscimol, e ao inibidor do transportador de GABA do tipo GAT1, o ácido nipecótico, houve proteção significativa de 37,07 e 44,81\%, respectivamente, se comparada ao grupo VE1, indicando inespecificidade da PW11 no sistema gabaérgico. Após ISQ/REP, as densidades celulares na CCG das retinas tratadas com $0,05,0,10$ e $0,20 \mu \mathrm{g} / \mu \mathrm{L}$ de PW11 foram, respectivamente, 32,88, 24,05 e 28,27\% maiores do que a das retinas do grupo VE1. Já na CNI, as densidades celulares após os tratamentos com PW11 foram, respectivamente, 38,78, 35,25 e 30,96\% maiores do que a das retinas do grupo VE1. Com relação à presença de neurônios em degeneração marcados com Fluro-Jade C, as retinas dos animais tratados apresentaram menos marcações na CNI, CPI e CCG, se comparadas com as dos grupos VE1 e DMSO. Diante destes efeitos, conclui-se que a PW11 pode ser uma interessante ferramenta para o desenvolvimento de terapias que combinemdiferentes drogas no tratamento do glaucoma e de outras neuropatologias. 


\begin{abstract}
Rosa, M. N. Neuroprotective activity of Parawixin 11, isolated from Parawixiabistriata (Araneae, Araneidae) spider venom, in Wistar rats submitted to an experimental model of acute glaucoma. 104p. Master dissertation - College of Philosophy, Sciences and Literature of Ribeirão Preto, University of São Paulo, Ribeirão Preto, 2012.
\end{abstract}

Glaucoma is defined as a typical optic neuropathy characterized by ganglion cells loss and consequent optic nerve damage, resulting in a gradual reduction of the visual field and eventual blindness. In regard to compounds present in spider venoms, they represent an interesting source of bioactive molecules and the study about the possible neuroprotective effects of these substances, in experimental models of glaucoma, is an important step to developed new drugs to treating this disease. Therefore, our research group has investigated neuroactive compounds isolated from Parawixia bistriata spider venom. Nowadays, three purified molecules, PbTx1.2.3 (Parawixin 1), FrPbAII (Parawixin 2) and Parawixin 10 showed anticonvulsant and neuroprotective effects. They enhance the L-gluatamate uptake (Parawixin 1 and 10) or inhibit the GABA uptake (Parawixin 2). In addition these compounds, we also isolated the Parawixin 11 (PW11). So far, the results with PW11 showed the anticonvulsant effect in rats after seizures drug-induced and neuroprotetive effect after Status epilepticus pilocarpine -induced. Nevertheless, this study was to exemine if Pw11 could also be neuroprotective in acute glaucoma model and attempt to infer the mechanism of action, comparing it and associating it to muscimol, nipecotic acid, ALX 5407 and riluzole. For this, the model used was the intraocular pressure (IOP) elevation, disrupting the blood flow in retina and causing ischemia. It was used a system with air pressure, comprising of a $27 \mathrm{G}$ venous puncture needle connected to an air reservoir coupled to a manometer. Male Wistar rats (200$250 \mathrm{~g}$ ) were anesthetized and each group $(\mathrm{n}=4)$ received an intravitreal injection (volumn $=1,2$ $\mu \mathrm{L}$ ) in the left eye of one of the following substances: deionized water (VE1); DMSO 4,7\%, $0,05 \mu \mathrm{g} / \mu \mathrm{L}$ of PW11; $0,10 \mu \mathrm{g} / \mu \mathrm{L}$ of $\mathrm{PW} 11 ; 0,20 \mu \mathrm{g} / \mu \mathrm{L}$ of $\mathrm{PW} 11 ; 5 \mu \mathrm{g} / \mu \mathrm{L}$ of muscimol; $3 \mu \mathrm{g} / \mu \mathrm{L}$ of nipecotic acid; $0,30 \mu \mathrm{g} / \mu \mathrm{L}$ of ALX $5407 ; 23,45 \mu \mathrm{g} / \mu \mathrm{L}$ of riluzole. Other groups received an injection (volumn $=2,4 \mu \mathrm{L}$ ) with one of the following associations: 0,10 $\mu \mathrm{g} / \mu \mathrm{L}$ of PW11+muscimol; $0,10 \mu \mathrm{g} / \mu \mathrm{L}$ of PW11+nipecotic acid; $0,10 \mu \mathrm{g} / \mu \mathrm{L}$ of PW11+ALX 5407 and $0,10 \mu \mathrm{g} / \mu \mathrm{L}$ of PW11+riluzole. Fifteen minutes later, the IOP was raised up to 120 $\mathrm{mmHg}$ for $45 \mathrm{~min}$, inducing retinal ischemia. Some animals, which were ischemia group (ISCH), were sacrificed immediately thereafter. The ischemia/reperfusion (ISCH/REP) group animals had IOP normalizedduring $15 \mathrm{~min}$, after ischemia, making possible the blood flow return and, then, they were euthanized. Then, the eyes were removed and fixed in ALFAC solution. The ischemic retinas with or without reperfusion showed piknotic nuclei, citoplasmatic vacuolization, edema and disorganization of the retinal layers, characteristics of this lesion type. After ISCH, treatments with 0.1 and $0.2 \mu \mathrm{g} / \mu \mathrm{L}$ of PW11 preserved, respectively, 17.51 and $37.45 \%$ of cells in the INL if compared with VE1 group. In the GCL, when PW11 was associated to muscimol, a $\mathrm{GABA}_{\mathrm{A}}$ receptor agonist, and to nipecotic acid, a GAT-1 transporter inhibtor, there was significant protection of 37.07 and $44.81 \%$, respectively, if compared with VE1 group, indicating nonspecificity of PW11 in gabaergic system. After ISCH/REP, cell densities in GCL of treated retinas with $0.05,0.10 \mathrm{ad} 0.20 \mu \mathrm{g} / \mu \mathrm{L}$ of PW11 were 32.88, 24.05 and $28.27 \%$ higher than that of VE1 group retinas, respectively. In INL, the cell densities after PW11 treatments were $38.78,35.25$ and $30.96 \%$ higher than that of VE1 group retinas, respectively. Regarding the presence of Fluoro-Jade C (FJC) stained degenerating neurons, retinas from treated animals showed less FJC-positive neurons in INL, IPL and GCL if compared with those of VE1 and DMSO groups. In view of these effects, it is concluded that the PW11 can be a useful tool to developed therapies that combine different drugs in glaucoma and other neuropathology treatments. 


\section{INTRODUÇÃO}




\subsection{Retina}

A retina é um neuroepitélio que reveste internamente a cavidade do bulbo ocular e é derivada da mesma vesícula primordial, da qual se origina o diencéfalo (Machado, 2000). A estrutura da retina é extremamente complexa, distinguindo-se nela dez camadas: epitélio pigmentar da retina (EPR), camada de fotorreceptores, membranas limitantes externa (MLE) e interna (MLI), camadas nucleares externa (CNE) e interna (CNI), camadas plexiformes externa (CPE) e interna (CPI), camada de células ganglionares (CCG) e camada de fibras do nervo óptico (CFN) (Shepherd, 1974; Dantas, 1989).

A CNE contém corpos celulares de fotorreceptores (cones e bastonetes) que estabelecem sinapses com as células bipolares (Shepherd, 1974; Machado 2000).A CNI contém corpos celulares de células horizontais, células bipolares, células amácrinas e células de Müller(Dantas, 1989).A CCG é constituída de células amácrinas deslocadas e células ganglionares (CG). As células bipolares da CNI fazem sinapses com as células ganglionares, cujos axôniosformam o nervo óptico, que adentra o encéfalo etermina em diferentes áreas subcorticais (Lilley\& Robbins, 2005).

Com relação às células gliais, é interessante ressaltar que, na retina da maioria dos mamíferos, são encontrados três tipos de células gliais: as micróglias, localizadas nas camadas internas da retina ( $\mathrm{CFN}, \mathrm{CCG}$ e $\mathrm{CPI})$, os astrócitos, localizados nas mesmas camadas das micróglias, mas com prolongamentos que se estendem até a MLI e as células de Müller, principal célula glial, com prolongamentos que se estendem por várias camadas retinianas. Nas retinas de coelhos, também é encontrado um quarto tipo, os oligodendrócitos, localizados nos feixes de fibra mielinizada ("raios medulares") (Bringmann et al., 2006). 
Entre a CNE e a CNI, localiza-se a CPE, onde os axônios dos fotorreceptores realizam sinapses com as células bipolares e com as horizontais (Dantas, 1989). As sinapses entre as células bipolares e as ganglionares ocorrem na CPI, última região sináptica da retina (Dantas, 1989).

É pelo envolvimento de vários neurotransmissores, durante as sinapses citadas, que a luz absorvida pela retina se modifica em impulso elétrico, levando a informação visual às estruturas encefálicas relacionadas com a visão, tais como: o núcleo supraquiasmático, o corpo geniculado lateral, o colículo superior, dentre outros. (Osborne et al., 2004; Wässle, 2004).

\subsection{Neurotransmissão inibitória}

O GABA é o mais importante neurotransmissor inibitório no processamento visual e Sistema Nervosos Central (SNC) de vertebrados (Yang, 2004). Além dele, a glicina, encontrada na retina, também pode participar da neurotransmissão inibitória (Pow, 2001).

Com relação ao GABA, sabe-se que o aumento de sua função, via ativação de seus receptores, resulta, de modo geral, no aumento do fluxo de íons de cloreto através da membrana pós- sináptica, hiperpolarizando a célula e reduzindo a neurotransmissão excitatória (Green etal., 2000). Há evidências consistentes sobre a expressão de receptores de GABA dos tipos $\mathrm{A}, \mathrm{C}$ e $\mathrm{B}$ na camada de fotorreceptores. Os tipos $\mathrm{A}$ e Ctambém são encontrados nas camadas de células horizontais e bipolares, e os tipos A e B, nas camadas de células amácrinas e ganglionares (Yang, 2004). O GABA é retirado do meio extracelular por transportadores específicos de alta- afinidade (GAT), 
localizados em neurônios e processos gliais em rato, e são divididos em quatro subtipos: GAT-1, GAT-2, GAT-3 e BGT-1 (transportador do tipo betaína/ GABA). O subtipo GAT-1é fortemente expresso na CPI, onde ocorrem processos das células amácrinas (Honda et al., 1995), o subtipo GAT-2 é mais comum no EPR e na CFN, embora nessa última camada a expressão seja mais fraca. O GAT-3 é preferencialmente expresso em células de Müller e em algumas células amácrinas (Johnson et al., 1996). O subtipo BGT-1, embora já tenha sido localizado em algumas regiões do encéfalo de ratos, como no hipocampo, ainda não foi encontrado na retina (Dalby, 2003; Zhu et al., 2004).

Com relação à glicina, mais da metade de células amárcinas a utilizam como principal neurotransmissor. Os receptores para a ação inibitória da glicina localizam-se principalmente na CPI e sãocanais para íons de $\mathrm{Cl}^{-}$, ativados por ligante, que podem ser antagonizados pela estriquinina (Pow, 2001; Wässle et al., 2009).Até o momento, nas retinas de ratos, o único transportador de glicina encontrado foi o do tipo GlyT-1 que se localiza nos neurônios (diferentemente do que ocorre no encéfalo, onde ele é encontrado em células gliais) (Pow, 2001).

\subsection{Neurotransmissão excitatória}

O aminoácido L-glutamato (L-GLU) é o principal neurotransmissor excitatório do SNC e da retina de mamíferos (Collingride \& Lester, 1989).

O L-GLU se liga a receptores que podem ser classificados em dois tipos: ionotrópicos, cujo funcionamento consiste na abertura integral de canais iônicos para íns específicos, e os metabotrópicos, que são acoplados a proteínas $\mathrm{G}$ e modulam a produção de mensageiros intracelulares (Nakanishi, 1992). 
Dentre os receptores ionotrópicos encontram-se os subtipos: N-metil-D-aspartato (NMDA), ácido $\alpha$-amino-3-hidróxi-5-metil-4-propriônico isoxazol (AMPA) e cainato (Ozawa et al., 1998). Dentre os metabotrópicos, encontram-se oito subtipos distribuídos em três grupos, da seguinte forma: mGluR1 e mGluR5 no grupo I; mGluR2 e mGluR3 no grupo II; mGluR3, mGluR6, mGluR7 e mGluR8 no grupo III (Ozawa etal., 1998).

O L-GLU normalmente é removido da fenda sináptica, rapidamente, por transportadores glutamatérgicos dependentes de íons de sódio, localizados em neurônios e glias (Lin et al., 2008). Até o momento, foram identificados 5 transportadores de aminoácidos excitatórios (EAAT1-5) em humanos (Danbolt, 2001). Todos os transportadores de L-GLU encontrados em humanos possuem seus correspondentes na retina de ratos, sendo que o transportador GLAST (EAAT1 em humanos) está localizado em células de Müller e astrócitos, enquanto o GLT-1 (EAAT2) é expresso em maior quantidade nas células bipolares e nos cones. O EAAC1 (EAAT3) está presente em células horizontais, algumas células amácrinas e células ganglionares, já o EAAT5 é mais encontrado em bastonetes (Rauen et al., 1998; Pow \& Barnett, 2000). Os astrócitos da retina também expressam o EAAT4, principalmente próximo à camada de fibras do nervo óptico (Ward et al., 2004).

A ação destes transportadores impede a ocorrência da excitotoxicidade, ou seja, evita o acúmulo de L-GLU na fenda sináptica, que poderia levar a uma incessante ativação de receptores glutamatérgicos e constante liberação de substâncias no interior dos neurônios e para o meio extracelular, que acabariam contribuindo para a lesão no tecido (Choi et al., 1990; Maragakis \& Rothsein, 2001). 


\subsection{A lesão isquêmica e a excitotoxicidade}

A isquemia retiniana ocorre como conseqüência de várias doenças, tais como glaucoma, neuropatia óptica isquêmica anterior, oclusão da artéria retiniana, retinopatia diabética, acidente vascular encefálico (AVE), dentre outras (Jeng et al., 2006).

Segundo Osborne et al. (2004), a isquemia resulta da ausência ou insuficiência do fluxo sanguíneo, reduzindo os níveis de oxigênio e substratos, incluindo a glicose. Como as taxas de glicólise e fosforilação oxidativa diminuem, então os níveis de adenosina trifosfato (ATP) caem, causando deterioração da função da membrana celular e desequilíbrio iônico, iniciando as cascatas que finalmente levam à morte neuronial (Osborne et al., 2004).

Com a redução da energia na célula, ocorre falência das bombas dependentes de ATP, como a $\mathrm{Na}^{+} / \mathrm{K}^{+}$-ATPase e subseqüente despolarização dos neurônios, induzindo a liberação de neurotransmissores, principalmente o L-GLU (Osborne et al., 2004).

Devido à redução do transporte ativo pela bomba de $\mathrm{Na}^{+} / \mathrm{K}^{+}$-ATPase, a repolarização dos neurônios, após despolarização, é inibida, causando desbloqueio do sítio de íons de $\mathrm{Mg}^{2+}$ nos receptores NMDA,conforme descrito por Osborne et al. (2004). Então, os receptores NMDA são despolarizados, o influxo de íons de $\mathrm{Ca}^{2+}$ aumenta, e ocorre a liberação de neurotransmissores excitatórios (Louzada-Jr, 1992; Meldrum, 2000). Também são ativados receptores glutamatérgicos ionotrópicos do tipo AMPA/ cainato, levando ao influxo de íons de $\mathrm{Ca}^{2+}$, de $\mathrm{Na}^{+}, \mathrm{de}^{-} \mathrm{Cl}^{-}$e água, que contribuempara o edema (Choi \& Rothman, 1990).

Além disso, em neurônios isquêmicos, também ocorrem alterações nas proteínasde membranas NCX, responsáveis pelo transporte de íons de $\mathrm{Na}^{+} / \mathrm{Ca}^{2+}$. De acordo com Choi (2005) os níveis de íons de $\mathrm{Ca}^{2+}$ intracelular permanecem elevados, 
mesmo com a restauração do fluxo sanguíneo e de gradientes de íons de $\mathrm{Na}^{+}$, devido à clivagem da NCX pela enzima calpaína, impossibilitando o transporte deíons de $\mathrm{Ca}^{+}$ para o exterior da célula.

Este aumento nos níveis intracelulares de cálcio resulta na ativação de várias enzimas dependentes da ação deste cátion para atividade plena, como por exemplo, proteína quinase $\mathrm{C}$ e óxido nítrico sintase (NOS). Estas enzimas produzem alterações que levam à desregulação de mecanismos homeostáticos celulares e da integridade estrutural, levando à morte da célula. Além disso, pode ocorrer a liberação citoplasmática de fatores promotores demorte celular, como o citocromo $\mathrm{C}$ e iniciação da morte celular por apoptose (Osborne et al., 2004) (Fig.1).

Mesmo com reperfusão após isquemia, a lesão não diminui, pelo contrário, ela aumenta, pois a reoxidação durante este período causa superprodução de espécies reativas de oxigênio e nitrogênio, desencadeando um desequilíbrio entre a produção e a remoção destas espécies reativas, uma vez que o sistema de defesa antioxidante se torna insuficiente (Chen \& Tang, 2011).

Os processos citados acima se combinam promovendo a morte de neurônios, a qual pode ocorrer mais rapidamente, devido à morte por necrose, ou pode ser mais tardia, causada por apoptose (Kawaguchiet al., 2005). A necrose é caracterizada por vacuolização do citoplasma, quebra da membrana plasmática e produção de resposta inflamatória. $\mathrm{Na}$ morte por apoptose, caracterizada pela fragmentação do DNA, é necessária a atividade de caspases e, devido à formação de corpos apoptóticos, o sistema imune não é ativado (Lipton, 1999).

Para minimizar os danos que ocorrem durante a isquemia, podem ser feitas intervenções farmacológicas nas principais vias causadoras da morte celular, por exemplo, impedindo a entrada de íons e água para o interior do neurônio, prevenindo a 
produção excessiva de radicais livres, reduzindo os processos inflamatórios, reduzindo a neurotransmissão excitatória ou reforçando a neurotransmissão inibitória (Szabadfi et al., 2010).

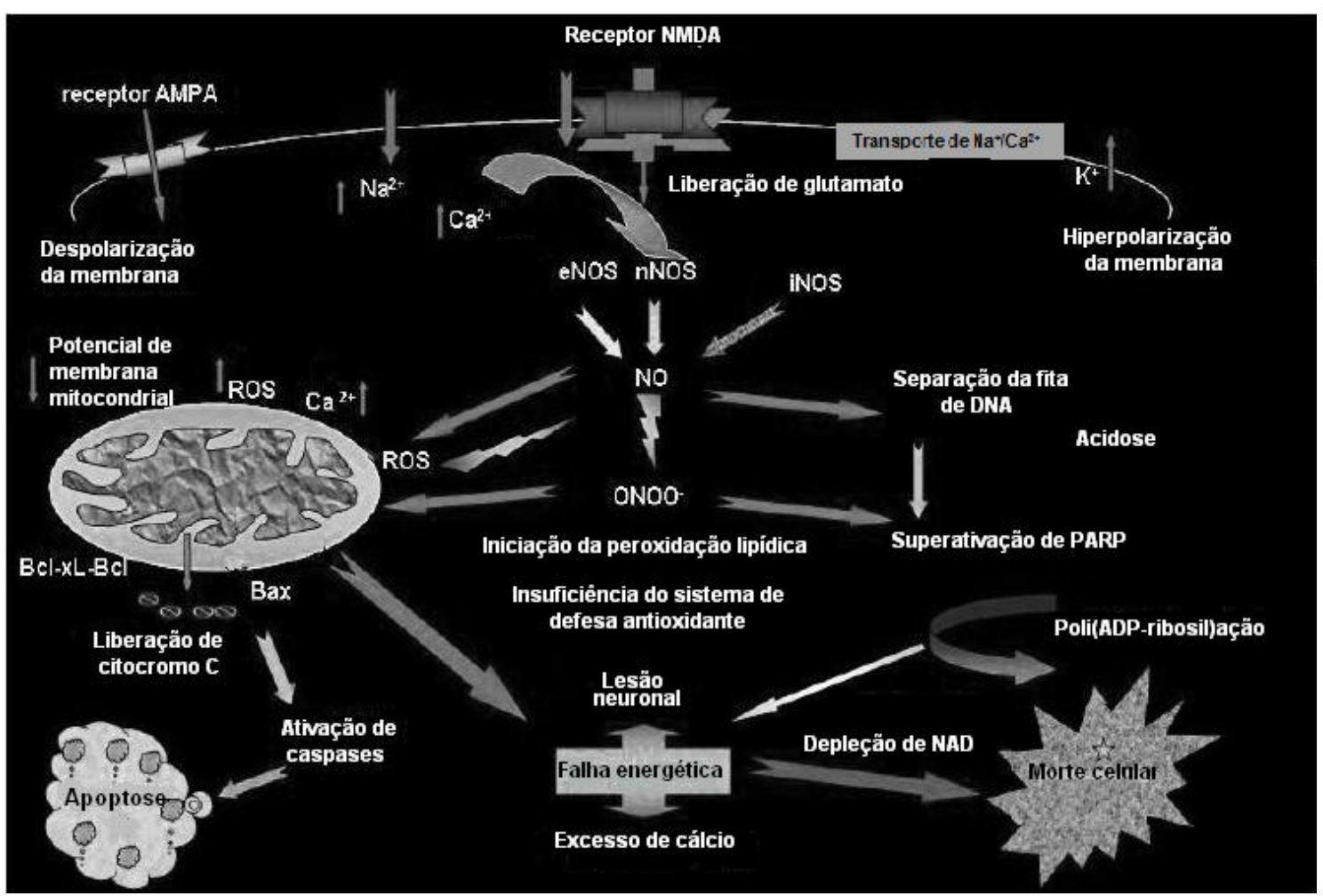

Figura 1: Esquema mostrando algumas etapas da cascata isquêmica. Figura modificada de Dohare et al. (2008).

\subsection{Neuroproteção}

Em doenças neurodegenerativas como glaucoma, esclerose lateral amiotrófica (ELA), epilepsia, mal de Alzheimer e AVE, ocorre a excitotoxicidade (Maragakis \& Rothsein, 2001). Sendo assim, para tentar desenvolver tratamentos para essas neuropatologias, tem sido constante abusca por substâncias, cujos mecanismos minimizem os danos causados pelo excesso de L-GLU. 
Neste sentido, uma das maneiras de reduzir a excitotoxicidade consiste no uso de inibidoresda liberação de L-GLU, como alguns agentes testados em estudos préclínicos de isquemia ou em ensaios clínicos de AVE, tais como antagonistas competitivos e não competitivos dos receptores NMDA e AMPA, na tentativa de limitar o tamanho e a gravidade da lesão isquêmica (Danbolt, 2001; Ginsberg, 2008).

Além desta, uma alternativa é o uso de agentes que estimulam a recaptação do L-GLU, como o riluzol, usado no tratamento da ELA, que além de aumentar a recaptação do L-GLU, também inibe sua liberação, agindo, portanto, em receptores e transportadores (Azbill et al., 2000; Fumagalli et al.,2008).

Bloqueadores de canais para certos íons também possuem potencial terapêutico. Exemplo disso são as toxinas Tx3-3 e Tx3-4, ambas bloqueadoras de canais para íons de $\mathrm{Ca}^{2+}$ e isoladas da peçonha da aranha Phoneutria nigriventer, que protegemfatias de hipocampo de ratoscontra dano neuronal isquêmico (Pinheiro et al., 2009).

Substâncias capazes de promover um aumento na concentração extracelular de GABA também têm sido estudadas. Neste contexto, pode-se citar como exemplo de mecanismo neuroprotetor, a ação de substâncias que potencializam a atividade de receptores gabaérgicos, como o agonista seletivo de $\mathrm{GABA}_{\mathrm{A}}$, muscimol, cujas propriedades neuroprotetoras estão fortemente comprovadas em vários modelos experimentais de AVE (Tuttolomondo et al., 2009). Estudos mais recentes mostram que o propofol, embora seja amplamente usado como anestésico sistêmico, também atua como agonista do receptor $\mathrm{GABA}_{\mathrm{A}}$ nas células bipolares da retina de ratos(Yue et al., 2010).

Outra forma de neuroproteção é o uso de inibidoresda recaptação do GABA liberado, como a tiagabina, bloqueadorado transportador GAT-1,que é usada no tratamento das crises parciais de indivíduos epilépticos (Dalby, 2000). 


\subsection{O glaucoma experimental}

O glaucoma é definido como uma típica neuropatia óptica cuja característica é a perda de células ganglionares e consequente lesão no nervo óptico, ocasionando redução gradual do campo visual, que pode levar à cegueira (Soltau \& Zimmerman, 2002; Osborne et al., 2004; Guizzo etal., 2005). Logo, o desenvolvimento de modelos experimentais é de grande importância para pesquisa e descoberta de novos medicamentos e tratamentos que ajudem a minimizar tais danos.

Vários artigos descrevem metodologias de indução do glaucoma utilizando modelos animais, tais como aumento da PIO (Louzada-Jr et al., 1992;Osborne et al., 2004), oclusão de artéria cerebral (Kalesnykas et al., 2008), lesão no nervo óptico (Yoles \& Schwartz, 1998) e cauterização da veia episcleral (Hernández etal., 2008).

Neste trabalho de mestrado, o glaucoma experimental que foi utilizado consistiu no aumento da pressão na câmara anterior do olho para bloquear o suprimento capilar para a retina, conforme descrito por Hughes (1991), Louzada-Jr et al., (1992) e modificado por Guizzoet al. (2005).

A reperfusão, neste modelo de glaucoma experimental, consiste no restabelecimento do suprimento sanguíneo e dos níveis normais da PIO. Durante esta fase, segundo Louzada-Jr. et al. (1992), há um aumento do dano tecidual se comparado à fase de isquemia, o qual pode ser verificado entre 15 e 20 min de reperfusão. Tal dano tecidual parece ser mediado por L-GLU, tanto direta como indiretamente, através de receptores NMDA (Louzada-Jr. et al., 1992). Células que tinham sofrido somente danos reversíveis na isquemia podem ser lesionadas durante a reperfusão, tornando mais agravante o quadro da doença (Osborneet al., 2004). 
Para o tratamento do glaucoma, geralmente são utilizados alguns medicamentos que reduzem a PIO, como, por exemplo, agonistas colinérgicos e bloqueadores adrenérgicos (Soltau \& Zimmerman, 2002). No entanto, mesmo pacientes com PIO reduzida sofrem perda visual devido ao glaucoma. Isso tem motivado a pesquisa de substâncias neuroprotetoras, que já tenham se mostrado eficazes no tratamento de alguma outra doença do SNC, capazes de reduzir a morte de células ganglionares. No entanto, nem sempre essas substâncias chegam a ser comercializadas com este novo propósito, como pôde ser observado com a memantina. Essa droga, utilizada no tratamento da doença de Alzheimer e cujo mecanismo de ação consiste no bloqueio de receptores do tipo NMDA, foi testada em pacientes com glaucoma primário de ângulo aberto (Cheung et al., 2008), porém na segunda parte da fase III do ensaio clínico, não apresentou resultados suficientemente satisfatórios para que fosse aprovadapara o tratamento do glaucoma (Osborne 2009).

Considerando que os compostos presentes em peçonhas de aranhas representam uma fonte interessante de moléculas bioativas e com atividade no SNC (Beleboni et al., 2004; Mortari et al. 2007), o estudo sobre os possíveis efeitos neuroprotetores destas substâncias em modelos de glaucoma experimental é o passo inicial para que novos fármacos, cujos efeitos colaterais sejam reduzidos, possam ser desenvolvidos para tratar tal doença.

\subsection{Neurotoxinas de aranhas}

No mundo todo têm sido descritas aproximadamente 40.000 espécies de aranhas, cujas peçonhas são constituídas de moléculas, com uma grande variedade de massa 
molecular (0,1-4,0 kDa). No entanto, apenas 100 dessas espécies, aproximadamente, têm suas peçonhas estudadas, sendo que, dentre estas, poucas são investigadas detalhadamente (Rash \& Hodgson, 2002; Vassilevski et al., 2009).

Essas peçonhas são constituídas por substâncias de diferentes composições químicas, podendo apresentar compostos como: acilpoliaminas, proteínas, aminoácidos, enzimas, alcalóides, peptídeos complexos, dentre outros (Mortari et al., 2007).

Diante desta diversidade de substâncias bioativas, as moléculas presentes nas peçonhas podem agir, dentre outros locais, em vários sítios dos sistemas nervosos de insetos e mamíferos, podendo atuar sobre receptores colinérgicos e glutamatérgicos, canais para íons de $\mathrm{Na}^{+}$, de $\mathrm{K}^{+}$e de $\mathrm{Ca}^{2+}$ e transportadores de L-GLU e GABA (Beleboni et al., 2004; Estrada et al., 2007).

As neurotoxinas têm sido utilizadas como ferramentas para ampliar o conhecimento dos mecanismos moleculares de neurotransmissão. Logo, o estudo dessas substâncias é de grande importância para a pesquisa, tanto básica como clínica, devido ao potencial terapêutico que elas possuem (Beleboni et al., 2004).

\subsection{A aranha Parawixia bistriata (Araneae: Araneidae)}

A aranha colonial Parawixia bistriata é encontrada na América Central e do Sul, principalmente na região sudeste do Brasil. Esta aranha possui hábitos noturnos e se agrupa em ninhos (Levi, 1992).

A caracterização dos componentes da peçonha foi iniciada em nosso laboratório quando se observou que a injeção da peçonha bruta em térmitas (cupins) provoca paralisia destes isópteros (Fontana et al., 2000). Com tal observação, foi possível 
concluir que os componentes da peçonha da $P$. bistriata pudessem agir no SNC de ratos e outros mamíferos, uma vez que se sabe que as sinapses na junção neuromuscular de insetos são predominantemente gabaérgicas e glutamatérgicas (Usherwood \& Blagbrough, 1991).

Rodrigues et al. (2001) mostraram que injeção por via intracerebroventricular (i.c.v.) da peçonha bruta da $P$. bistriata provoca crises límbicas, cujas alterações comportamentais são diferentes daquelas que ocorrem pela injeção do agonista glutamatérgico, ácido caínico, sugerindo que há múltiplos sítios de ação dos componenetes convulsivantes. A peçonha desnaturada quando injetada por via i.c.v. bloqueia crises tônico-clônicas induzidas pelos antagonistas gabaérgicos bicuculina, picrotoxina e pentilenotetrazol (PTZ) e, in vitro, inibe captação de GABA em sinaptossomas cérebro- corticais de ratos (SCCR) (Cairrão et al., 2002).

Diversos compostos foram identificados na peçonha da aranha $P$. bistriata, como a inosina que apresenta efeito paralisante em insetos e pró-convulsivante em ratos (Rodrigues et al., 2004).

No intuito de identificar novas toxinas que possam servir como ferramenta farmacológica, continuou-se o isolamento dos componentes da peçonha da P. bistriata, o que revelou a presença de vários compostos de baixa massa molecular, como as Parawixinas 1 e 2 (Fontana et al., 2003; Beleboni et al., 2006).

Em estudos envolvendo a Parawixina 1, Fontana et al. (2003) verificaram que ela estimula a recaptação de glutamato (L-Glu) em SCCR, além de atuar como neuroprotetora em retinas submetidas a um modelo de glaucoma experimental agudo em ratos. Em outro estudo, para determinar a especificidade de ação da Parawixina1, para diferentes espécies de transportadores, células COS-7 foram transfectadas com EAAT1, EAAT2 e EAAT3 e incubadas com Parawixina1. Quando realizada a captação 
na presença de L- $\left[{ }^{3} \mathrm{H}\right]$ glutamato, comprovou-se que houve um aumento significante na captação pelo transportador EAAT2, o que não ocorreu com os outros subtipos, mesmo em concentrações maiores da Parawixinal (Fontana et al., 2007). Essa capacidade de afetar especifica e diretamente esse tipo de transportador diferencia a Parawixina1 de outros compostos, que modulam indiretamente a atividade de EAATs, tornando esta molécula o ponto de partida para drogas moduladoras do L-GLU (Torres-Salazar \& Fahlke, 2007).

Nos experimentos com a Parawixina 2, Beleboni et al. (2006) verificaram que essa molécula inibe a recaptação de GABA e glicina em SCCR e, após indução de glaucoma experimental agudo pelo aumento da PIO, possui atividade neuroprotetora na retina. Além disso, ela apresenta efeito ansiolítico, quando injetada no hipocampo dorsal de ratos, e bloqueia crises induzidas pela estimulação da Area tempestas, quando injetada na Substância Negra do mesencéfalo (Liberato et al., 2006).Também foi verificado que a Parawixina 2 possui atividade anticonvulsivante contra indução de crises agudas por picrotoxina, PTZ, ácido caínico e pilocarpina, em ratos Wistar (Gelfuso et al., 2007).

Também foi feito isolamento e experimentos com a Parawixina 10, que não induz alterações locomotoras em ratos e bloqueia a expressão de crises convulsivas generalizadas, induzidas por ácido caínico, NMDA e PTZ. Nos experimentos in vitro, a Parawixina 10 aumenta a recaptação de L- $\left[{ }^{3} \mathrm{H}\right]$ glutamato e, com menor intensidade, a de $\left[{ }^{3} \mathrm{H}\right]$ glicina em SCCR, sem alterar a de $\left[{ }^{3} \mathrm{H}\right] \mathrm{GABA}$ (Fachim et al., 2011)

Outros constituintes da peçonha da $P$. bistriata foram isolados e têm sido estudados para investigar possíveis atividades neuroprotetora e anticonvulsivante.

Um desses compostos em estudo é a Parawixina 11 (PW11), que tem uma massa molecular relativa de 728,5 e ainda não teve sua estrutura química determinada. O pré- 
tratamento com a PW11 foi anticonvulsivante contra a expressão de crises comportamentais agudas induzidas por NMDA (agonista do receptor de L-GLU NMDA), estriquinina (antagonista de glicina), PTZ (antagonista não-competitivo do receptor $\mathrm{GABA}_{\mathrm{A}}$ ), pilocarpina (agonista colinérgico tipo muscarínico) e bicuculina (antagonista competitivo de $\mathrm{GABA}_{\mathrm{A}}$ ). Os melhores resultados foram observados contra asinjeções de NMDA, uma vez que a dose de PW $11(0,025 \mu \mathrm{g} / \mu \mathrm{L})$ foi oito vezes menor do que a dose que impediu as crises por estriquinina, PTZ e pilocarpina $(0,20$ $\mu \mathrm{g} / \mu \mathrm{L})$ e 12 vezes menor do que a dose que impediu as crises por bicuculina $(0,30$ $\mu \mathrm{g} / \mu \mathrm{L})$. A PW11 também induz um leve aumento na atividade exploratória dos animais, em relação ao grupo controle, no open field, podendo indicar que ela não induz efeito sedativo quando administrada por via i.c.v. (Pereira et al., em preparação ${ }_{a}$ ).

Em estudos preliminares in vitro, foi demonstrado que estecomposto aumenta significativamente a ligação de GABA em SCCR. Contudo, a atividade biológica da PW11 ainda não está definida e deve ser investigada mais detalhadamente. 
2. OBJETIVOS 


\subsection{Objetivo geral}

Analisar os possíveis efeitos neuroprotetores de diferentes concentrações da Parawixina 11, utilizando um modelo de glaucoma agudo, com e sem reperfusão, em ratos Wistar.

\subsection{Objetivos específicos}

- Quantificar as células viáveis e analisar morfologicamente as lesões, decorrentes do glaucoma experimental agudo, nas retinas dos ratos de cada grupo experimental, pela histologia (H-E e Fluoro-Jade C);

- Comparar, separadamente, o efeito neuroprotetor da Parawixina 11 com o de drogas neuroprotetoras de ação já conhecida, tais como: muscimol, ácido nipecótico, ALX 5407 e riluzol.

- Verificar se a associação da Parawixina 11 com as drogas citadas anteriormentepotencializou o efeito destas e, com isso, inferir a possívelatividade biológica deste composto. 
3. MATERIAIS E MÉTODOS 
Todos os protocolos experimentais envolvendo animais foram estabelecidos conforme as diretrizes para uso de animais em pesquisa, constante na lei $\mathrm{N}^{\mathrm{o}} 11794$, de 8 de outubro de 2008. Esta criou o Conselho Nacional de Controle de Experimentação Animal (CONCEA) e regulamentou os comitês de ética na experimentação animal (CEUAs). Portanto, este trabalho foi aprovado pelo Comitê de Ética para o Uso de Animais (CEUA) da Universidade de São Paulo, Campus de Ribeirão Preto (protocolo: 2010.1.795.53.6).

\subsection{Animais}

Foram utilizados ratos Wistar, pesando entre 200-250 g, que foram fornecidos pelo Biotério Central da Universidade de São Paulo, Campus de Ribeirão Preto. Os animais foram acondicionados em grupos de quatro, em caixas de polietileno, e alojados no Biotério de Manutenção do Departamento de Biologia, com ciclo claro/escuro de 12/12 horas, temperatura $\left(25^{\circ} \mathrm{C}\right)$, umidade $(55 \%)$ controladas, com disponibilidade de água e comida ad libitum.

\subsection{Coleta das aranhas e extração das glândulas}

As aranhas (Fig. 2A) foram coletadas em Marília (SP), nos municípios vizinhos à Ribeirão Preto (SP) e em Três Lagoas (MS) e foram armazenadas em gelo durante a coleta. A extração das glândulas (Fig. 2B) foi realizada com auxílio de pinça e tesoura oftálmicas, sendo o material armazenado à $-80^{\circ} \mathrm{C}$, até posterior utilização. 


\subsection{Isolamento da Parawixina 11}

Aproximadamente quatro mil glândulas e seus reservatórios de veneno foram acondicionados em tubos tipo Eppendorf (300 glândulas por tubo), macerados e homogeneizados, formando extratos, aos quais foram adicionados $100 \mu \mathrm{L}$ de água deionizada (modelo E-pure D4641, Barnstead, EUA) por tubo. A suspensão foi centrifugada por $20 \mathrm{~min}$ a $8.500 \mathrm{xg}$, a $4^{\circ} \mathrm{C}$ em centrifuga (Eppendorf, Alemanha). $\mathrm{O}$ sobrenadante foi filtrado em filtro de $13 \mathrm{~mm}$ de diâmetro, com membrana de difluoreto de polivinilideno (PVDF) de 0,45 $\mu \mathrm{m}$ de poro (Millipore, EUA). Em seguida, foi filtrado em filtro com retenção de moléculas abaixo de 3000 Da (modelo Microcon, Millipore, EUA). Finalmente o extrato contendo apenas compostos de baixa massa molecular foi liofilizado e pesado.

O material assim obtido foi solubilizado em água deionizada e acetonitrila (9:1; v/v) e submetido à cromatografia líquida de alta eficiência (RP-HPLC; Shimadzu, Japan), usando uma coluna de fase reversa ODS C18 (15 $\mu \mathrm{L}, 20 \times 250 \mathrm{~mm}$; Phenomenex-Jupiter, EUA), injetando2 mL (40 mg/mL) da solução de peçonha e um sistema de detecção de luz ultravioleta a $215 \mathrm{~nm}$. Como solventes foram utilizados: na bomba A, água deionizada a 0,07\% de ácido trifluorácetico (TFA) e na bomba B, acetonitrila com $0,07 \%$ de TFA a um fluxo a $8,0 \mathrm{~mL} / \mathrm{min}$. O gradiente de eluição foi linear de 0 a 20 minutos a $1 \%$ de B; de 20 a 25 minutos até $20 \%$ de B e de 30 a 40 minutos até $100 \%$ de $\mathrm{B}$.

As frações obtidas foram identificadas, coletadas, liofilizadas, pesadas e monitoradas em espectrômetro de massa de alta resolução com ionização por eletrospray (Bruker Daltonics, EUA) a $10 \mathrm{~mL} /$ minuto. Água deionizada foi utilizada e o intervalo da varredura foi de m/z 50-2000. 
Esta etapa de purificação (Fig. 2C), quefoi padronizada pela Prof ${ }^{\mathrm{a}}$. Dr ${ }^{\mathrm{a}}$ Márcia Renata Mortari, também foi feita pelo Prof ${ }^{\circ}$ Dr. Leonardo Gobbo-Neto e realizada em colaboração com Prof. Dr. Norberto Peporine Lopes no Laboratório de Química Orgânica, da Faculdade de Ciências Farmacêuticas de Ribeirão Preto/ USP. A Parawixina 11, obtida pelo fracionamento sob as condições descritas acima, foi ressuspendida em salina a $0.9 \%$ para a realização dos ensaios biológicos e foi mantida em freezer à $-21^{\circ} \mathrm{C}$.

\subsection{Cirurgia: glaucoma experimental agudo - isquemia/reperfusão}

O modelo utilizado foi o de pressão de ar na câmara anterior do olho do animal, induzida por um sistema semelhante ao descrito por Louzada-Jr et al. (1992) e Guizzo. et al. (2005), que inclui uma agulha do tipo escalpe (27 G) conectada a um reservatório de ar acoplado a um manômetro. O rato, depois de anestesiado com uretana (4 mL/kg) i.p., foi contido em uma mesa cirúrgica e, em seguida, iniciou-se o aumento da pressão no olho esquerdo (experimental) (Fig. 2E), sendo o olho direito contralateral, o controle. Durante a isquemia, a pressão foi aumentada para $120 \mathrm{mmHg}$ e controlada por um manômetro, por 45 min. Nos experimentos em que houve reperfusão, a pressão foi reduzida aos níveis normais por 15 min, após a isquemia.Já nos experimentos somente de isquemia, os animais, ainda sob efeito da anestesia, foramsacrificados logo após os $45 \mathrm{~min}$.

As drogas utilizadas para tratamento foram injetadas por via intravítrea15 minutos antes do início da isquemia (Fig. 2D) no olho experimental. A injeção foi feita por um sistema constituído de uma agulha gengival (30 G) acoplada a um fio de 
polietileno que, por sua vez, foi acoplado a uma micro-seringa (Hamilton 10 $\mu \mathrm{L}$, EUA) movida por uma bomba de infusão (Insight, Brasil) com fluxo de $1 \mu \mathrm{L} / \mathrm{min}$.

\subsection{Drogas}

As drogas foram selecionadas de acordo com o tipo de receptor ou transportador com os quais cada uma interage, permitindo uma tentativa de análise de possíveis alterações no efeito da PW11 quando associada a estas drogas. Os experimentos de associação das drogas foram feitos com a concentração intermediária da PW11 (0,10 $\mu \mathrm{g} / \mu \mathrm{L})$.

Foram utilizados um agonista do receptor de $\mathrm{GABA}_{\mathrm{A}}$, o muscimol (Greenet al., 2000; Li et al., 2009); um inibidor de alta afinidade do GAT1, o ácido nipecótico (Gelfusoet al., 2007; Kvistet al., 2009;); um inibidor seletivo do transportador de glicina do tipo GLYT1, o ALX 5407 (Atkinson et al., 2001); e uma droga que aumenta a recaptação de L-GLU, o riluzol (Azbillet al., 2000; Fumagalli et al., 2008). Todas foram adquiridas da Sigma- Aldrich (EUA) e o volume injetado via intravítrea foi de 1,2 $\mu \mathrm{L}$ para cada droga, ou seja, nas associações entre duas drogas, o volume total injetado foi

2,4 $\mu \mathrm{L}$. O anestésico utilizado foi a uretana $(0,25 \mathrm{~g} / \mathrm{mL}$ diluída em água deionizada) (Acros Organics, Bélgica), injetada por via intraperitoneal (i.p.).

As diluições de muscimol, ácido nipecótico e ALX 5407 foram feitas em água deionizada. A diluição de riluzol foi em dimetilsulfóxido (DMSO) a 4,7\% (em água deionizada). As concentrações são apresentadas na Tabela 1. 
Tabela 1: Grupos experimentais estudados nesse mestrado.

\begin{tabular}{|c|c|c|c|c|c|}
\hline \multirow{2}{*}{ Grupos } & \multirow{2}{*}{ Tratamento } & \multirow{2}{*}{ ISQ } & \multirow{2}{*}{ ISQ/REP } & \multicolumn{2}{|c|}{ Histologia } \\
\hline & & & & H-E & FJC \\
\hline NAÏVE & Olho saudável (direito) & - & - & $\mathrm{X}$ & $\mathrm{X}$ \\
\hline SHAM & Somente incisão da agulha, sem aumento da PIO & - & - & $\mathrm{X}$ & $\mathrm{X}$ \\
\hline VE1 & Água deionizada (veículo) & $\mathbf{X}$ & $\mathbf{X}$ & $\mathrm{X}$ & $\mathrm{X}$ \\
\hline DMSO & DMSO 4,7\% (veículo) & $\mathbf{X}$ & $\mathbf{X}$ & $\mathrm{X}$ & $\mathrm{X}$ \\
\hline PW1 & Parawixina $11(0,05 \mu \mathrm{g} / \mu \mathrm{L})$ & $\mathbf{x}$ & $\mathbf{x}$ & $\mathrm{X}$ & $\mathrm{X}$ \\
\hline PW2 & Parawixina $11(0,10 \mu \mathrm{g} / \mu \mathrm{L})$ & $\mathbf{X}$ & $\mathbf{X}$ & $\mathrm{X}$ & $\mathrm{X}$ \\
\hline PW3 & Parawixina $11(0,20 \mu \mathrm{g} / \mu \mathrm{L})$ & $\mathbf{X}$ & $\mathbf{X}$ & $\mathrm{X}$ & $\mathrm{X}$ \\
\hline MUS & Muscimol $(5 \mu \mathrm{g} / \mu \mathrm{L})$ & $\mathbf{x}$ & $\mathbf{x}$ & $\mathrm{x}$ & $\mathrm{x}$ \\
\hline NIP & Ác. nipecótico $(3 \mu \mathrm{g} / \mu \mathrm{L})$ & $\mathbf{X}$ & $\mathbf{x}$ & $\mathrm{X}$ & $\mathrm{X}$ \\
\hline ALX & $\operatorname{ALX} 5407(0,30 \mu \mathrm{g} / \mu \mathrm{L})$ & $\mathbf{X}$ & $\mathbf{X}$ & $\mathrm{X}$ & $\mathrm{X}$ \\
\hline RIL & Riluzol $(23,45 \mu \mathrm{g} / \mu \mathrm{L})$ & $\mathbf{X}$ & $\mathbf{x}$ & $\mathrm{X}$ & $\mathrm{X}$ \\
\hline PW2+MUS & Parawixina $11(0,10 \mu \mathrm{g} / \mu \mathrm{L})+$ muscimol $(5 \mu \mathrm{g} / \mu \mathrm{L})$ & $\mathbf{X}$ & $\mathbf{X}$ & $\mathrm{X}$ & $\mathrm{X}$ \\
\hline PW2+NIP & Parawixina 11 $(0,10 \mu \mathrm{g} / \mu \mathrm{L})+$ ác. nipecótico $(3 \mu \mathrm{g} / \mu \mathrm{L})$ & $\mathbf{X}$ & $\mathbf{X}$ & $\mathrm{X}$ & $\mathrm{X}$ \\
\hline PW2+ALX & Parawixina $11(0,10 \mu \mathrm{g} / \mu \mathrm{L})+$ ALX $5407(0,30 \mu \mathrm{g} / \mu \mathrm{L})$ & $\mathbf{X}$ & $\mathbf{X}$ & $\mathrm{X}$ & $\mathrm{X}$ \\
\hline PW2+RIL & Parawixina $11(0,10 \mu \mathrm{g} / \mu \mathrm{L})+$ riluzol $(23,45 \mu \mathrm{g} / \mu \mathrm{L})$ & $x$ & $x$ & $x$ & $x$ \\
\hline
\end{tabular}

Nota: grupo SHAM, $n=2$. Demais grupos, $n=4$. ISQ $=$ isquemia. $I S Q / R E P=$ isquemia seguida por reperfusão. $\mathrm{H}-\mathrm{E}=$ hematoxilina-eosina. $\mathrm{FJC}=$ Fluoro-Jade $\mathrm{C} . \mathrm{X}=$ sim. - = não.

\subsection{Histologia}

\subsubsection{Coloração com Hematoxilina-Eosina (H-E)}

Para verificar as características estruturais da retina e quantificar as células viáveis foi realizada a coloração com H-E. Esta técnica consiste na marcação de componentes ácidos, como os núcleos, pela hematoxilina e de componentes básicos, como o citoplasma, pela eosina.

Os olhos experimentais (esquerdos) e os contralaterais foram enucleados rapidamente, imersos em solução de $\operatorname{ALFAC}(85 \mathrm{~mL}$ de álcool a $80 \%, 10 \mathrm{~mL}$ de formaldeído a $37 \%$ e $5 \mathrm{~mL}$ de ácido acético) por um período de 12 horas e, em seguida, mantidos em uma solução de álcool a $80 \%$ por até 4 dias. Depois de fixados, as córneas 
e os cristalinos foram removidos, restando uma estrutura em formato de cálice (os eyecups), queforam destinados à desidratação. Para inclusão em parafina, os eycups foram colocados em uma posição na qual a abertura ficava para os lados, na forma de um "C". Após a montagem dos blocos de parafina, as retinas foram cortadas transversalmente a $5 \mu \mathrm{m}$ de espessura e os cortes, dispostos nas lâminas, foram retirados próximos ao nervo óptico. Em seguida foram corados com H-E.

\subsubsection{Fluoro-Jade C (FJC)}

Para avaliar a degeneração dos neurônios, foi utilizado o marcador FJC. Foi utilizado um protocolo baseado no descrito por Schumed et al. (2005), com algumas modificações realizadas por Chidlow et al. (2009). Secções de $6 \mu \mathrm{m}$ de espessura foram distendidas em lâminas previamente gelatinizadas e, em seguida, essas lâminas com os cortes foram mantidas em uma estufa a $50{ }^{\circ} \mathrm{C}$ por cerca de 18 horas. Depois foram mantidas em estufa a $37{ }^{\circ} \mathrm{C}$ por, no mínimo, 6 horas. Os cortes foram desparafinizados em três banhos de xilol, reidratados em dois banhos de etanol a 100\%, um banho a 95\%, um a 75\% e um em água destilada. Em seguida, foram transferidos para uma solução de permanganato de potássio a $0,06 \%$ por $13 \mathrm{~min}$, lavados em água destilada e incubados, durante $26 \mathrm{~min}$, em 0,0001\% de solução de Fluoro-Jade C. Esta solução foi obtida adicionando 1,0 mL da solução estoque de Fluoro-Jade C (0,001\% de Fluoro-Jade C em água destilada) à $99 \mathrm{~mL}$ da solução de $0,1 \%$ de ácido acético em água destilada. As lâminas foram lavadas em três banhos de água destilada e montadas com uma solução na proporção de 1:1 (v/v) de Fluormount (Sigma-Aldrich, EUA) e 0,1\% de ácido acético. 


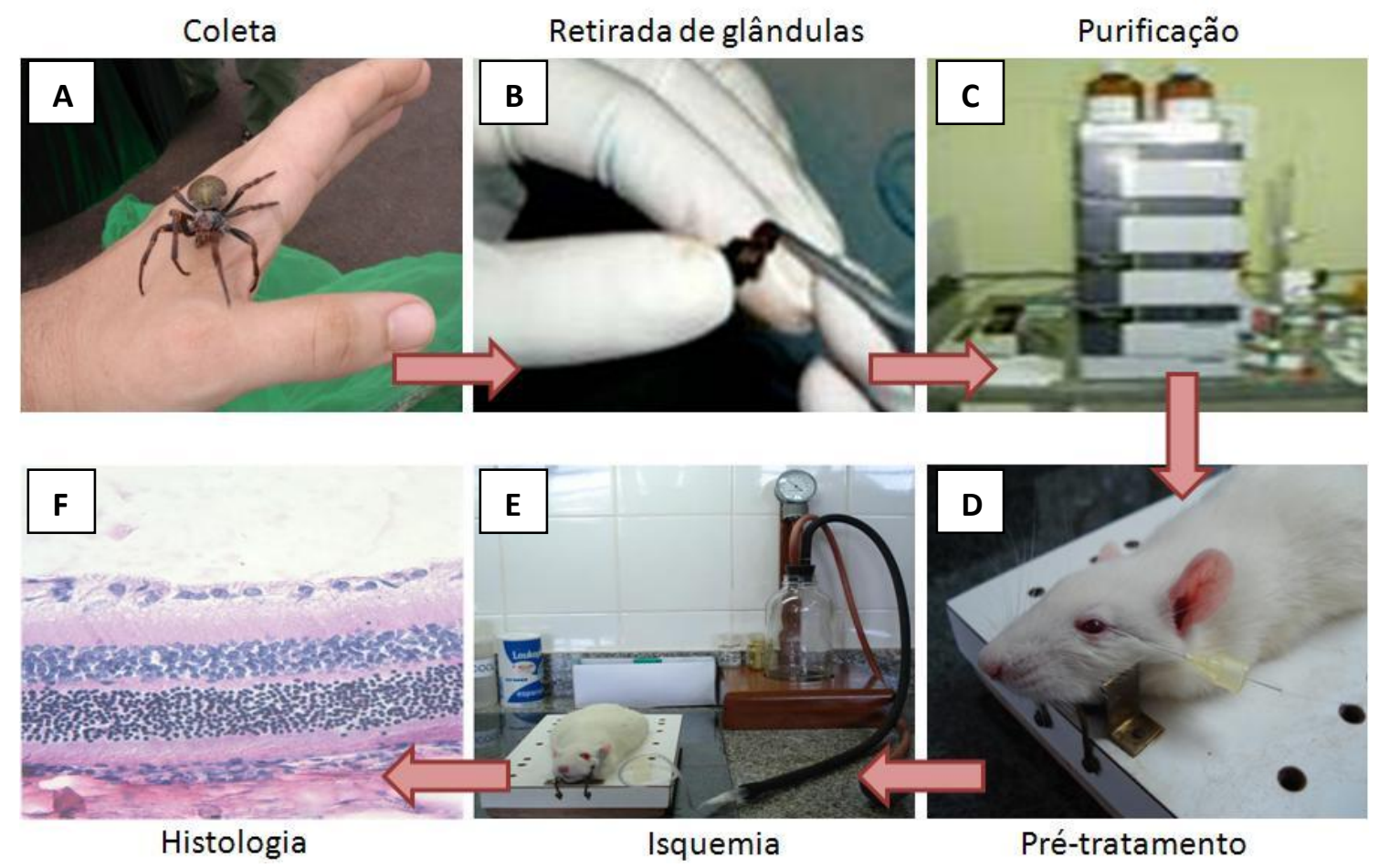

Figura 2: Fluxograma ilustrando as etapas experimentais. Fotografias dos arquivos do Laboratório de Neurobiologia e Peçonhas FFCLRP/USP. (A) aranha P. bistriata; (B) processo de separação do cefalotórax para a retirada das glândulas contendo a peçonha; (C) cromatógrafo líquido de alta eficiência usado no fracionamento da peçonha; (D) animal recebendo a injeção com um dos tratamentos; (E) sistema utilizado para elevar a $\mathrm{PIO}$ e induzir a isquemia; (F) imagem representativa da estrutura de uma retina corada com H-E.

\subsection{Captura das imagens}

Para os cortes destinados à coloração $H-E$, de cada grupo experimental $(n=4)$ foram feitas cinco capturas de imagens por retina, totalizando 20 imagens por grupo, utilizando objetiva de 40x. Os cortes foram examinados sob campo claro e a captura foi feita por um sistema que compreende uma câmera digital colorida (DFC300 FX, Leica, Alemanha), um microscópio de epifluorescência (DM 5000 B Leica, Alemanha), ambos acoplados a um computador, e o auxílio do software Q- Win (Leica Microsystems, Alemanha) para estabelecer as dimensões das imagens. 
Das lâminas destinadas à marcação por FJC, 3 imagens por retina foram examinadas utilizando uma luz de mercúrio de alta pressão e um filtro de excitação para fluoresceína/FITC. A captura foi feita pelo mesmo sistema usado para H-E.

\subsection{Análise qualitativa}

Além da organização das camadas, os aspectos morfológicos analisados nas retinas coradas com H-E, após o insulto isquêmico, foram:

- $\quad$ Picnose nuclear: ocorre devido a alterações caracterizadas por intensa contração e condensação da cromatina, tornando o núcleo reduzido de volume e hipercorado (Faria, 1977; Filho, 2004);

- Vacuolização: ocorre devido ao acúmulo de água nas mitocôndrias, transformando-as em vesículas, e por penetração de água no retículo endoplasmático, dilatando os canais que o formam (Faria, 1977);

- Edema extracelular: consiste no acúmulo de líquido no interstício, aumentando o espaço entre as células (Filho, 2004).

\subsection{Análise semi-quantitativa}

A análise das retinas marcadas com FJC foi feita de forma subjetiva, observando-se o aspecto das células FJC-positivas (FJC) e o grau de marcação das camadas analisadas. Para obter um valor numérico dessas observações, utilizou-se uma escala de medidas semi-quantitativas. Essa escala considerou a intensidade de células 
marcadas com FJC, em determinada camada, e os valores nela representados foram: $0=$ ausência de reatividade, $1=$ pouca reatividade, $2=$ reatividade moderada e $3=$ reatividade intensa. Tal forma de análise foi baseada na escala descrita por Martinez et al. (2007).

\subsection{Análise quantitativa}

Após a obtenção das cinco imagens de retinas coradas com H-E, a contagem das células foi feita manualmente, de forma mascarada, utilizando o software ImageJ (National Institutes of Health, EUA)As áreas das camadas foram medidas com o auxílio do software Q- Win (Leica Microsystems, Alemanha) e a quantidade de células viáveis por área analisada foi expressa em densidade média (células/ $\mathrm{mm}^{2} \pm$ E.P.M.). Os resultados foram normalizados utilizando o método de correção de Abercrombie (Abercrombie, 1946), de acordo com a seguinte fórmula:

$$
N\left(\text { por } \mathrm{mm}^{2}\right)=n[T /(T+D)] / A
$$

Onde $N$ é o número real de células; $n$ é o número observado de células; $T$ é a espessura da secção, $D$ é o diâmetro do núcleo e $A$ é a área medida $\left(\mathrm{mm}^{2}\right)$.

\subsection{Análise estatística}

Para a análise de dados provenientes de grupos de duas amostras (controle versus tratamento) foi utilizado o teste $\mathrm{t}$ de Student, verificando se houve diferença significativa entre estas $(\mathrm{p}<0,05$ e $\mathrm{p}<0,01)$. Para análise dos dados de mais de duas amostras de distribuições normais de variância semelhante foi utilizada análise de 
variância (ANOVA) de uma via, seguida do pós-teste de Student Newman-Keuls, tanto para as análises qualitativas, quanto para a semi-quantitativa. O programa estatístico utilizado foi o Graph Prism (versão 4.0, GraphPad Software, EUA). 
4. RESULTADOS 


\subsection{Análise qualitativa}

\subsubsection{Retinas submetidas à ISQ e ISQ/REP após injeção de veículos}

Algumas alterações que indicam degeneração tecidual e são comumente encontradas em retinas submetidas à ISQ e ISQ/REP estão agrupadas na Fig. 3, onde é destacado um núcleo picnótico (Fig. 3A.3), uma célula com vacuolização citoplasmática (Fig. 3B.1) e uma região com edema na CNI (Fig. 3C). Na Fig. 3 também está representada uma retina isqêmica sem edema na CNI (Fig. 3A), bem como núcleos de células saudáveis (Fig. 3A.1 e 3A.2). Após 45 minutos de isquemia, as retinas dos animais que receberam injeção de VE1 ou DMSO apresentaram vários núcleos picnóticos, vacuolização e desorganização, principalmente nas CNI e CCG (Fig. 4). Na CNE foi verificado edema leve e células deslocadas em algumas retinas.

Após 15 minutos de reperfusão, núcleos picnóticos foram observados nas CNI e CCG e edema na CNI. As retinas do grupo ISQ/REP apresentaram algumas células vacuolizadas, além de desorganização das camadas. 


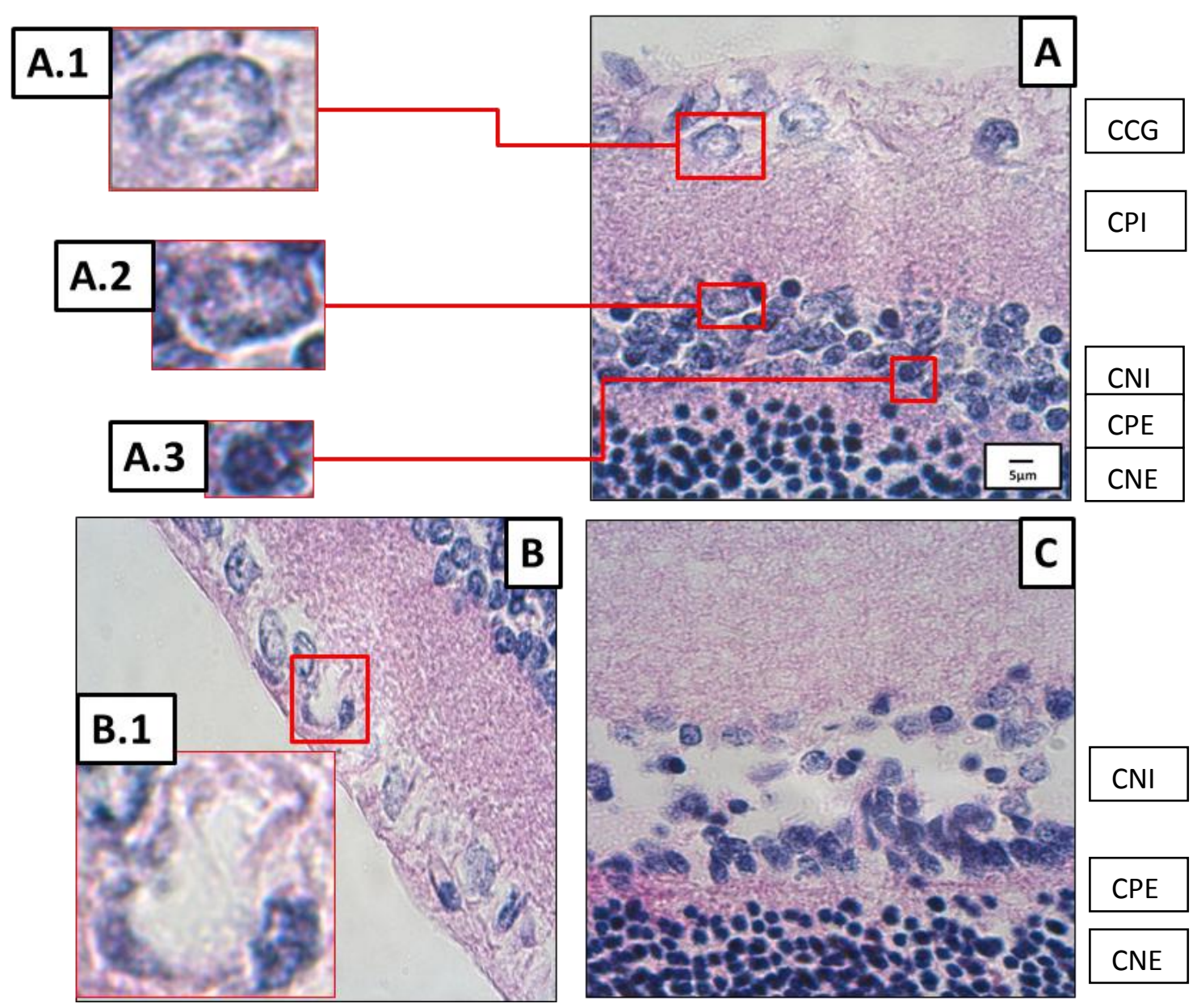

Figura 3. Fotos representativas de algumas células normais e lesionadas da retina isquêmica, sem tratamento, de ratos Wistar, em nosso estudo. Aumento de 1000x em A, B e C. A figura A apresenta a CNI sem edema. Em A1 e A2 estão destacados os núcleos de células normais, aumentados 4 e 3 vezes, respectivamenteem relação à Fig. A. Em A3está destacado um núcleo picnótico aumentado em 2 vezes também em relação à Fig. A. Em B, notar parte da CCG. Em B1, está destacada uma vacuolização, aumentada em 4,5 vezes em relação ao aumento da Fig. B. A figura Cmostra o edemaciamento da CNI. Valor da barra: $5 \mu \mathrm{m}$, inclusive para B e C.

\subsubsection{Retinas tratadas submetidas à isquemia e isquemia/reperfusão}

Nas Figuras de 4 a 9 estão representadas as retinas de todos os grupos experimentais. No decorrer das análises, foi verificada uma variação no tamanho e no formato dos núcleos presentes na CCG entre os diferentes tratamentos. 


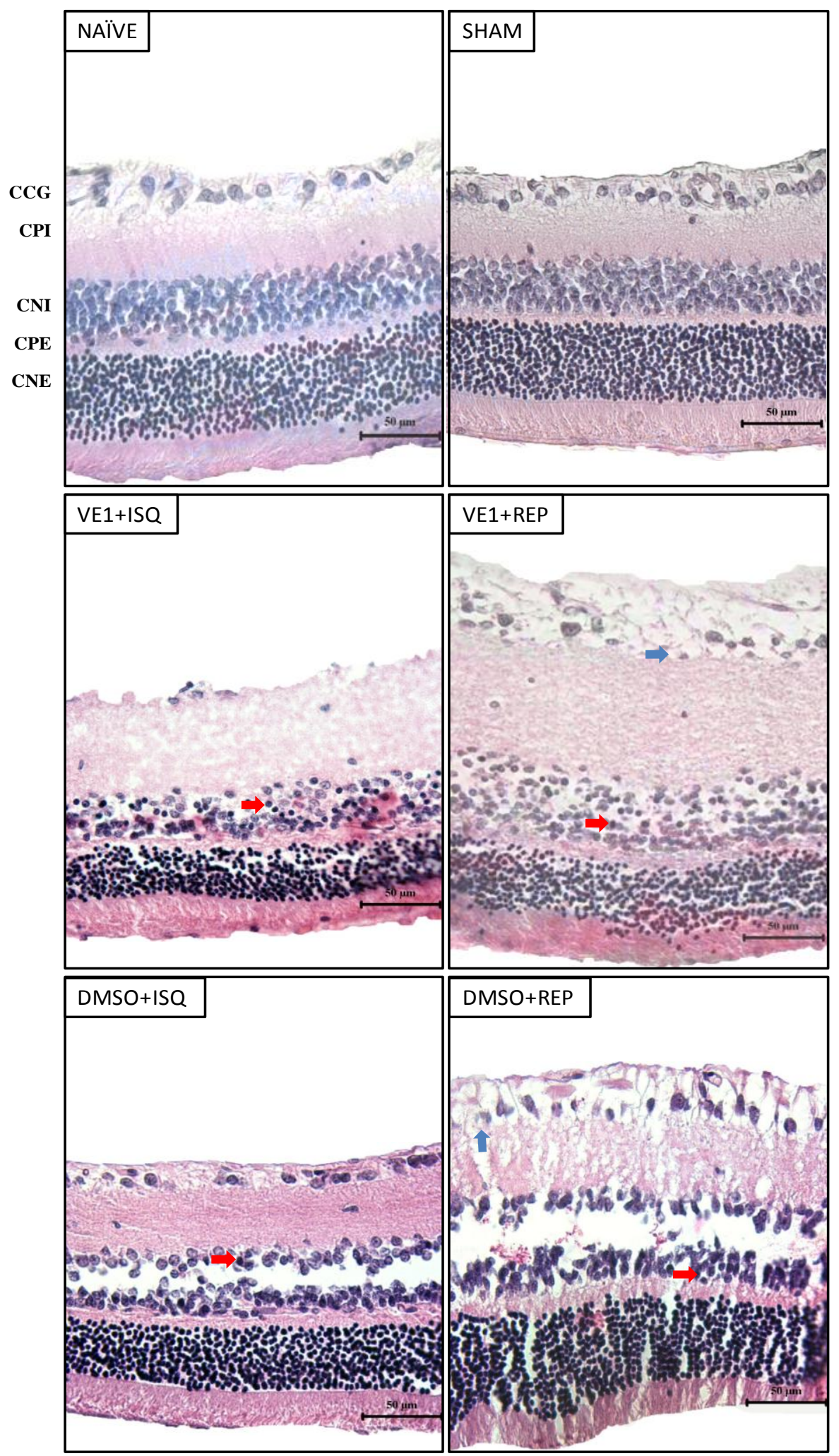

Figura4: Imagens representativas das lâminas de retinas de ratos Wistar coradas com H-E. Aumento de 400x. NAÏVE; SHAM; retinas isquêmicas pré-tratadas com: (VE1+ISQ) veículo;DMSO+ISQ; retinas isquêmicas/reperfundidas pré-tratadas com: (VE1+REP) veículo; DMSO+REP. Setas vermelhas indicam núcleos picnóticos. Setas azuis indicam vacuolização citoplasmática. Valor das barras: $50 \mu \mathrm{m}$. 
$\mathrm{Na}$ figura 5 estão representadas as retinas dos animais tratados com todas as concentrações de PW11. As retinas de ratos tratados com 0,05 e $0,10 \mu \mathrm{g} / \mu \mathrm{L}$ apresentaram alguns núcleos picnóticos na CCG e na CNI, após ISQ e ISQ/REP. Nas mesmas retinas também foi verificado um edema acentuado nessas camadas, exceto na CNI após ISQ tratada com $0,10 \mu \mathrm{g} / \mu \mathrm{L}$, que permaneceu mais conservada. A CNE manteve sua organização normal.

As retinas de ratos tratados com $0,20 \mu \mathrm{g} / \mu \mathrm{L}$ PW11 apresentaram alguns núcleos picnóticos nas CNI e CCG após ISQ e ISQ/REP. A CNI apresentou pouco edema e mostrou-se bastante conservada após isquemia. A CNE também se apresentou conservada. 


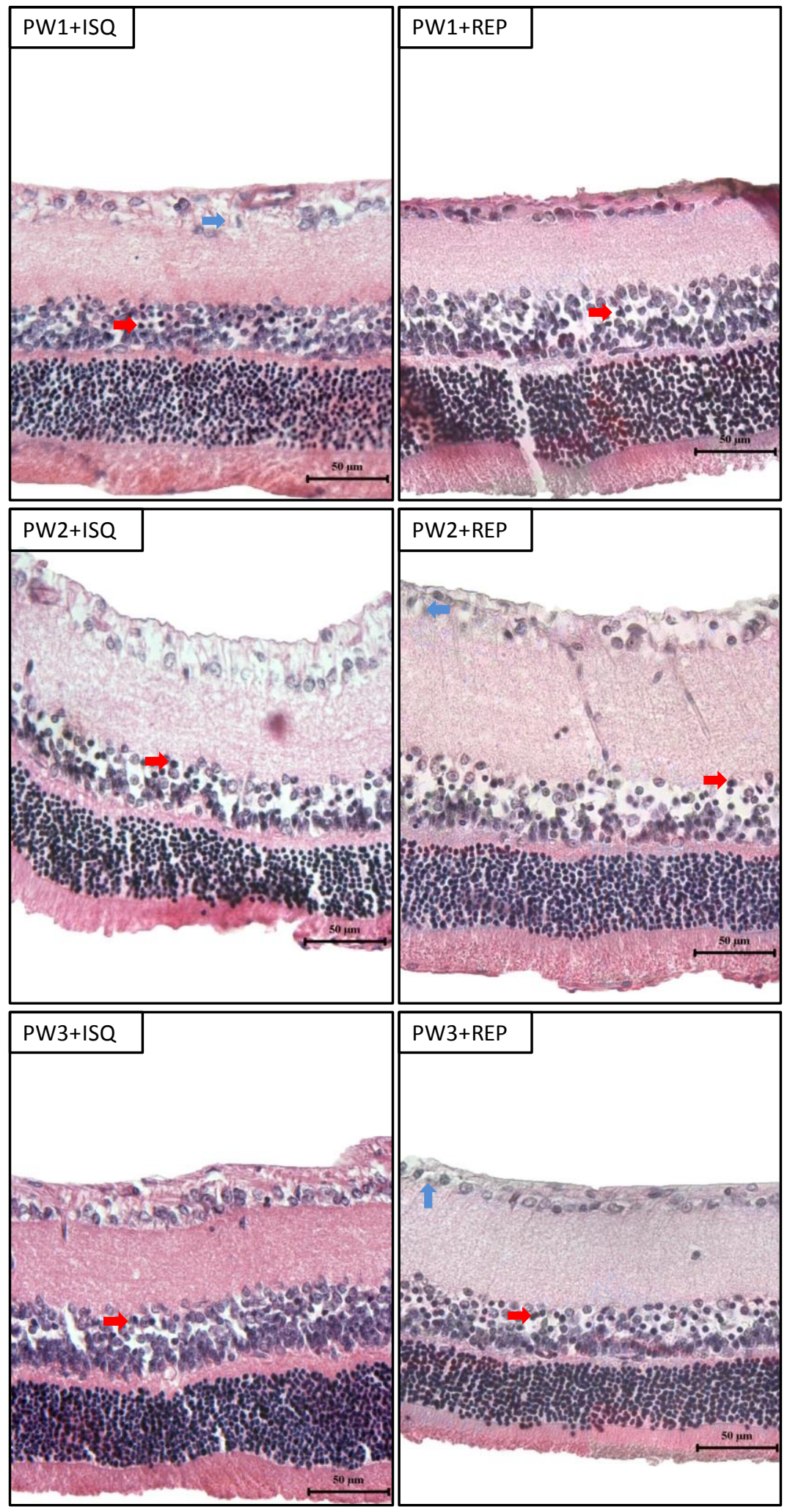

Figura 5: Imagens representativas das lâminas de retinas de ratos Wistar coradas com H-E. Aumento de 400x.Retinas isquêmicas pré-tratadas com PW11 nas doses de:

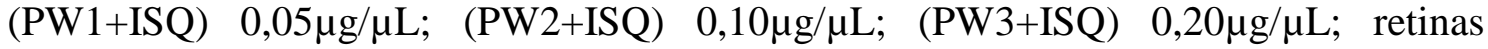
isquêmicas/reperfundidas pré-tratadas comPW11 nas doses de: (PW1+REP) 0,05 $\mu \mathrm{g} / \mu \mathrm{L}$; (PW2+REP)0,10 $\mu \mathrm{g} / \mu \mathrm{L}$; (PW3+REP) $0,20 \mu \mathrm{g} / \mu \mathrm{L}$. Setas vermelhas indicam núcleos picnóticos. Setas azuis indicam vacuolização citoplasmática. Valor das barras: $50 \mu \mathrm{m}$. 
Após ISQ, tanto as retinas pré-tratadas com $6,0 \mu \mathrm{g}$ de muscimol, como com sua associação à $0,10 \mu \mathrm{g} / \mu \mathrm{L}$ de PW11 mostraram-se organizadas, com raros núcleos picnóticos nas CNI e CCG e pouco edema nas CNE e CNI. Após ISQ/REP, nas retinas de animais tratados com muscimol e com PW2 + muscimol, alguns núcleos picnóticos foram encontrados na CNI e ocorreu pouco edema (Fig. 6).

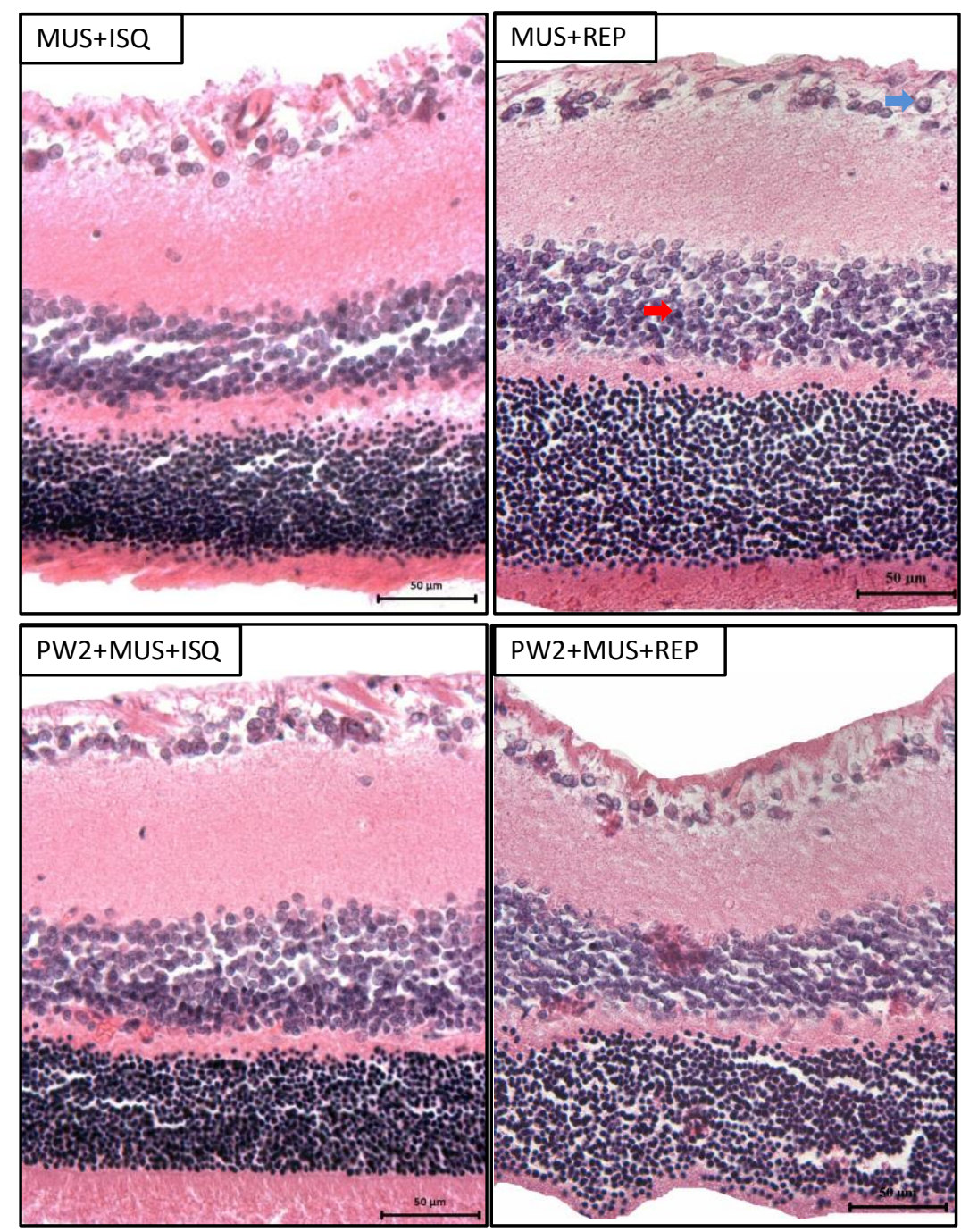

Figura 6: Imagens representativas das lâminas de retinas de ratos Wistar coradas com H-E. Aumento de 400x. Retinas isquêmicas pré-tratadas com: (MUS+ISQ) muscimol; (PW2+MUS+ISQ) muscimol + 0,10 $\mu \mathrm{g} / \mu \mathrm{L}$ de PW11; retinas isquêmicas/reperfundidas pré-tratadas com: (MUS+REP) muscimol; (PW2+MUS+REP) muscimol $+0,10 \mu \mathrm{g} / \mu \mathrm{L}$ de PW11. Setas vermelhas indicam núcleos picnóticos. Setas azuis indicam vacuolização citoplasmática. Valor das barras: $50 \mu \mathrm{m}$

As retinas tratadas com 3,6 $\mu \mathrm{g}$ de ácido nipecótico apresentaram quantidade de núcleos picnóticos e edema moderados na CCG, após ISQ e ISQ/REP. Já a CNI 
apresentou edema moderado e muitos núcleos picnóticos após ISQ, com redução após ISQ/REP. A CNE apresentou edema após ISQ/REP. As retinas dos animais tratados com PW2 + ácido nipecótico apresentaram raros núcleos picnóticos na CCG e edema reduzido nesta camada, após ISQ e ISQ/REP. Após ISQ, uma quantidade moderada de núcleos picnóticos foi encontrada na CNI, também houve edema (Fig. 7).

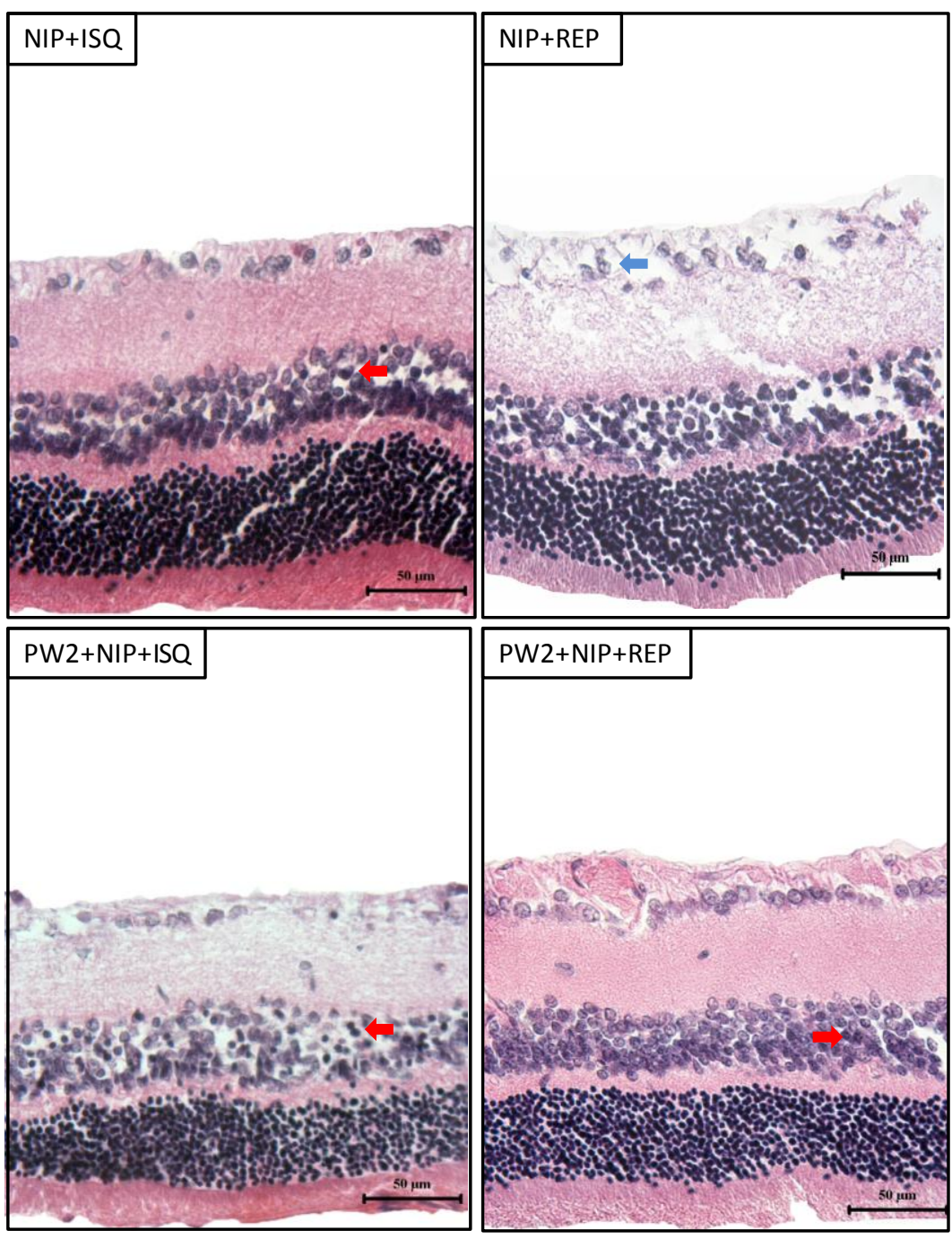

Figura 7: Imagens representativas das lâminas de retinas de ratos Wistar coradas com H-E. Aumento de 400x. Retinas isquêmicas pré-tratadas com: (NIP+ISQ) ácido nipecótico; (PW2+NIP+ISQ)ácido nipecótico $+0,10 \mu \mathrm{g} / \mu \mathrm{L}$ de $\mathrm{PW} 11$; retinas isquêmicas/reperfundidas pré-tratadas com: (NIP+REP) ácido nipecótico; $(\mathrm{PW} 2+\mathrm{NIP}+\mathrm{REP})$ ácido nipecótico $+0,10 \mu \mathrm{g} / \mu \mathrm{L}$ de PW11. Setas vermelhas indicam núcleos picnóticos. Setas azuis indicam vacuolização citoplasmática. Valor da barra: 50 $\mu \mathrm{m}$. 
As retinas pré-tratadas com $0,36 \mu$ g de ALX 5407 mostraram alguns núcleos picnóticos na CCG e na CNI, além de edema moderado, nas CNI e CCG após ISQ e ISQ/REP. Após ISQ, houve pouco edema na CNE, que passou a ser moderado após ISQ/REP. A associação com $0,10 \mu \mathrm{m} / \mu \mathrm{L}$ de PW1 apresentou vários núcleos picnóticos na CNI após reperfusão (Fig. 8).

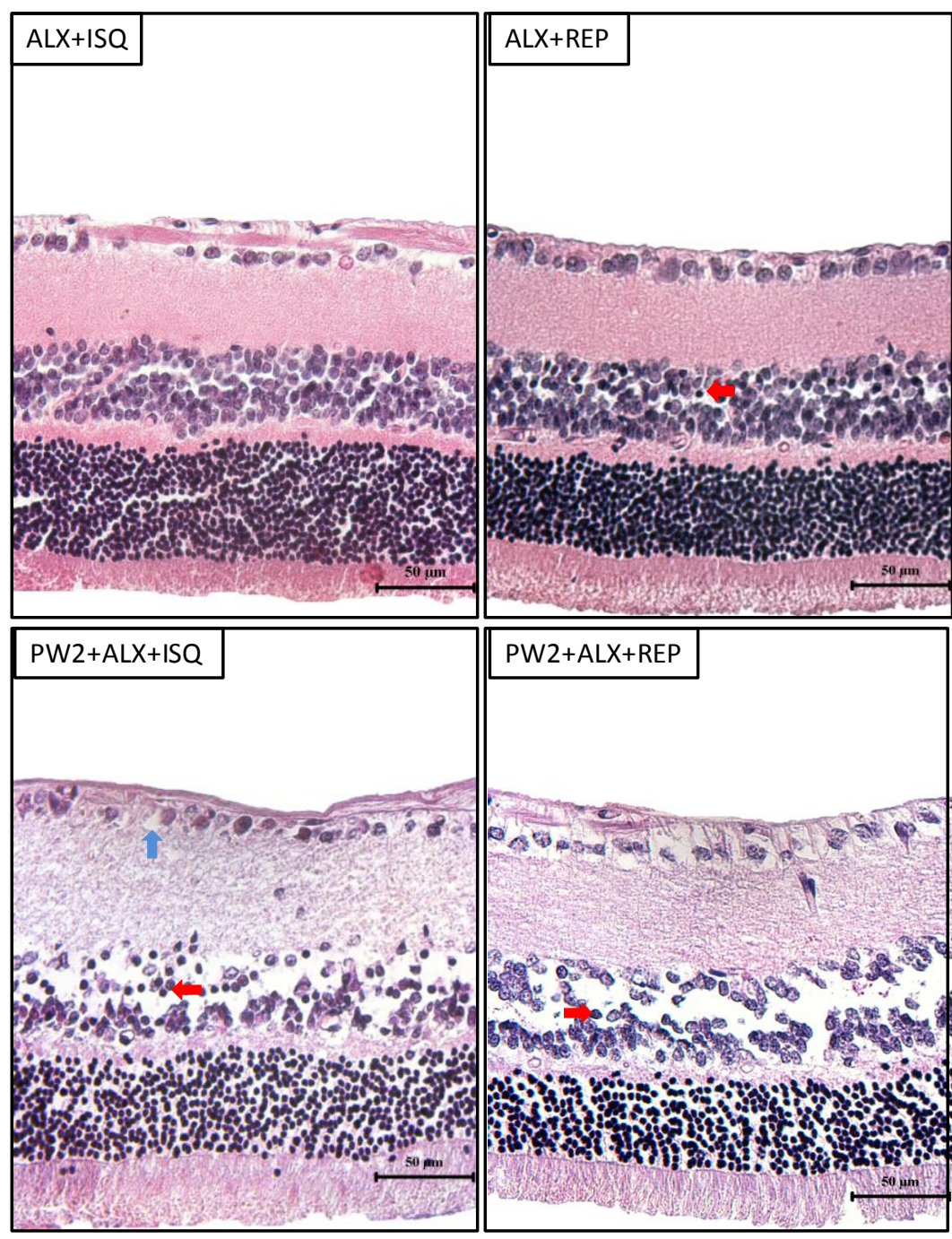

Figura 8: Imagens representativas das lâminas de retinas de ratos Wistar coradas com H-E. Aumento de 400x. Retinas isquêmicas pré-tratadas com: (ALX+ISQ) ALX 5407; $(\mathrm{PW} 2+\mathrm{ALX}+\mathrm{ISQ}) \mathrm{ALX} 5407+0,10 \mu \mathrm{g} / \mu \mathrm{L}$ de Parawixina; retinas isquêmicas/reperfundidas pré-tratadas com: (ALX+REP) ALX 5407; $(\mathrm{PW} 2+\mathrm{ALX}+\mathrm{REP})$ ALX $5407+0,10 \mu \mathrm{g} / \mu \mathrm{L}$ de Parawixina. Setas vermelhas indicam núcleos picnóticos. Setas azuis indicam vacuolização citoplasmática. Valor da barra: 50 $\mu \mathrm{m}$. 
As retinas pré-tratadas com $28,1 \mu \mathrm{g}$ de riluzol apresentaram raros núcleos picnóticos nas CNI e CCG, bem como edema reduzido na CNI e CCG após ISQ. Após ISQ/REP o edema foi moderado na CNI. A CNE apresentou edema moderado após ISQ e ISQ/REP. A quantidade de núcleos picnóticos passou a ser moderada na CNI e CCG quando houve associaçãode riluzol $+0,10 \mu \mathrm{m} / \mu \mathrm{L}$ de PW11, após ISQ e ISQ/REP, além disso, edema leve foi observado na CNI após ISQ (Fig. 9).

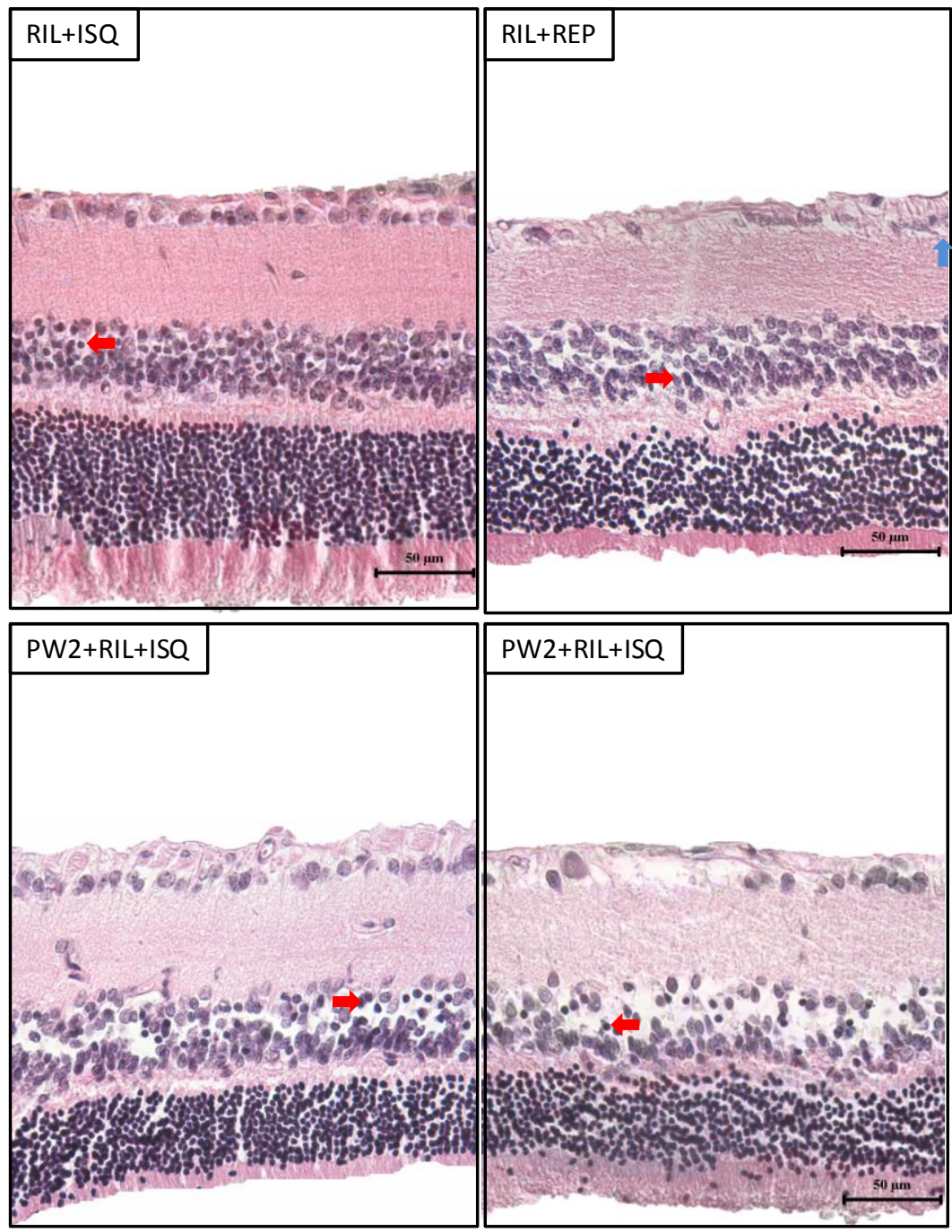

Figura 9: Imagens representativas das lâminas de retinas de ratos Wistar coradas com H-E. Aumento de 400x. Retinas isquêmicas pré-tratadas com: (RIL+ISQ) riluzol; (PW2+RIL+ISQ)riluzol + 0,10 $\mu \mathrm{g} / \mu \mathrm{L}$ de PW11; retinas isquêmicas/reperfundidas prétratadas com: (RIL+REP) riluzol; (PW2+RIL+REP) riluzol + 0,10 $\mu \mathrm{g} / \mu \mathrm{L}$ de PW11. Setas vermelhas indicam núcleos picnóticos. Setas azuis indicam vacuolização citoplasmática. Valor da barra: $50 \mu \mathrm{m}$. 


\subsubsection{Fluoro-Jade C}

Para avaliar degeneração de neurônios, foi feita a coloração com Fluoro-Jade C. Nas Figuras de 10 a 15 estão representadas as retinas de cada tratamento.

Após isquemia, as retinas NAÏVE e SHAM não apresentaram marcação de neurônios, já as retinas de ratos que receberam VE1 ou DMSO apresentaram grande quantidade de neurônios FJC-positivosna CCG (Fig.10). Na CNI, as retinas tratadas com VE1+ISQ também apresentaram intensa marcação. Após REP, houve intensa marcação de axônios na CPI nos grupos que receberam VE1 e DMSO. 


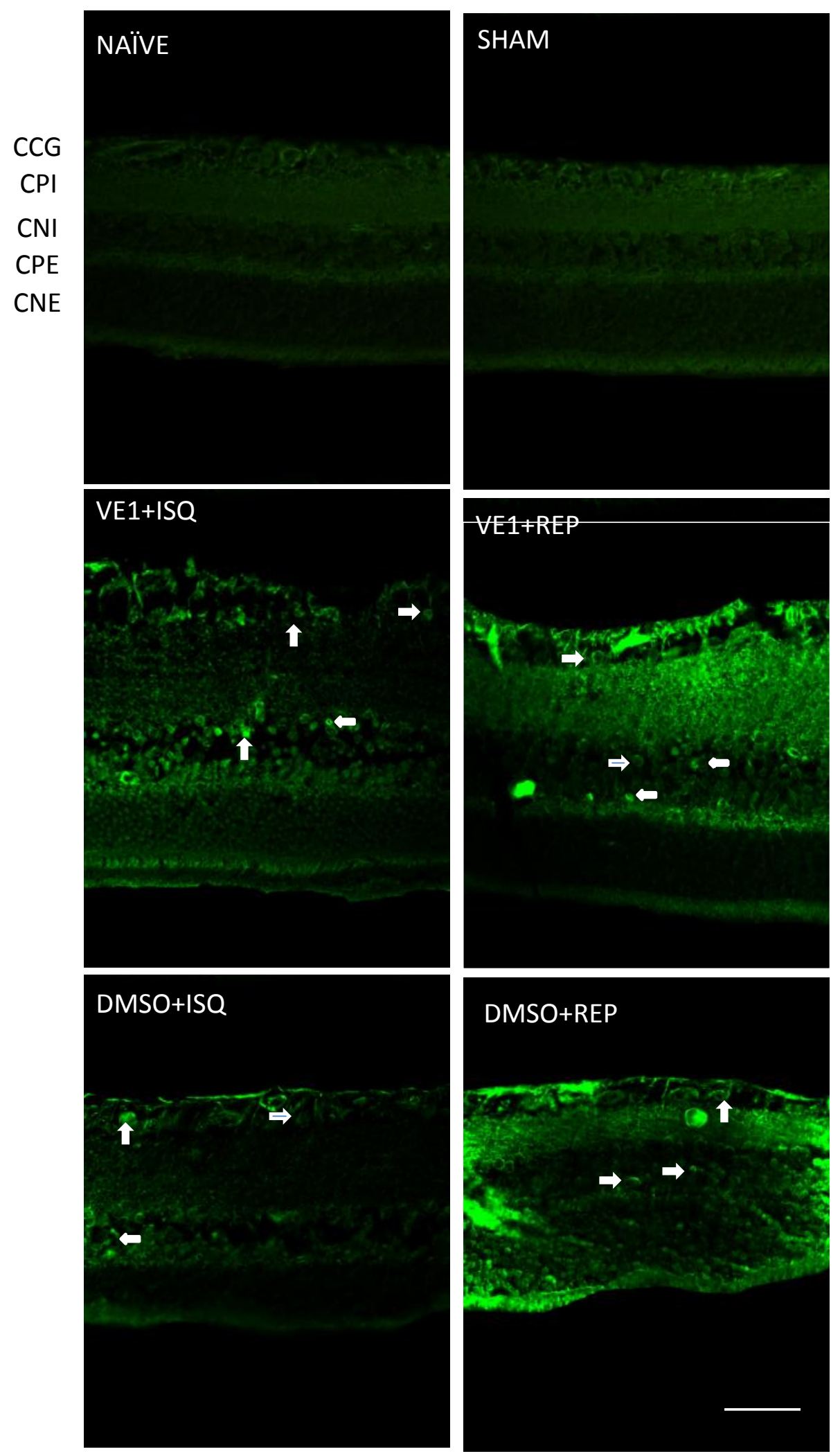

Figura 10: Imagens representativas das lâminas de retinas de ratos Wistar coradas com FJC. Aumento de 400x. NAÏVE; SHAM; retinas isquêmicas pré-tratada com: (VE1+ISQ) veículo;DMSO+ISQ; retinas isquêmicas/reperfundidas pré-tratadas com: (VE1+REP) veículo; DMSO+REP.Setas brancas apontam para alguns pontos mais fluorescentes, indicando células em degeneração. Valor da barra: $50 \mu \mathrm{m}$. 
As retinas dos ratos tratados com $0,05 \mu \mathrm{g} / \mu \mathrm{L}$ e $0,1 \mu \mathrm{g} / \mu \mathrm{L}$ de PW11 apresentaram algumas células em degeneração na CNI e na CCG, após ISQ e ISQ/REP. As retinas tratadas com $0,2 \mu \mathrm{g} / \mu \mathrm{L}$ apresentaram algumas células FJCpositivas na CCG, mas poucas foram encontradas na CNI, após ISQ e ISQ/REP (Fig. $11)$. 


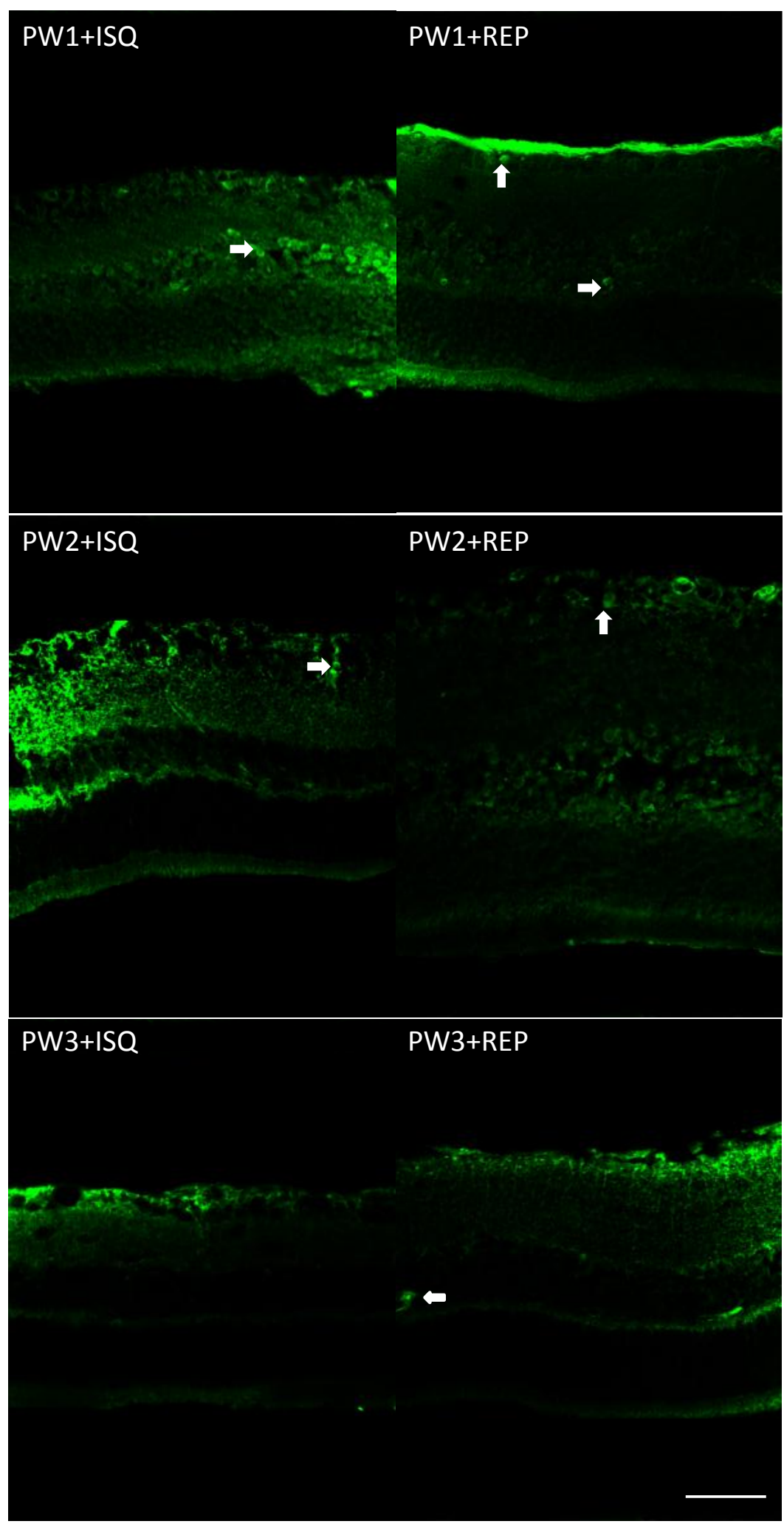

Figura 11: Imagens representativas das lâminas de retinas de ratos Wistar coradas com FJC. Aumento de 400x. Retinas isquêmicas pré-tratadas com PW11 nas doses de:

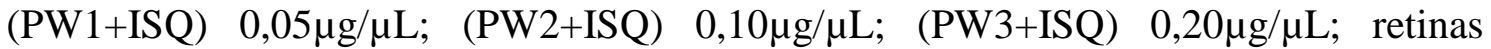
isquêmicas/reperfundidas pré-tratadas com PW11 nas doses de: (PW1+REP)

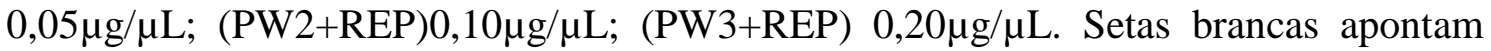
para alguns pontos mais fluorescentes, indicando células em degeneração. Valor da barra: $50 \mu \mathrm{m}$. 
As retinas tratadas com $6,0 \mu \mathrm{g}$ de muscimol apresentaram pouca degeneração de neurônios na CNI após ISQ e ISQ/REP. As retinas tratadas com PW2+MUS apresentaram um pouco mais de marcação na CPI após ISQ/REP e algumas células na CCG e na CNI após ISQ/REP como pode ser verificado na Fig. 12.

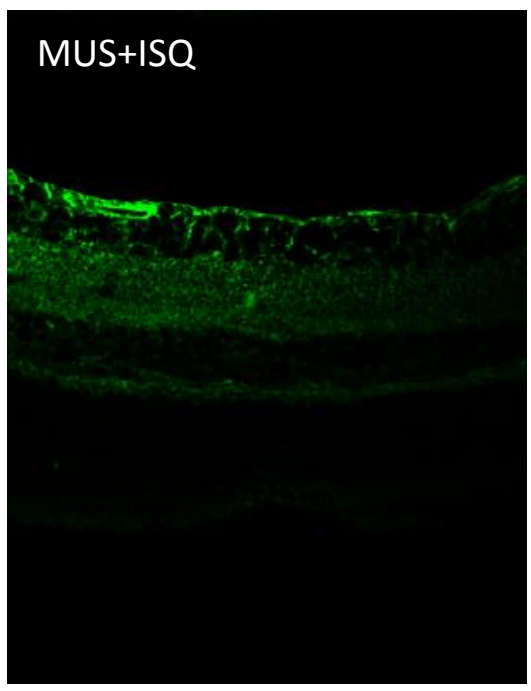

\section{MUS+REP}
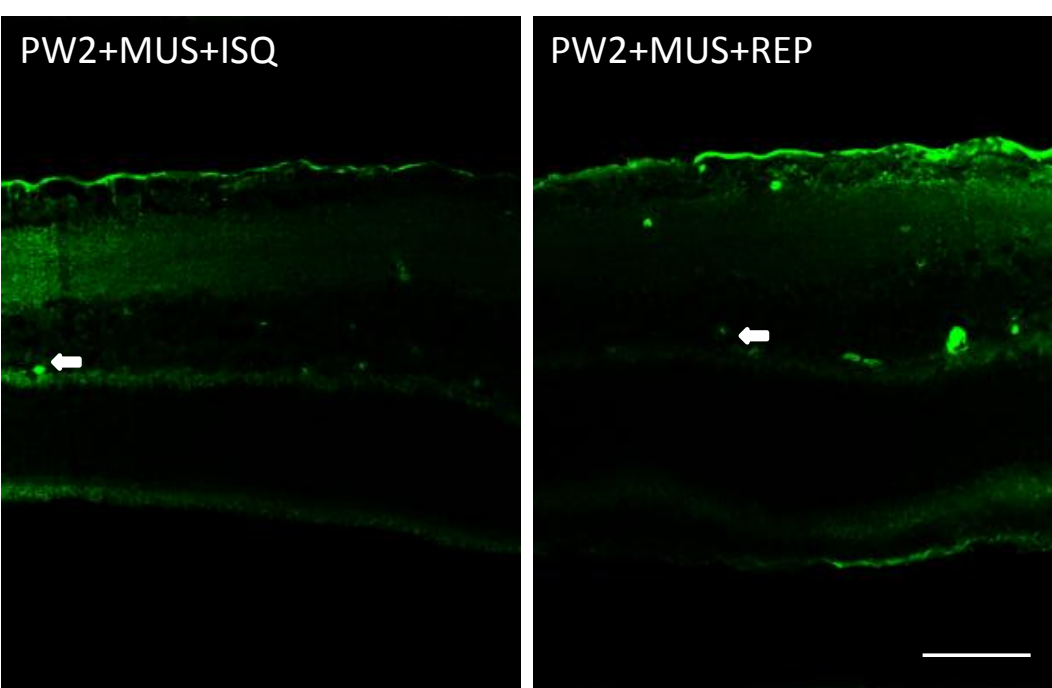

Figura 12: Imagens representativas das lâminas de retinas de ratos Wistar coradas com FJC. Aumento de 400x. Retinas isquêmicas pré-tratadas com: (MUS+ISQ) muscimol; (PW2+MUS+ISQ) muscimol $+0,10 \mu \mathrm{g} / \mu \mathrm{L}$ de PW11; retinas isquêmicas/reperfundidas pré-tratadas com: (MUS+REP) muscimol; (PW2+MUS+REP) muscimol +0,10 $\mu \mathrm{g} / \mu \mathrm{L}$ de PW11. Setas brancas apontam para alguns pontos mais fluorescentes, indicando células em degeneração. Valor da barra: $50 \mu \mathrm{m}$. 
As retinas tratadas com 3,6 $\mu \mathrm{g}$ de ácido nipecótico apresentaram alguns neurônios em degeneração na CNI, após ISQ e ISQ/REP. As retinas dos animais tratados com PW2+NIP apresentaram marcação mais intensa na CNI, se comparadas com o tratamento somente com NIP, após ISQ (Fig.13).

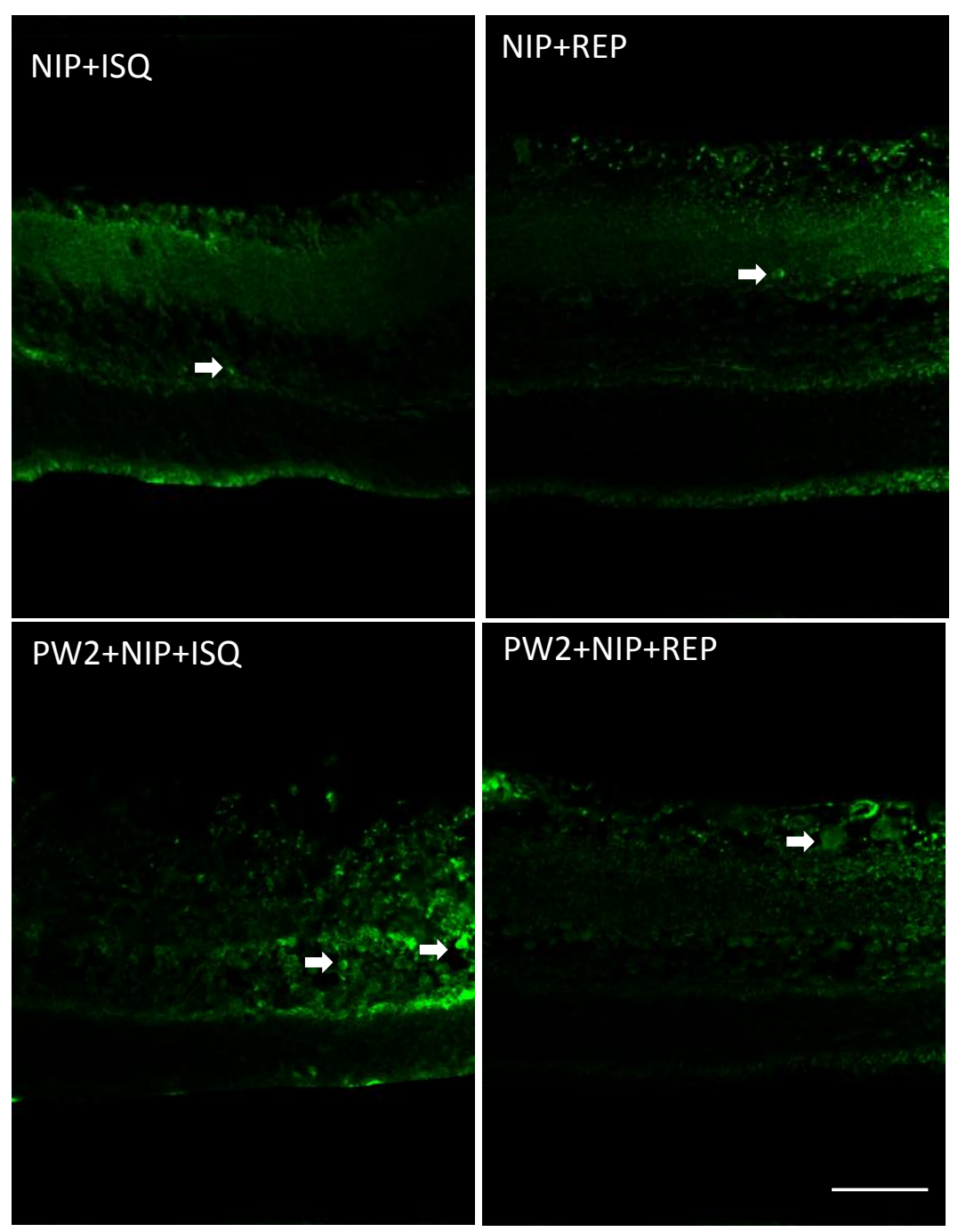

Figura 13: Imagens representativas das lâminas de retinas de ratos Wistar coradas com FJC. Aumento de 400x. Retinas isquêmicas pré-tratadas com: (NIP+ISQ) ácido nipecótico; (PW2+NIP+ISQ)ácido nipecótico $+0,10 \mu \mathrm{g} / \mu \mathrm{L}$ de $\mathrm{PW} 11$; retinas isquêmicas/reperfundidas pré-tratadas com: (NIP+REP) ácido nipecótico; (PW2+NIP+REP) ácido nipecótico $+0,10 \mu \mathrm{g} / \mu \mathrm{L}$ de PW11. Setas brancas apontam para alguns pontos mais fluorescentes, indicando células em degeneração. Valor da barra: 50 $\mu \mathrm{m}$. 
As retinas tratadas com $0,36 \mu \mathrm{g}$ de ALX apresentaram algumas células em degeneração na CNI e na CCG (Fig.14). Após tratamento com PW2+ALX a marcação na CCG e na CNI foi mais intensa após ISQ, se comparada com a do tratamento somente com ALX. Após ISQ/REP houve menos marcação da CPI nas retinas do grupo PW2+ALX, se comparada com a do grupo ALX.
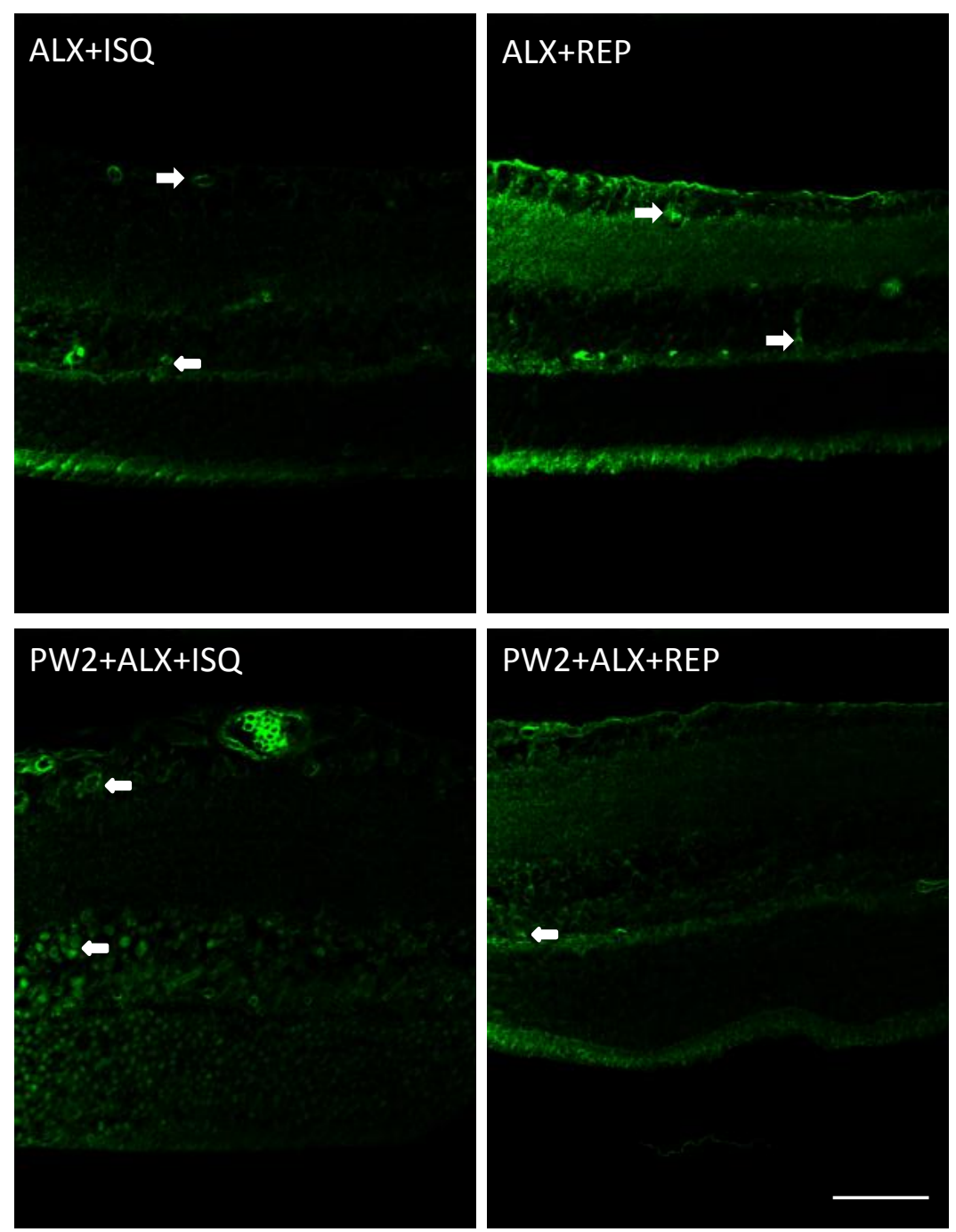

Figura 14: Imagens representativas das lâminas de retinas de ratos Wistar coradas com FJC. Aumento de 400x. Retinas isquêmicas pré-tratadas com: (ALX+ISQ) ALX 5407; (PW2+ALX+ISQ) ALX $5407+0,10 \mu \mathrm{g} / \mu \mathrm{L}$ de PW11; retinas isquêmicas/reperfundidas pré-tratadas com: (ALX+REP) ALX 5407; (PW2+ALX+REP) ALX $5407+0,10 \mu \mathrm{g} / \mu \mathrm{L}$ de PW11. Setas brancas apontam para alguns pontos mais fluorescentes, indicando células em degeneração. Valor da barra: $50 \mu \mathrm{m}$. 
Na CNI das retinas tratadas com RIL poucas células em degeneração foram encontradas, após ISQ e ISQ/REP. Na CNI e na CCG das retinas tratadas com PW2+RIL houve um pequeno aumento na marcação se comparada às retinas tratadas somente com RIL após ISQ/REP (Fig 15).

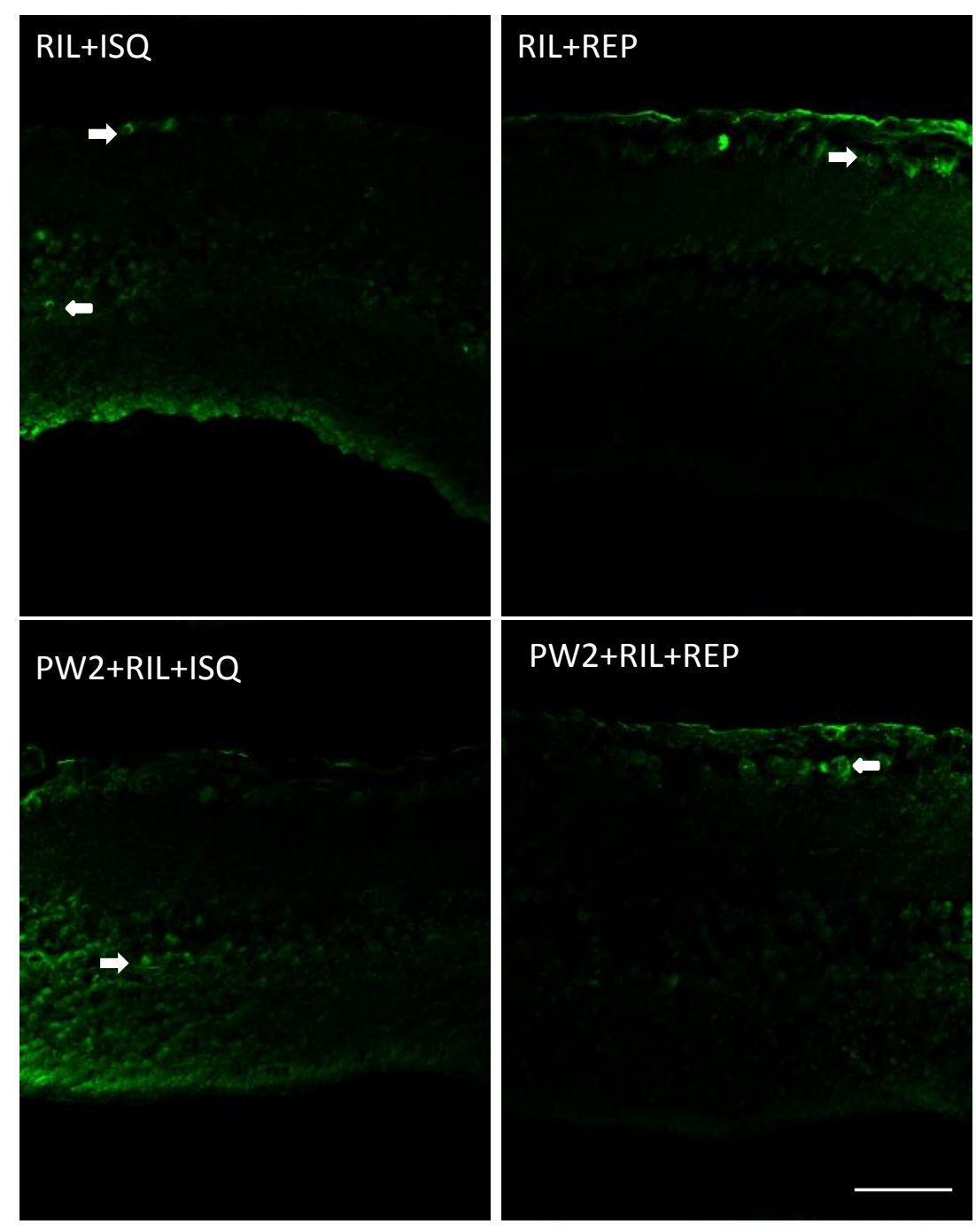

Figura 15: Imagens representativas das lâminas de retinas de ratos Wistar coradas com FJC. Aumento de 400x. Retinas isquêmicas pré-tratadas com: (RIL+ISQ) riluzol; (PW2+RIL+ISQ)riluzol $+0,10 \mu \mathrm{g} / \mu \mathrm{L}$ de PW11; retinas isquêmicas/reperfundidas prétratadas com: (RIL+REP) riluzol; (PW2+RIL+REP) riluzol + 0,10 $\mu \mathrm{g} / \mu \mathrm{L}$ de PW11. Setas brancas apontam para alguns pontos mais fluorescentes, indicando células em degeneração. Valor da barra: $50 \mu \mathrm{m}$. 


\subsection{Análise semi-quantitativa das retinas}

Para a análise semi-quantitativa das retinas marcadas com FJC, um valor foi atribuído de acordo com os aspectos das camadas nucleares. A CNE da maioria dos animais, não apresentou células FJC-positivas, portanto, foram analisadas somente as CCG e CNI. Os animais do grupo NAÏVE e SHAM não apresentaram neurônios em degeneração já os animais do grupo VE1 e DMSO apresentaram marcação intensa após ISQ e ISQ/REP. Os demais grupos apresentaram pouca marcação na CCG e, na CNI, somente o grupo PW2+ALX apresentou marcação moderada (Tabela 2).

Dentre as três doses de PW11, a PW3 foi a que apresentou os menores valores

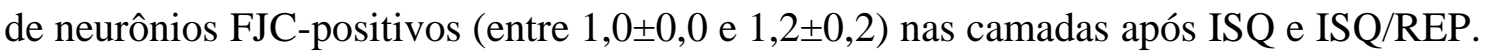
A PW2 apresentou valores entre $1,2 \pm 0,2 \mathrm{e} 1,7 \pm 0,2$ e a PW1 entre $1,2 \pm 0,2$ e $1,3 \pm 0,2$.

As associações da PW11 que apresentaram as camadas com menos neurônios em degeneração após ISQ foram: PW2+RIL ( $p<0,001)$ e PW2+MUS ( $p<0,01)$, na CCG; PW2+MUS e PW2+NIP (ambos p < 0,001) e PW2+RIL (p < 0,01), na CNI. Já após reperfusão, essses tratamentos foram: PW2+MUS, PW2+NIP e PW2+ALX (ambos $\mathrm{p}<0,001$ ), na CCG; todas as associações foram significativamente protetoras $(\mathrm{p}<0,001)$ na CNI, mas as que apresentaram menores valores foram PW2+MUS e PW2+ALX. 
Tabela 2. Intensidade de células FJC-positivas, baseada na escala de Martinez et al. (2007), na CCG e CNI após ISQ e ISQ/REP.

\begin{tabular}{lcccc}
\hline & \multicolumn{2}{c}{ Isquemia } & \multicolumn{2}{c}{ Isquemia/Reperfusão } \\
\hline & CCG & CNI & CCG & CNI \\
NAÏVE & $0,0 \pm 0,0$ & $0,0 \pm 0,0$ & $0,0 \pm 0,0$ & $0,0 \pm 0,0$ \\
SHAM & $0,0 \pm 0,0$ & $0,0 \pm 0,0$ & $0,0 \pm 0,0$ & $0,0 \pm 0,0$ \\
\hline VE1 & $2,7 \pm 0,2^{\mathrm{c}}$ & $2,8 \pm 0,2^{\mathrm{c}}$ & $2,8 \pm 0,2^{\mathrm{c}}$ & $3,0 \pm 0,0^{\mathrm{c}}$ \\
DMSO & $2,5 \pm 0,2^{\mathrm{c}}$ & $2,2 \pm 0,3^{\mathrm{c}}$ & $2,5 \pm 0,2^{\mathrm{c}}$ & $2,5 \pm 0,2^{\mathrm{c}}$ \\
PW1 & $1,3 \pm 0,2^{\mathrm{b}}$ & $1,3 \pm 0,2^{\mathrm{c}}$ & $1,3 \pm 0,2^{\mathrm{c}}$ & $1,2 \pm 0,2^{\mathrm{c}}$ \\
PW2 & $1,2 \pm 0,2^{\mathrm{c}}$ & $1,2 \pm 0,2^{\mathrm{c}}$ & $1,7 \pm 0,2^{\mathrm{c}}$ & $1,5 \pm 0,2^{\mathrm{c}}$ \\
PW3 & $1,2 \pm 0,2^{\mathrm{c}}$ & $1,0 \pm 0,0^{\mathrm{c}}$ & $1,2 \pm 0,2^{\mathrm{c}}$ & $1,2 \pm 0,2^{\mathrm{c}}$ \\
MUS & $1,5 \pm 0,2^{\mathrm{b}}$ & $1,0 \pm 0,0^{\mathrm{c}}$ & $1,2 \pm 0,2^{\mathrm{c}}$ & $1,0 \pm 0,0^{\mathrm{c}}$ \\
PW2+MUS & $1,5 \pm 0,2^{\mathrm{b}}$ & $1,2 \pm 0,2^{\mathrm{c}}$ & $1,2 \pm 02^{\mathrm{c}}$ & $1,0 \pm 0,0^{\mathrm{c}}$ \\
NIP & $1,2 \pm 0,1^{\mathrm{c}}$ & $1,0 \pm 0,0^{\mathrm{c}}$ & $1,8 \pm 0,3^{\mathrm{b}}$ & $1,3 \pm 0,2^{\mathrm{c}}$ \\
PW2+NIP & $1,7 \pm 0,3^{\mathrm{a}}$ & $1,3 \pm 0,2^{\mathrm{c}}$ & $1,2 \pm 0,2^{\mathrm{c}}$ & $1,3 \pm 0,2^{\mathrm{c}}$ \\
ALX & $1,3 \pm 0,2^{\mathrm{b}}$ & $1,2 \pm 0,2^{\mathrm{c}}$ & $1,2 \pm 0,2^{\mathrm{c}}$ & $1,2 \pm 0,2^{\mathrm{c}}$ \\
\hline PW2+ALX & $1,8 \pm 0,3^{\mathrm{a}}$ & $2,0 \pm 0,3^{\mathrm{b}}$ & $1,3 \pm 0,2^{\mathrm{c}}$ & $1,0 \pm 0,0^{\mathrm{c}}$ \\
RIL & $1,5 \pm 0,2^{\mathrm{a}}$ & $1,2 \pm 0,2^{\mathrm{b}}$ & $1,3 \pm 0,2^{\mathrm{b}}$ & $1,2 \pm 0,2^{\mathrm{c}}$ \\
\hline PW2+RIL & $1,0 \pm 0,0^{\mathrm{c}}$ & $1,2 \pm 0,2^{\mathrm{b}}$ & $1,5 \pm 02^{\mathrm{b}}$ & $1,3 \pm 0,2^{\mathrm{c}}$ \\
\hline
\end{tabular}

Nota: Os dados representam a média + E.P.M de uma escala de valores da quantidade de neurônios FJC-positivos nas retinas de ratos Wistar. Foram analisadas 6 imagens por grupo. A escala contém as seguintes categorias: $0=$ ausência; $1=$ pouca; $2=$ moderada $\mathrm{e}$ $3=$ intensa. Considerar $\mathrm{a}=\mathrm{p}<0,05, \quad \mathrm{~b}=\mathrm{p}<0,01$ e $\mathrm{c}=\mathrm{p}<0,001$ em relação aos respectivos veículos (DMSO para RIL e PW2+RIL e VE1 para os demais grupos).

\subsection{Análise quantitativa das retinas}

\subsubsection{Retinas submetidas à isquemia}

Nos experimentos de isquemia, as médias da densidade celular mostraram que houve diferença entre os tratamentos na $\mathrm{CNE}\left[\mathrm{F}_{(14,246)}=6,157 ; \mathrm{p}<0,0001\right]$, na CNI $\left[\mathrm{F}_{(14,260)}=8,710 ; \mathrm{p}<0,0001\right]$ e na CCG $\left[\mathrm{F}_{(14,258)}=9,120 ; \mathrm{p}<0,0001\right]$. 
Na CCG, após ISQ (Fig. 16), as retinas dos grupos de ratos que receberam veículo e DMSO apresentaram uma redução na densidade celular de 37,33 e 58,55\%, respectivamente, em relação às retinas do grupo NAÏVE e redução de 34,40 e 56,60\% em relação às retinas do grupo SHAM. Os tratamentos com 0,05 e 0,2 $\mu \mathrm{g} / \mu \mathrm{L}$ de PW11, com PW2+ALX e com NIP não protegeram a CCG. As retinas tratadas com $0,1 \mu \mathrm{g} / \mu \mathrm{L}$ de PW11 e com MUS apresentaram, respectivamente, 5,95 e 4,06\% mais células do que as do grupo VE1. As associações PW2+MUS e PW2+NIP protegeram significativamente 37,07 e 44,81\%, das retinas quando comparadas ao grupo VE1, respectivamente. O ALX protegeu 20,73\% das retinas quando comparado com o grupo VE1. O RIL protegeu significativamente $70,41 \%$ da CCG em comparação com o grupo DMSO.O tratamento com PW2+RIL preservou54,79\% da CCG, em comparação com o DMSO.

O tratamento com PW2+MUS protegeu 31,70 e 29,35\% mais células do que os grupos tratados somente com MUS ou PW2, respectivamente. Além disso, a associação de PW2+NIP protegeu 45,09 e 36,67 \% mais células do que os grupos tratados somente com NIP ou PW2, respectivamente. A associação de PW2+ALX, reduziu a densidade celular em 22,66 e 11,87\%, quando comparada com ALX e PW2, respectivamente. As retinas dos animais tratados com PW2+RIL apresentaram 9,16 e 3,36\% menos células, em comparação aos grupos RIL e PW2, respectivamente (Tabela 3).

Comparando o efeito individual das drogas testadas, a densidade de células na CCG foi similar entre os tratamentos com PW2 (889 células $/ \mathrm{mm}^{2}$ ) e com MUS (873 células $/ \mathrm{mm}^{2}$ ). 


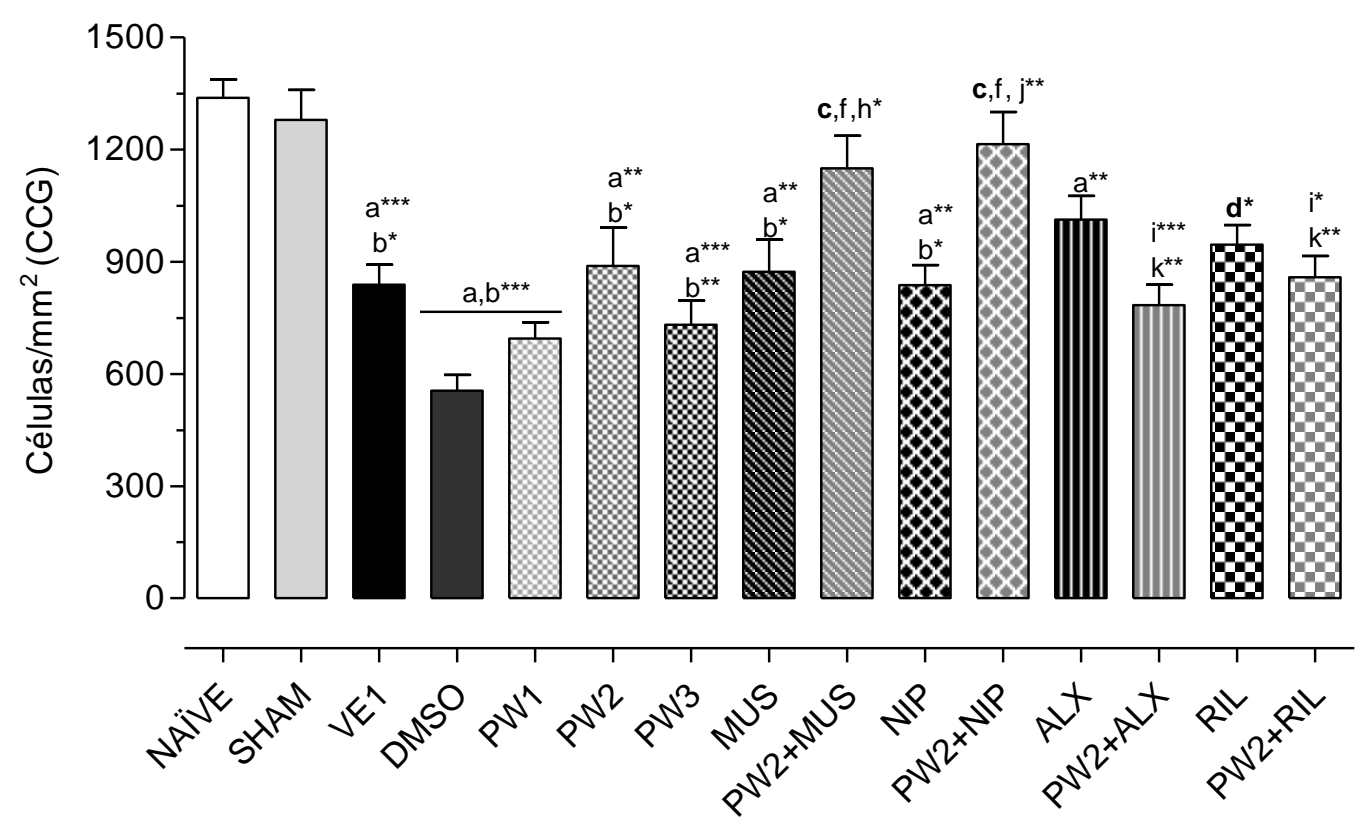

Figura 16: Média da densidade celular na CCG das retinas de ratos Wistar submetidos à isquemia por 45 min. No gráfico estão representados os seguintes grupos: (a- NAÏVE) olho saudável; (b-SHAM) olho operado sem pressão; isquemia pré-tratada com: (cVE1) veículo 1; d-DMSO; (PW1) 0,05 $\mu \mathrm{g} / \mu \mathrm{L}$ de Parawixina 11; (f- PW2) 0,10 $\mu \mathrm{g} / \mu \mathrm{L}$ de Parawixina11; (PW3) 0,20 $\mu \mathrm{g} / \mu \mathrm{L}$ de Parawixina 11; (h- MUS) muscimol; iPW2+MUS; (j- NIP) ácido nipecótico; k- PW2+NIP; (ALX) ALX-5407; PW2+ALX; (RIL) riluzol; PW2+RIL. Dados representam médias \pm E.P.M. Considerar $* \mathrm{p}<0,05, * *$ $\mathrm{p}<0,01, * * * \mathrm{p}<0,001$.

Na CNI (Fig. 17), as retinas dos grupos veículo e DMSO apresentaram redução na densidade celular de, respectivamente, 37,34 e 58,55\%, quando comparadas às do grupo NAÏVE ede 34,40 e $56,60 \%$ quando comparadas às do grupo SHAM. A densidade celular das retinas tratadas com $0,1 \mu \mathrm{g} / \mu \mathrm{L}$ de PW11 foi $17,51 \%$ maior do que ado grupo tratado com VE1. Já a densidade das tratadas com $0,2 \mu \mathrm{g} / \mu \mathrm{L}$ de PW11 foi significativamente maior do que a do grupo que recebeu VE1, protegendo $37,45 \%$ das células. Ainda comparado com o grupo VE1, os tratamentos com MUS (29,62\%), PW2+MUS (40,53\%), NIP (50,47\%) e ALX 5407 (37,42\%) também protegeram a CNI; e os tratamentos com PW2+ALX $(28,65 \%)$ e PW2+NIP $(16,05 \%)$ apresentaram uma tendência em conservar um maior número de células nessa camada. Em comparação com o grupo DMSO, o tratamento com RIL protegeu $43,60 \%$ e o tratamento 
comPW2+RIL conservou 13,92\%, apresentando uma tendência em preservar as células na CNI. Com exceção dos grupos PW2+ALX, PW2+NIP e PW2+RIL, todos os tratamentos apresentaram uma aumento estatisticamente significativo na densidade celular com relação aos veículos.

O tratamento com PW2+MUS protegeu 8,41 e 16,38\% mais células, se comparado, respectivamente, com o grupo MUS e PW2. No tratamento com PW2+NIP, houve umatendência em preservar as células,porém a densidade celular foi 22,88\% menor, se comparada com a do grupo NIP, e $21,90 \%$ menor, se comparada com do grupo PW2.A associação PW2+ALX também apresentou uma tendência em preservar os neurônios, porém a densidade celular foi $6,37 \%$ menor do que a do tratamento com ALX; e 9,48\% maior do que a do tratamento com PW2. O tratamento com PW2+RIL apresentou uma tendência em preservaras células, porém a densidade celular foi $20,66 \%$ menor do que a do tratamento com RIL (Tabela 3).

A densidade celular do grupo de ratos tratados com PW3 (6969 células $/ \mathrm{mm}^{2}$ ) foi muito próxima da densidade do grupo de ratos ratados com ALX (6967 células/mm²), na CNI. 


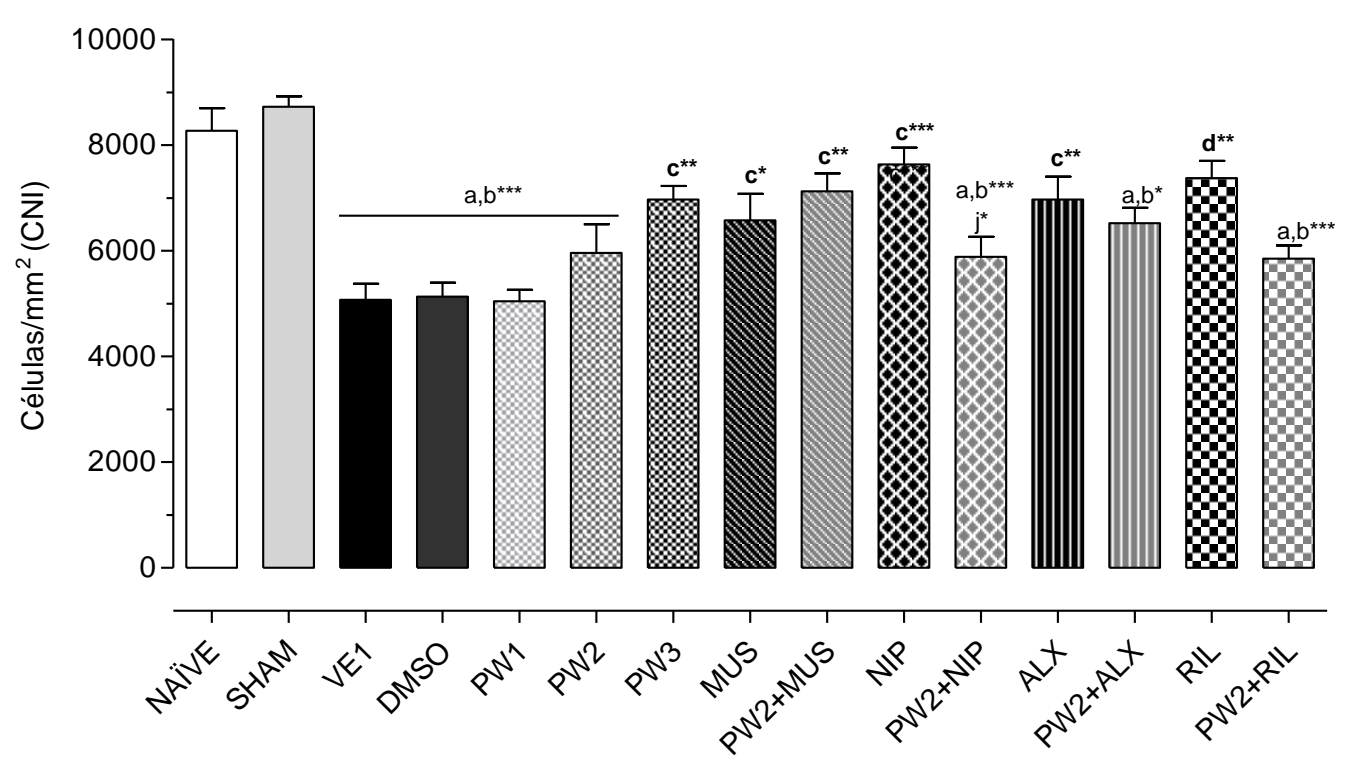

Figura 17: Média da densidade celular na CNI das retinas de ratos Wistar submetidos à isquemia por 45 min. Nos gráficos estão representados os seguintes grupos: (a-NAÏVE) olho saudável; (b-SHAM) olho operado sem pressão; isquemia pré-tratada com: (cVE1) veículo; d-DMSO; (PW1) $0,05 \mu \mathrm{g} / \mu \mathrm{L}$ de Parawixina 11; (PW2) 0,10 $\mu \mathrm{g} / \mu \mathrm{L}$ de Parawixina11; (PW3) 0,20 $\mu \mathrm{g} / \mu \mathrm{L}$ de Parawixina 11; (MUS) muscimol; PW2+MUS; (jNIP) ácido nipecótico; PW2+NIP; (ALX) ALX-5407; PW2+ALX; (RIL) riluzol; PW2+RIL. Dados representam médias \pm E.P.M. Considerar $* p<0,05, * * p<0,01, * * *$ $\mathrm{p}<0,001$.

Na CNE (Fig 18), não houve diferença significante dos grupos veículo e DMSO comparado ao NAÏVE e SHAM. Somente a diferença de densidade celular dos grupos ALX, PW2+MUS e PW2+RIL foram estatisticamente significantes em comparação com o grupo NAÏVE (Fig. 18). 


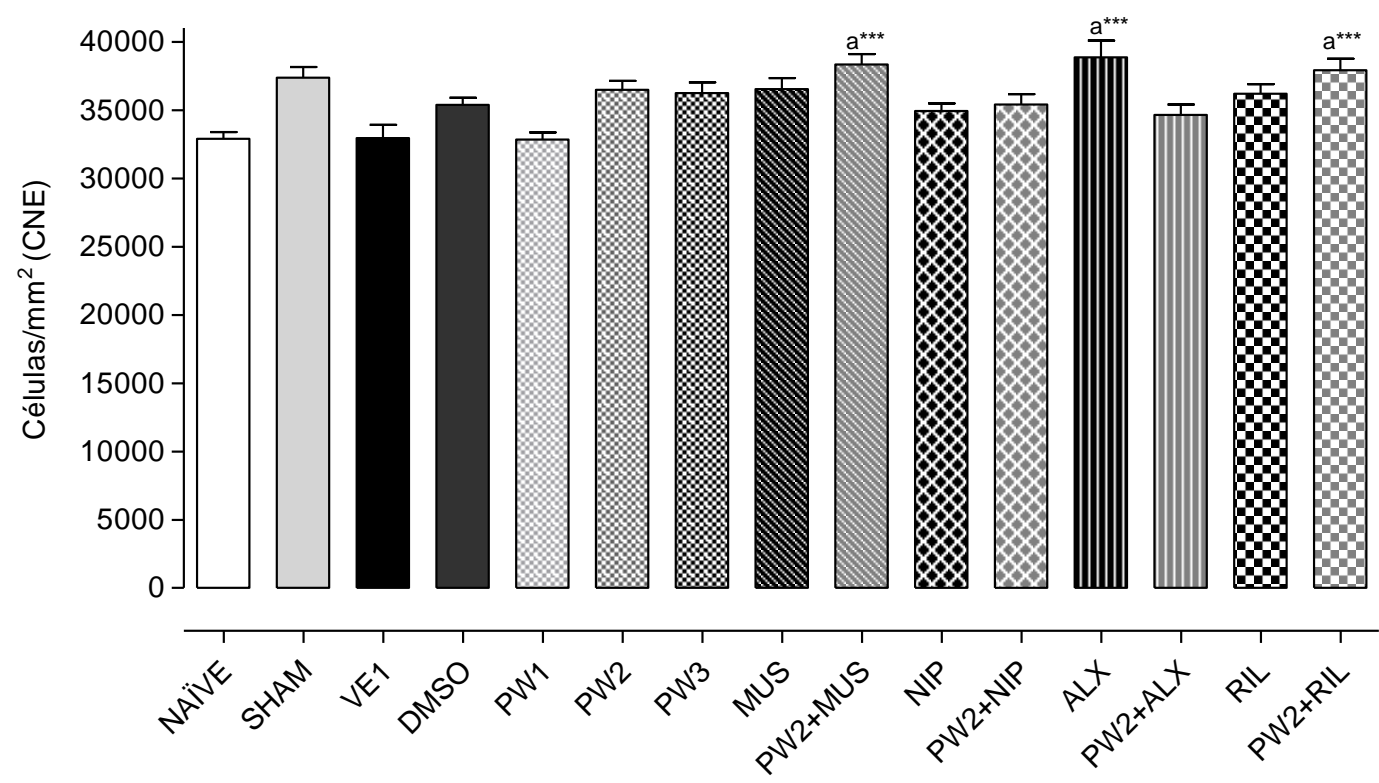

Figura 18: Média da densidade celular na CNE das retinas de ratos Wistar submetidos à isquemia por $45 \mathrm{~min}$. Nos gráficos estão representados os seguintes grupos: (aNAÏVE) olho saudável; (b-SHAM) olho operado sem pressão; isquemia pré-tratada

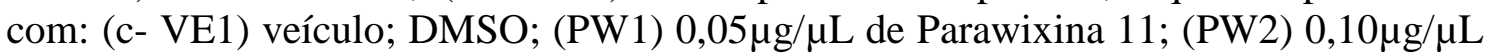
de Parawixina11; (PW3) 0,20 $\mu \mathrm{g} / \mu \mathrm{L}$ de Parawixina 11; (MUS) muscimol; PW2+MUS; (NIP) ácido nipecótico; PW2+NIP; (ALX) ALX-5407; PW2+ALX; (RIL) riluzol; PW2+RIL. Dados representam médias \pm E.P.M. Considerar $* \mathrm{p}<0,05, * * \mathrm{p}<0,01$, *** $\mathrm{p}<0,001$.

Tabela 3. Efeitos da associação de $0,01 \mu \mathrm{g} / \mu \mathrm{L}$ de Parawixina $11 \mathrm{com}$ as demais drogas na ISQ.

\begin{tabular}{|c|c|c|c|c|c|c|c|c|c|}
\hline \multicolumn{10}{|c|}{ ISQUEMIA } \\
\hline Tratamento (Associação) & \multicolumn{2}{|c|}{ PW2+MUS } & \multicolumn{2}{|c|}{ PW2+NIP } & \multicolumn{2}{|c|}{ PW2+ALX } & \multicolumn{2}{|c|}{ PW2+RIL } & \\
\hline $\begin{array}{l}\text { Efeito neuroprotetor ou } \\
\text { tendência em preservar células }\end{array}$ & \multicolumn{2}{|c|}{$>$} & \multicolumn{2}{|c|}{$>$} & \multicolumn{2}{|c|}{$<$} & \multicolumn{2}{|c|}{$<$} & \multirow{4}{*}{ CCG } \\
\hline \multirow{3}{*}{$\begin{array}{l}\text { \% de células em relação ao } \\
\text { tratamento somente com }\end{array}$} & MUS & PW2 & NIP & PW2 & ALX & PW2 & RIL & PW2 & \\
\hline & $31 \%$ & $29 \%$ & $45 \%$ & $37 \%$ & $23 \%$ & $12 \%$ & $9 \%$ & $3 \%$ & \\
\hline & $p<0,05$ & $p<0,05$ & $p<0,01$ & $p<0,01$ & - & - & - & - & \\
\hline $\begin{array}{l}\text { Efeito neuroprotetor ou } \\
\text { tendência em preservar células }\end{array}$ & \multicolumn{2}{|c|}{$>$} & \multicolumn{2}{|c|}{$<$} & $<$ & $>$ & $<$ & & \multirow{4}{*}{ CNI } \\
\hline \multirow{3}{*}{$\begin{array}{l}\text { \% de células em relação ao } \\
\text { tratamento somente com }\end{array}$} & MUS & PW2 & NIP & PW2 & ALX & PW2 & RIL & PW2 & \\
\hline & $8 \%$ & $16 \%$ & $23 \%$ & $22 \%$ & $6 \%$ & $9 \%$, & $21 \%$ & $1 \%$ & \\
\hline & - & - & $p<0,05$ & - & - & - & - & - & \\
\hline
\end{tabular}

Notas: $>=$ maior, $<=$ menor, $-=$ não foi estatisticamente significativo. 


\subsubsection{Retinas submetidas à isquemia/reperfusão}

Nos experimentos de ISQ/REP, as médias das densidades celulares mostraram que houve diferença entre os tratamentos na $\mathrm{CNE}\left[\mathrm{F}_{(14,232)}=4,853 ; \mathrm{p}<0,0001\right]$, na CNI $\left[\mathrm{F}_{(14,232)}=9,538 ; \mathrm{p}<0,0001\right]$ e na $\operatorname{CCG}\left[\mathrm{F}_{(14,228)}=7,386 ; \mathrm{p}<0,0001\right]$.

Após ISQ/REP, os grupos VE1 e DMSO apresentaram redução de 44,39 e 56,69\%, respectivamente, na densidade celular da CCG (Fig. 19), quando comparados ao grupo NAÏVE. Também houve redução de 36,78 e 50,77\%, respectivamente, em comparação ao grupo SHAM. Os animais do grupo PW2+NIP tiveram 53,40\% de sua CCG preservada, significativamente, se comparados com o grupo VE1. O tratamento com riluzol manteve $75 \%$ da CCG preservada se comparado com o grupo DMSO.

Embora não tenha sido estatisticamente significante, se comparados ao grupo VE1, os seguintes tratamentos apresentaram uma tendência em preservar as células: $0,05(32,88 \%) ; 0,10(24,05 \%)$ e $0,20(28,27 \%) \mu \mathrm{g} / \mu \mathrm{L}$ de PW11, MUS $(25,24 \%)$, PW2+MUS (31,32\%), NIP (25,74\%), ALX (28,79\%), PW2+ALX (33,96\%) (Fig. 19).

A associação PW2+MUS aumentou, não significativamente, a densidade celular em 4,85 e 5,86\% se comparada com as dos grupos MUS e PW2, respectivamente. A associação PW2+NIP elevou em 22,00 e 23,66\% a densidade, em comparação com os grupos NIP e PW2, respectivamente. O tratamento com PW2+ALX aumentou, não significativamente, a densidade em 4,02 e 7,99\%, quando comparado aos tratamentos com ALX e PW2, respectivamente. Por fim, a associação PW2+RIL apresentou densidade celular 18,26 e 9,84\%, menor, quando comparada, respectivamente, com RIL e PW2 (Tabela 4).

A densidade de células viáveis na CCG foi aproximada entre o tratamento com PW3 (936 células $/ \mathrm{mm}^{2}$ ) e com ALX (940 células $/ \mathrm{mm}^{2}$ ). Também houve semelhança 
entre a densidade celular do grupo de ratos tratados com PW2 (906 células $/ \mathrm{mm}^{2}$ ), com MUS (914 células/mm²) e com NIP (918 células/mm²).

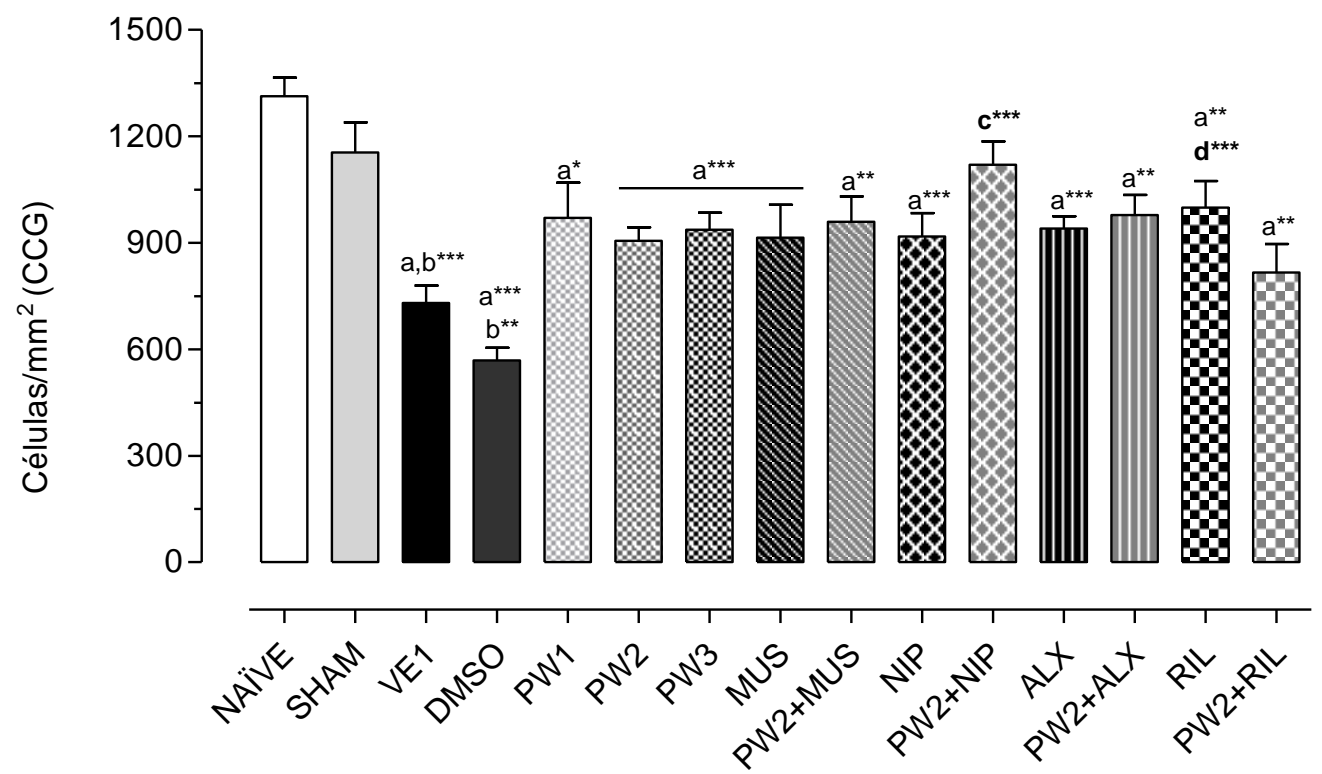

Figura 19: Média da densidade celular na CCG das retinas de ratos Wistar submetidos à isquemia por 45 min +15 min de reperfusão. Nos gráficos estão representados os seguintes grupos: (a- NAÏVE) olho saudável; (b- SHAM) olho operado sem aumento da pressão; isquemia pré-tratada com: (c- VE1) veículo; d- DMSO; (PW1) 0,05 $\mu \mathrm{g} / \mu \mathrm{L}$ de Parawixina 11; (PW2) 0,10 $\mu \mathrm{g} / \mu \mathrm{L}$ de Parawixina11; (PW3) $0,20 \mu \mathrm{g} / \mu \mathrm{L}$ de Parawixina 11; (MUS) muscimol; PW2+MUS; (NIP) ácido nipecótico; PW2+NIP; (ALX) ALX5407; PW2+ALX; (RIL) riluzol; PW2+RIL. Dados representam médias \pm E.P.M. Considerar $* \mathrm{p}<0,05, * * \mathrm{p}<0,01, * * * \mathrm{p}<0,001$.

$\mathrm{Na}$ CNI (Fig. 20), após ISQ/REP as retinas dos ratos que receberam VE1 tiveram uma redução de 40,49 e 43,55\% de células se comparadas às do grupo NAÏVE e SHAM, respectivamente. Houve proteção significativa com os tratamentos com MUS (71,23\%), NIP (44,98\%), PW2+NIP (58,37\%) e ALX (39,65\%), se comparados com o grupo VE1. Também as retinas dos ratos que receberam DMSO tiveram uma redução de 42,77\% de células comparadas com as do grupo NAÏVE, e de 45,72\%, comparadas ao grupo SHAM. O RIL protegeu 63,97\% das células em relação ao grupo DMSO (Fig. 20). 
Embora não tenha sido estatisticamente significante, se comparados aos seus respectivos veículos, os seguintes tratamentos apresentaram uma tendência em preservar as células: $0,05(38,76 \%) ; 0,10(35,25 \%)$ e 0,20 (30,96\%) $\mu \mathrm{g} / \mu \mathrm{L}$ de PW11, PW2+MUS (20,91\%), PW2+ALX (28,01\%); PW2+RIL (28,92\%).

A associação PW2+MUS apresentou densidade celular 29,39 e 10,60\% menor, se comparada com os tratamentos com MUS e PW2, respectivamente. A associação PW2+NIP apresentou densidade celular 9,23 e 17,09\% maior, se comparada com o tratamento com NIP e PW2, respectivamente; além disso, dentre as quatro associações, foi a única cuja densidade celular foi estatisticamente maior do que a do veículo. $\mathrm{O}$ tratamento com PW2+ALX apresentou densidade celular 8,33 e 5,35\%menor, se comparada com os tratamentos com ALX e PW2, respectivamente. O tratamento com PW2+RIL apresentou densidade celular 21,38 e 8,34\% menor, quando comparado com RIL e PW2, respectivamente (Tabela 4).

As densidades celulares das retinas dos animais do grupo PW1 (6830 células $/ \mathrm{mm}^{2}$ ) e do grupo ALX (6874 células $/ \mathrm{mm}^{2}$ ) foram parecidas. 


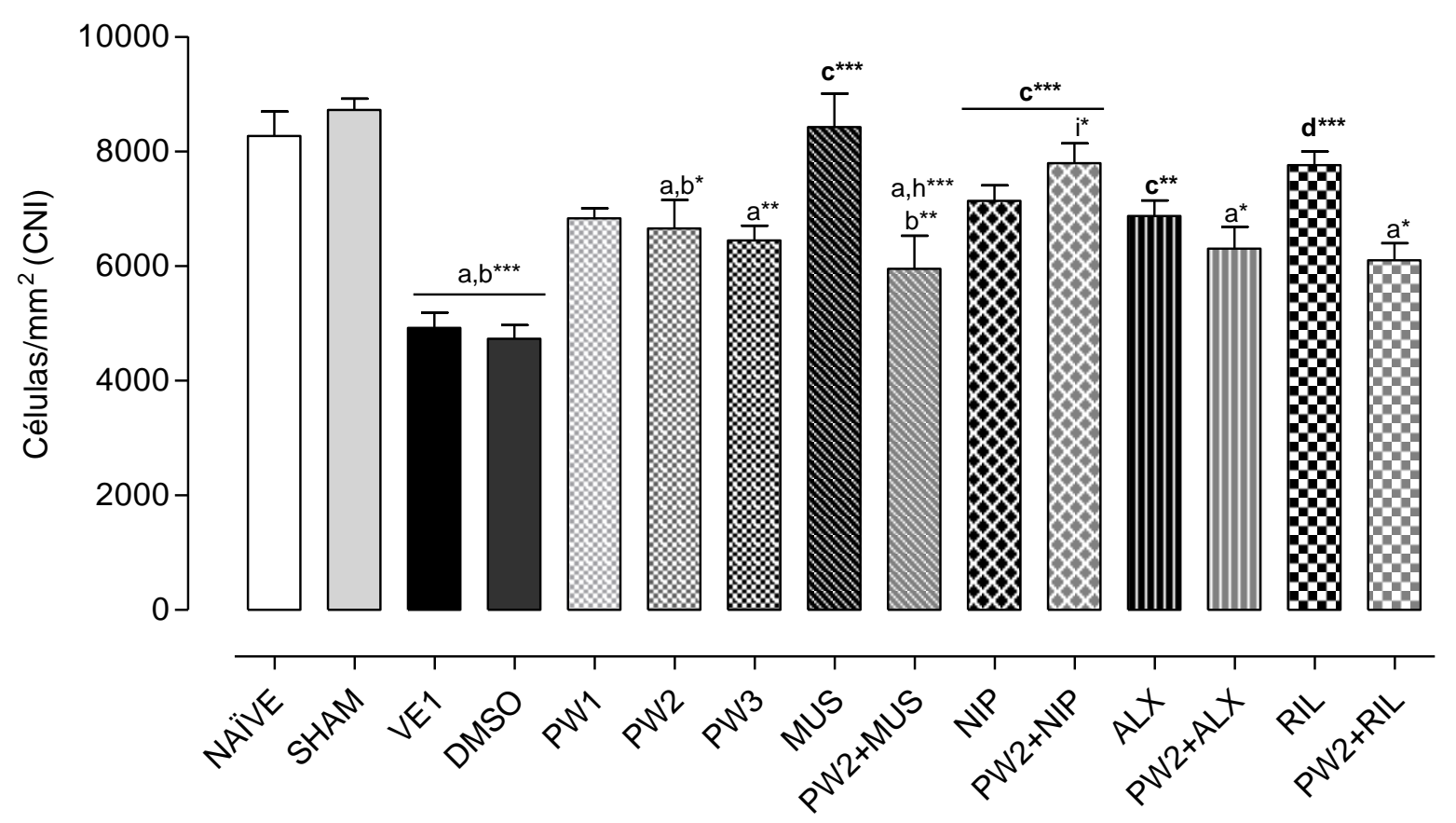

Figura 20: Média da densidade celular na CNI das retinas de ratos Wistar submetidos à isquemia por $45 \mathrm{~min}+15 \mathrm{~min}$ de reperfusão. Nos gráficos estão representados os seguintes grupos: (a- NAÏVE) olho saudável; (b- SHAM) olho operado sem aumento da pressão; isquemia pré-tratada com: (c-VE1) veículo; d-DMSO; (PW1) 0,05 $\mu \mathrm{g} / \mu \mathrm{L}$ de Parawixina 11; (PW2) 0,10 $\mu \mathrm{g} / \mu \mathrm{L}$ de Parawixina11; (PW3) $0,20 \mu \mathrm{g} / \mu \mathrm{L}$ de Parawixina 11; (h- MUS) muscimol; i- PW2+MUS; (NIP) ácido nipecótico; PW2+NIP; (ALX) ALX-5407; PW2+ALX; (RIL) riluzol; PW2+RIL. Dados representam médias \pm E.P.M. Considerar $* \mathrm{p}<0,05, * * \mathrm{p}<0,01, * * * \mathrm{p}<0,001$.

Na CNE (Fig. 21), só houve diferença estatisticamente significante entre os grupos PW3, PW2+MUS, PW2+NIP e RIL em relação ao grupo NAÏVE. 


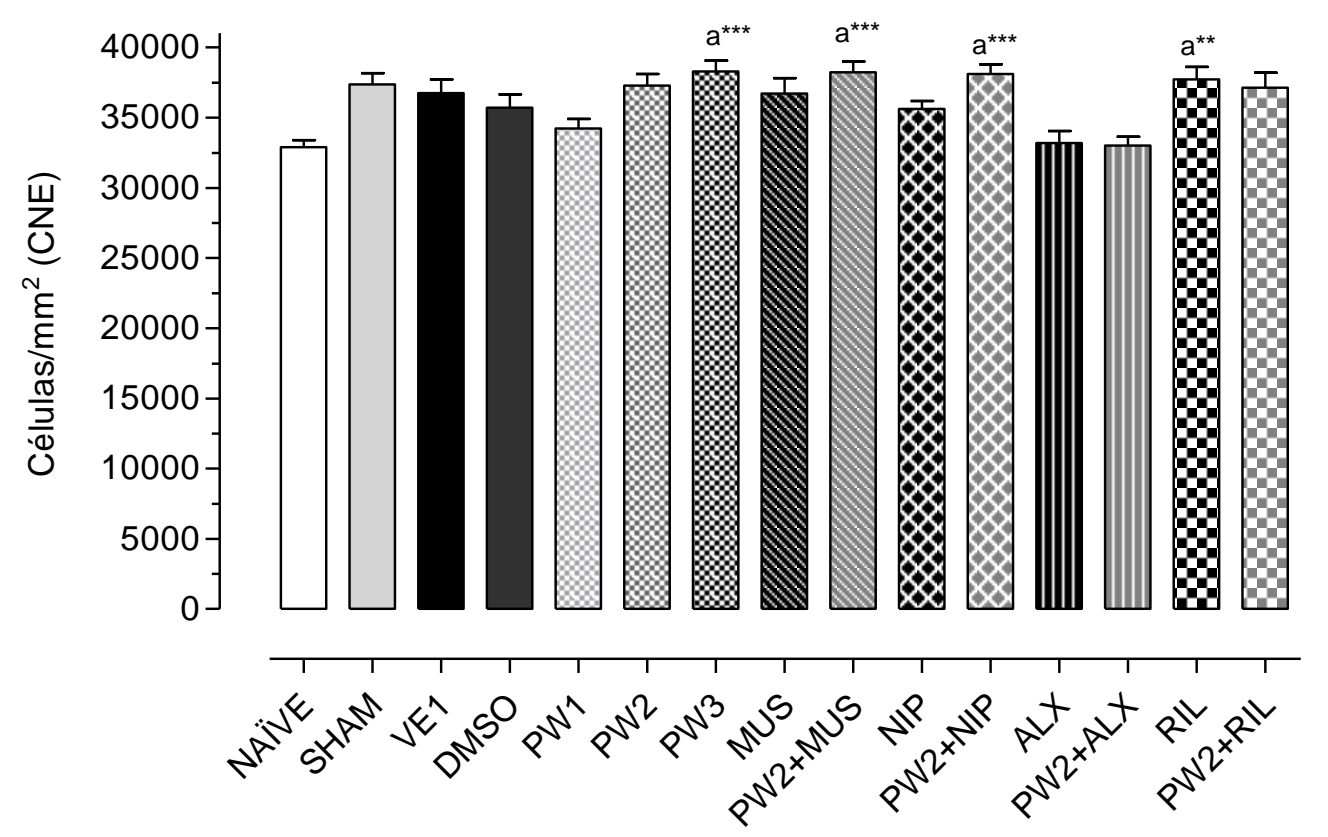

Figura 21: Média da densidade celular na CNE das retinas de ratos Wistar submetidos à isquemia por $45 \mathrm{~min}+15$ min de reperfusão. Nos gráficos estão representados os seguintes grupos: (a- NAÏVE) olho saudável; (SHAM) olho operado sem aumento da pressão; isquemia pré-tratada com: (VE1) veículo; DMSO; (PW1) 0,05 $\mu \mathrm{g} / \mu \mathrm{L}$ de Parawixina 11; (PW2) 0,10 $\mu \mathrm{g} / \mu \mathrm{L}$ de Parawixina11; (PW3) $0,20 \mu \mathrm{g} / \mu \mathrm{L}$ de Parawixina 11; (MUS) muscimol; PW2+MUS; (NIP) ácido nipecótico; PW2+NIP; (ALX) ALX5407; PW2+ALX; (RIL) riluzol; PW2+RIL. Dados representam médias \pm E.P.M. Considerar $* \mathrm{p}<0,05, * * \mathrm{p}<0,01, * * * \mathrm{p}<0,001$.

Tabela 4. Efeitos da associação de $0,01 \mu \mathrm{g} / \mu \mathrm{L}$ de Parawixina $11 \mathrm{com}$ as demais drogas na ISQ/REP.

\begin{tabular}{|c|c|c|c|c|c|c|c|c|c|}
\hline \multicolumn{10}{|c|}{ REPERFUSÃO } \\
\hline Tratamento (Associação) & \multicolumn{2}{|c|}{ PW2+MUS } & \multicolumn{2}{|c|}{ PW2+NIP } & \multicolumn{2}{|c|}{ PW2+ALX } & \multicolumn{3}{|c|}{ PW2+RIL } \\
\hline $\begin{array}{l}\text { Efeito neuroprotetor ou } \\
\text { tendência em preservar células }\end{array}$ & \multicolumn{2}{|l|}{$>$} & \multicolumn{2}{|r|}{$>$} & \multicolumn{2}{|c|}{$>$} & \multicolumn{2}{|c|}{$<$} & \multirow{4}{*}{ CCG } \\
\hline \multirow{3}{*}{$\begin{array}{l}\% \text { de células em relação ao } \\
\text { tratamento somente com }\end{array}$} & MUS & PW2 & NIP & PW2 & ALX & PW2 & RIL & PW2 & \\
\hline & $5 \%$ & $6 \%$ & $22 \%$ & $24 \%$ & $4 \%$ & $8 \%$ & $18 \%$ & $10 \%$ & \\
\hline & - & - & - & - & - & - & - & - & \\
\hline $\begin{array}{l}\text { Efeito neuroprotetor ou } \\
\text { tendência em preservar células }\end{array}$ & \multicolumn{2}{|c|}{$<$} & \multicolumn{2}{|r|}{$>$} & \multicolumn{2}{|c|}{$<$} & \multicolumn{2}{|c|}{$<$} & \multirow{4}{*}{ CNI } \\
\hline \multirow{3}{*}{$\begin{array}{l}\text { \% de células em relação ao } \\
\text { tratamento somente com }\end{array}$} & MUS & PW2 & NIP & PW2 & ALX & PW2 & RIL & PW2 & \\
\hline & $29 \%$ & $11 \%$ & $9 \%$ & $17 \%$ & $8 \%$ & $5 \%$ & $21 \%$ & $8 \%$ & \\
\hline & $P<0,001$ & - & - & - & - & - & - & - & \\
\hline
\end{tabular}

Notas: $>=$ maior, $<=$ menor, $-=$ não foi estatisticamente significativo. 


\section{DISCUSSÃO}


O fato de a cascata isquêmica envolver redução de ATP, desequilíbrio iônico, ativação de canais para íons, liberação de neurotransmissores, geração de radicais livres, depleção dos fatores de crescimento e envolvimento do sistema imune resulta em um quadro de degeneração tecidual que pode causar a morte, inicialmente, de neurônios da CCG. Com isso, o meio extracelular que circunda estes neurônios sofre alterações, provocando uma segunda lesão, mais lenta e progressiva, que atinge os neurônios adjacentes, fato este que pode explicar porque a terapia de redução da PIO, no glaucoma, às vezes é ineficiente no controle da redução do campo visual em pacientes (Weinreb, 2007).

Na retina, as células mais afetadas, após lesão isquêmica, são as amácrinas e as ganglionares (Dijk \& Kamphuis, 2004; Almasieh et al., 2012). Essas células são mais suscetíveis devido ao repertório de receptores, canais iônicos e transportadores que elas possuem. As células bipolares, por exemplo, expressam grande quantidade de receptores glutamatérgicos ionotrópicos, principalmente do tipo NMDA (Joo et al., 1999; Lipton 2001). Assim sendo, a integridade, principalmente das ganglionares, é o principal indício de que uma determinada intervenção farmacológica foi neuroprotetora, no contexto do glaucoma.

Devido aos múltiplos fatores envolvidos na lesão isquêmica, foram escolhidas, para este trabalho, drogas neuroprotetoras já conhecidas que atuam em diferentes sítios, sendo possível analisar qual intervenção proporcionou maior redução dos danos teciduais. Além disso, também foi estudada a Parawixina 11, uma nova substância neuroativa pura, mas até o momento sem estrutura química definida, isolada da peçonha da aranha $P$. bistriata.

Para tentar evitar a morte neuronial causada pela isquemia, como já mencionado anteriormente, existem diversas estratégias, tais como o uso de antagonistas de canais 
iônicos, substâncias GABA- miméticas, antagonistas de receptores de L-GLU, inibidores de enzimas, substâncias que removem espécies reativas do oxigênio, imunossupressores e antibióticos (Green et al., 2000; Vasudevanet al., 2011).

Diante disso, uma grande variedade de substâncias neuroativas de aranhas tem apresentado atividade na inibição de canais iônicos ou no bloqueio de receptores glutamatérgicos. Dentre elas estão a Tx3-3 e a Tx3-4, isoladas da peçonha da aranha $P$. nigriventer, que bloqueiam canais para cálcio, protegendo os neurônios da CA1 após isquemia hipocampalin vitro, induzida por privação de oxigênio e glicose (Pinheiro et al., 2009). Também foi demonstrado que a toxina JSTX-3, da peçonha da aranha Nephila clavata, bloqueia subunidades específicas dos receptores do tipo AMPA/KA expressos em oócitos de Xenopus sp. (Blaschke et al., 1993). Isolada da aranha Agelenopsis aperta, a FTX 3.3 bloqueia canais para íons de $\mathrm{Ca}^{2+}$ voltagem- sensíveis do tipo P, em células de Purkinje de fatias do cerebelo de ratos (Dupere et al., 1996).

\subsection{Parawixina 11 versus ISQ e ISQ/REP}

Em nosso laboratório, os experimentos iniciais mostraram que a Parawixina 11 não induziu efeitos neurotóxicos sobre a atividade motora de ratos Wistar, submetidos aos testes open field e rotarod.Além disso, ela inibiu a expressão de crises convulsivas comportamentais agudas, induzidas por convulsivantes químicos já mencionados. O mesmo estudo também indicou que a PW11 pode ter uma ação preferencial sobre o sistema glutamatérgico, uma vez que ela apresentou um efeito anticonvulsivante, em ratos Wistar, mais potente contra o NMDA do que contra os outros convulsivantes testados. No entanto, em doses maiores do que as usadas contra o NMDA, ela também 
apresentou efeito anticonvulsivante contra estriquinina, pentilenotetrazol, pilocarpina e bicuculina (Pereira et al., em preparação $o_{a}$ ). Além desse, foi realizado outro estudo no qual se verificou que as três doses de PW11 foram neuroprotetoras no giro denteado dos hipocampos de ratos submetidos ao SE, bem como não comprometeram a localização espacial e a retenção de memória em ratos ensaiados no labirinto aquático de Morris (LAM). Nesse mesmo estudo, também se verificou que, apesar de não significativo, os ratos que receberam a PW11 por via i.c.v. apresentaram menor número de células imunopositivas para a subunidade GluR1 do receptor tipo AMPA, na região CA1, se comparadas com o grupo sham. Isso sugere que, no modelo utilizado, a PW11 preveniu o aumento de GluR1 e, consequentemente, o influxo exacerbado de íons de $\mathrm{Ca}^{2+}$ na região citada, exercendo assim seu efeito neuroprotetor e anticonvulsivante (Pereira $e t$ $a l .$, em preparação $)_{\mathrm{b}}$.

Nosso estudo sobre os possíveis efeitos neuroprotetores da PW11, no glaucoma experimental agudo induzido em ratos, mostrou que a PW11 foi neuroprotetora na CNI, após ISQ e ISQ/REP, e na CCG, após REP. Esse efeito foi significativo com o prétratamento com 0,2 $\mu \mathrm{g} / \mu \mathrm{L}$ de PW11 na ISQ. Além disso, as associações PW2 + muscimol e PW2 + ácido nipecótico protegeram a CCG após ISQ e ISQ/REP.

Com relação ao possível efeito da PW11 na redução da subunidade GluR1, no glaucoma experimental agudo, não foi possível realizar imunomarcação. Entretanto, os dados obtidos sugerem que o efeito neuroprotetor da PW11, na isquemia retiniana, esteja mais relacionado com o sistema gabaérgico do que com o glutamatérgico. Além disso, as retinas, após lesão isquêmica, expressam um padrão de subunidades do receptor AMPA diferente daquele encontrado no encéfalo (Dijk \& Kamphuis, 2004).

A partir de 12 h após isquemia global de $10 \mathrm{~min}$, a expressão do mRNA da subunidade GluR2, que torna o receptor AMPA impermeável ao cálcio, começa a 
declinar na CA1 do hipocampo de ratos, atingindo os menores valores com $24 \mathrm{~h}$ de reperfusão (Pellegrini-Giampietro et al., 1997). Já na retina, com 2 h de reperfusão após isquemia de 60 min, ocorre uma redução do mRNA de GluR2 e de GluR3, concomitantemente a um aumento do mRNA de GluR4. No entanto, os níveis de mRNA de ambas subunidades retornam aos níveis normais com $4 \mathrm{~h}$ de reperfusão e, a partir de $72 \mathrm{~h}$, a expressão de todas as subunidades(GluR1-4) é significativamente reduzida (Dijk etal., 2004). Dessa forma, com o passar do tempo, como não hádownregulation exclusiva de GluR2, conclui-se que a composição do receptor AMPA não é um fator crítico para a gravidade da isquemia retininana, mas sim as alterações em todas as subunidades, que prejudicariam a transmissão sináptica,principalmente na CPI (Dijk etal., 2004; Dijk \& Kamphuis, 2004).

As possíveis atividades biológicas da PW11 são descritas a seguir, comparando os efeitos da sua associação com outras drogas.

\subsection{Muscimol versus ISQ e ISQ/REP}

Diversos modelos experimentais de isquemia demonstram efeitos neuroprotetores de agonistas de receptores gabaérgicos. Dentre estes agonistas podemos citar o muscimol que, de acordo com Li et al. (2010), aumentou a sobrevivência celular no corpo estriado do encéfalo de ratos, após isquemia cerebral. Conforme já mencionado, o muscimol é um agonista dos receptores GABA dos tipos A e C, mas sua maior afinidade é pelo tipo A (Chebib \& Johnston, 1999). No nosso estudo esta droga também foi capaz de preservar a retina, uma vez que evitou a perda de grande quantidade de células da CNI e CCG após ISQ e ISQ/REP. Entretanto, na CCG não 
houve diferença estatisticamente significante quando comparado ao grupo que recebeu veículo.

A diminuição do efeito neuroprotetor do muscimol na CCG, em comparação com seu efeito na CNI, pode ter ocorrido devido à diferente distribuição dos subtipos de receptores gabérgicos nestas camadas. As células horizontais e bipolares da CNI expressam preferencialmente receptores de GABA tipo A e $\mathrm{C}$, sendo o tipo $\mathrm{B}$ encontrado preferencialmente apenas nas amácrinas. Já as células ganglionares expressam mais os tipos A e B(Yang, 2004). Dessa forma, o muscimol, na CNI, além de se ligar aosítio do receptor $\mathrm{GABA}_{\mathrm{A}}$, também pode ter se ligado ao sítio do receptor $\mathrm{GABA}_{\mathrm{C}}$, promovendo maior entrada de íons de $\mathrm{Cl}^{-}$nos neurônios e levando a uma hiperpolarização, maior do que aquela ocorrida quando apenas receptores GABA do tipo A são ativados. Logo, se na CCG não há receptores do tipo C, a hiperpolarização dos neurônios pode não ter sido suficiente para auxiliar na neuroproteção.

\section{3. Ácido nipecótico versus ISQ e ISQ/REP}

Em se tratando de neurotransmissão inibitória, muitos estudos demonstram que drogas inibidoras do transporte de GABA, como a tiagabina, têm efeitos neuroprotetores em neurônios estriatais submetidos à isquemia cerebral in vitro (Costa et al, 2004).

O ácido nipecótico é um potente inibidor do transportador de GABA tipo GAT-1 e um moderado inbidor dostransportadores dos tipos GAT-2 e GAT-3 (Kvist et al., 2009). Ele se liga à proteína transportadora, juntamente com duas moléculas de íons de 
$\mathrm{Na}^{+}$e uma de íon de $\mathrm{Cl}^{-}$, impedindo a ligação do GABA, o que levará a um aumento nos níveis extracelulares deste neurotransmissor (Soudijn \& Wijngaarden, 2000).

No nosso estudo, esta droga protegeu significativamente a CNI após ISQ e ISQ/REP e não foi protetora na CCG.

Em condições isquêmicas, o aumento de influxo de íons de $\mathrm{Cl}^{-}$no neurônio pode protegê-lo, devido à sua hiperpolarização que contrabalanceia a despolarização pelo LGLU (Osborne et al., 2004). Entretanto, esse mesmo influxo pode contribuir para a lesão. Diante disso, uma possível explicação para a ausência de efeito neuroprotetor do ácido nipecótico, na CCG, pode estar relacionada com o influxo excessivo de íons de $\mathrm{Cl}^{-}$nos neurônios, conforme o efeito observado por Zeevalk \& Nicklas (1997).

Esses pesquisadores demonstraram que o ácido nipecótico não protegeu as retinas de embriões de galinha submetidas ao estresse metabólico in vitro, devido ao fato do ácido nipecótico ser um inibidor de transporte que, por si só, leva ao aumento de GABA extracelular, por transporte reverso. Isso aumenta a ativação de receptores gabaérgicos e a condutância de íons de $\mathrm{Cl}^{-}$, que podem, em condições não homeostáticas, contribuir para o desequilíbrio osmótico e a entrada de água na célula (Zeevalk \& Nicklas, 1997).

\subsection{ALX 5407 versus ISQ e ISQ/REP}

No presente estudo, 0,36 $\mu \mathrm{g}$ de ALX 5407, um inibidor do transportador de glicina do tipo GlyT1, foi neuroprotetor na CNI tanto após ISQ, quanto após ISQ/REP. Esse resultado corrobora parcialmente outro estudo realizado em nosso laboratório, no qual Tostes (2009), injetando um total de 1,50 $\mu \mathrm{g}$ desta substância, verificou que o ALX 
5407 foi neuroprotetor tanto na CNI, como na CCG. No entanto, os efeitos de um aumento nos níveis de glicina extracelular, podem tanto fornecer neuroproteção, devido à ativação de receptores de glicina sensíveis à estriquinina, como podem contribuir para a excitotoxicidade, devido à ativação do sítio de glicina nos receptores NMDA (Tanabeetal., 2010).

Katsuki et al. (2007) relataram que a dose de $30 \mu \mathrm{M}$ de ALX 5407 não protegeu significativamente o tecido neural contra a citotoxicidade induzida por $15 \mu \mathrm{M}$ de NMDA, em culturas de fatias cerebrocorticais de ratos. No mesmo estudo foi confirmado que os níveis de glicina extracelular aumentaram significativamente $24 \mathrm{~h}$ após a aplicação de ALX 5407. Poucos trabalhos sobre os efeitos do ALX 5407 na retina foram encontrados na literatura. Portanto, para que pudéssemos comparar nossos resultados, selecionamos trabalhos envolvendo o aumento dos níveis de glicina extracelular e/ou efeitos de outros antagonistas do transportador de glicina do tipo GlyT1.

Hama et al. (2006), verificaram que os agonistas endógenos do sítio de glicina do receptor NMDA, a glicina e a D-serina, contribuem para a lesão retiniana induzida por NMDA in vitro, de maneira não uniforme. No entanto, trabalhos como o de Wang et al. (2007) demonstraram que o aminoácido taurina apresentou neuroproteção após isquemia/reperfusão em ratos, possivelmente mediada pela sua ligação em receptores gabaérgicos e glicinérgicos sensíveis à estriquinina. O neurotrasmissor D-serina, e não a glicina, é o principal coagonista para a neurotoxicidade mediada pelo receptor NMDA (Shleperet al., 2005). Diante disso, Zhang et al.(2008) demonstraram que, ao antagonizar o transportador de glicina do tipo GlyT1 com sarcosina (400 mg/Kg, aplicada via i.p.), o caminho principal para a glicina extracelular, a princípio, não seria sua ligação nos receptores NMDA, e sim nos sítios de receptores presentes em células 
de neurotransmissão inibitória, ou seja, nos receptores de glicina sensíveis à estriquinina. Isso por sua vez, proporcionaria um aumento no influxo de íons de $\mathrm{Cl}^{-}$, hiperpolarizando a célula e contribuindo para um balanço entre a neurotransmissão excitatória e inibitória, favorecendo a neuroproteção.

Diante dessa diversidade de efeitos, nossos dados contribuem com a hipótese neuroprotetora do aumento dos níveis de glicina, possivelmente devido à ativação de receptores glicinérgicos sensíveis à estriquinina, cujo efeito inibitório superaria a hiperatividade dos receptores NMDA.

\subsection{Riluzol versus ISQ e ISQ/REP}

O riluzol é uma droga neuroprotetora, utilizada no tratamento da ELA em humanos, com um mecanismo de ação complexo, envolvendo diversos efeitos, tais como bloqueio de canais para íons de $\mathrm{Na}^{+}$voltagem-dependentes, ativação de canais para íons de $\mathrm{K}^{+}$e de $\mathrm{Ca}^{2+}$ ativados por alta voltagem, inibição de proteína quinase $\mathrm{C}$, além de inibição da liberação de L-GLU e aumento da recaptação do L-GLU (Fumagalli et al., 2008; Ettaicheet al., 1999).

Dentre as drogas utilizadas neste trabalho, o riluzol foi a única que, separadamente, protegeu a CCG, principal camada afetada no glaucoma experimental agudo. Seu efeito também foi neuroprotetor na CNI após ISQ e ISQ/REP. Nossos resultados são corroboradospelos de Ettaiche et al. (1999), que verificaram que o tratamento tópico com 0,002 ng de riluzol, aplicados duas vezes ao dia, restabeleceu as ondas a e b da retina de ratos, principalmente 7 dias após isquemia retiniana induzida pelo aumento da PIO. No mesmo trabalho verificou-se que o riluzol reduziu a resposta 
ao GFAP em células de Müller e reduziu a morte celular por apoptose. O riluzol também reduziu a área de lesão no córtex cerebral após oclusão da artéria cerebral média em gerbils (Pratt et al., 1992) e em ratos da linhagem Sprague- Dawley (Wahlet al., 1993). No entanto, neste último trabalho não houve redução dos déficits neurológicos e de memória.

\subsection{Efeito das associações da PW11}

A associação com a PW11 potencializou significativamente o efeito do muscimol na CCG após ISQ. Já na CNI esse efeito foi mais moderado. Sendo assim, é possível que a potencialização na $\mathrm{CCG}$, seja devido à ativação de receptores gabaérgicos pela PW11.

Existem evidências que corroboram essa atividade da PW11 nos receptores gabaérgicos. Primeiramente, em estudos preliminares in vitro, a PW11 aumentou a ligação de GABA em SCCR. Além disso, na dose de $0,30 \mu \mathrm{g} / \mu \mathrm{L}$ in vivo, bloqueou a expressão de crises convulsivas comportamentais induzidas por um antagonista competitivo de $\mathrm{GABA}_{\mathrm{A}}$ (bicuculina) (Pereira et al., em preparação ${ }_{\mathrm{a}}$ ).

Essa atividade da PW11 na retina, relacionada com receptores gabaérgicos, difere da que foi encontrada no hipocampo, onde é dado enfoque nos receptores glutamatérgicos. No entanto, é importante ressaltar que essas diferenças podem ser decorrentes dos modelos animais utilizados. O modelo de glaucoma utilizado foi o agudo, e uma única dose de PW11 foi aplicada. Ao término do experimento, os animais já foram sacrificados. Já no modelo de indução de $S E$, os animais foram tratados mais 4 dias após o insulto e sacrificados após, aproximadamente, 18 dias (Pereira et al., em 
preparação $\mathrm{o}_{\mathrm{b}}$ ). Portanto, estudos mais detalhados são necessários para esclarecer a atividade da PW11 nessas duas classes de receptores.

$\mathrm{O}$ tratamento com PW2+NIP foi mais neuroprotetor do que com o ácido nipecótico ou a PW11 sozinhos, na CCG após ISQ e ISQ/REP. Isso sugere que pode ter havido uma soma dos efeitos da inibição do transporte de GABA e da possível atividade da PW11 nos receptores desse neurotransmissor. Entretanto, houve diminuição do efeito do ácido nipecótico na CNI após ISQ, indicando que a PW11 também poderia competir com o ácido nipecótico pelo transportador, ou que algum mecanismo da PW11 afetou indiretamente a atividade neuroprotetora do ácido nipecótico.

De modo geral, não houve interação entre $0,10 \mu \mathrm{g} / \mu \mathrm{L}$ de PW11 e o ALX 5407, sugerindo que o composto não potencializa o bloqueio do transportador de glicina do tipo GlyT1. No entanto, mesmo não havendo diferença estatística, após associaçãoa densidade celular foi menor na CCG após ISQ, se comparada ao grupo tratado somente com ALX 5407.

Esta redução pode ter ocorrido devido a algum mecanismo indireto. Como este efeito só foi encontrado na $\mathrm{CCG}$, é possível que esse mecanismo indireto esteja relacionado com a circuitaria desta camada, bem como com as condições do tecido. As células ganglionares recebem tanto impulso inibitório glicinérgico de células amácrinas (Wässle et al., 2009), como excitatório glutamatérgico das células bipolares (Kalloniatis et al., 1999). Logo, como as células ganglionares possuem uma grande quantidade de receptores glutamatérgicos (Lipton, 2001; Osborne, 2004; Kalloniatis \& Tomisich, 2008), a ativação dos receptores NMDA nas células ganglionares, durante a isquemia, pode ter sido mais significativa do que a ativação dos canais para cloreto ativados por ligante sensíveis à estriquinina. 
A associação PW2+RIL apresentou densidade celular menorna CNI do que o RIL, após ISQ, e menor nas CCG e CNI, após ISQ/REP, embora não tenha ocorrido diferença estatística . Estes resultados sugerem que a Parawixina 11 também possa atuar em algum mecanismo que bloqueie algum componente da ação do riluzol. Uma vez que a PW11 atua tanto potencializando o efeito neuroprotetor de agentes facilitadores da liberação e do transporte de GABA (como demonstrado com o muscimol e o ácido nipecótico), bem como reduzindo o efeito neuroprotetor do bloqueador do transporte e da liberação de L-GLU, é possível que ela tenha atuado em receptores do tipo GABA . Essa conclusão se deve às seguintes considerações: (i) o riluzol também potencializa a ação dos receptores do tipo GABA $($ Mohammadi, 2001; He, 2002; Jahn, 2008), (ii) houve uma tendência em proteger as células nas retinas dos grupos tratados com PW2+RIL se comparadas com as do grupo DMSO, porém, esse efeito não foi tão evidente quanto o do riluzol sozinho, (iii) o riluzol é neuroprotetor devido à soma de vários mecanismos e, se um desses mecanismos é bloqueado, a neuroproteção do riluzol é diminuída. Logo, a PW11 pode ter se ligado ao receptor $\mathrm{GABA}_{\mathrm{A}}$, reduzindo a ação potencializadora do riluzol neste receptor e, consequentemente, resultando em um efeito neuroprotetor mais brando.

Além disso, é importante destacar a presença dos corpos celulares das células de Müller, principais responsáveis pela recaptação de L-GLU na retina (Bringmann et al., 2009). Em condições isquêmicas, essas células gliais produzem substâncias neurotóxicas como TNF- $\alpha$ e óxido nítrico sintetase e, embora não sejam tão suscetíveis ao dano isquêmico quanto os neurônios, a sobrevivência delas não garante a manutenção de seu funcionamento normal. Isso ocorre porque várias funções são afetadas, podendo haver falha na recaptação do glutamato em excesso no meio extracelular, alteração na enzima glutamina sintetase, alteração da expressão e função 
dos canais para potássio e conseqüente alteração na homeostase do tecido, bem como desenvolvimento de edema (Izumiet al., 1999; Tezel, 2006). Portanto, esses fatores também podem ter contribuído para a redução do efeito neuroprotetor nas retinas tratadas com PW2+RIL.

\subsection{Fluoro-Jade C}

O FJC tem uma alta afinidade com moléculas de neurodegeneração endógenas. Algumas destas moléculas, tais como a putrescina, a cadaverina, a espermidina e a histamina, são poliaminas. Logo, acredita-se que a o FJC se ligue a uma dessas poliaminas, que são expressas na célula a partir da clivagem de moléculas maiores (Schumed et al., 2005).

No nosso estudo, o padrão de marcação das retinas dos ratos que receberam VE1 e DMSO foi semelhante ao encontrado por Chidlow et al. (2009), que realizaram um estudo comparando vários paradigmas de excitotoxicidade e isquemia na retina. Seis horas após injeção intravítrea de NMDA, os autores verificaram a presença de neurônios FJC-positivos nas CCG e na CNI, bem como uma marcação da árvore dendrítica na CPI. Na CNE foram localizadas poucas células FJC-positivas, o que também foi verificado por Chidlow et al. (2009).

Muitos trabalhos utilizam o marcador FJ para demonstrar a neuroproteção de determinadas substâncias contra a lesão isquêmica (Candelario-Jalilet al., 200; Simão et al., 2011). No nosso estudo, após os tratamentos com a PW11 foi observada uma redução de neurônios FJC-positivos, principalmente na CNI após ISQ e ISQ/REP, 
corroborando o efeito neuroprotetor após ISQ/REP e a tendência em proteger as células após ISQ, encontrados após contagem de células viáveis das retinas coradas com H-E.

De um modo geral, houve redução da marcação nas CNI e CCG, após o tratamento com todas as drogas testadas. Sendo assim, é plausível inferir que todas contribuíram para uma redução da lesão isquêmica. 


\section{CONCLUSÕES}


Após isquemia, a maior dose da Parawixina 11 foi neuroprotetora na CNI. Após reperfusão, ela apresentou uma tendência em preservar as células na CCG e na CNI.

Dependendo da camada e da dose utilizada, os efeitos da Parawixina 11 foram semelhantes tanto aos do muscimol, como aos do ALX-5407 e aos do ácido nipecótico.

$\mathrm{O}$ agonista do receptor do tipo $\mathrm{GABA}_{\mathrm{A}}$, muscimol, e a associação PW2 + muscimol foram neuroprotetores na CNI após ISQ. A associação também foi neuroprotetora na CCG após ISQ e apresentou uma tendência em proteger as células da CCG e da CNI após ISQ/REP. O muscimol sozinho também protegeu a CNI, após ISQ/REP.

Após ISQ, o inibidor do transporte de GABA do tipo GAT-1, o ácido nipecótico, foi neuroprotetor na CNI. A associação com a Parawixina 11, além de proteger a CNI após ISQ/REP, também protegeu a CCG após ISQ e ISQ/REP.

O ALX 5407 foi neuroprotetor na CNI após ISQ e ISQ/REP. A associação com a Parawixina 11não apresentou efeito neuroprotetor estatisticamente significante.

O efeito neuroprotetor do riluzol foi o mais eficiente tanto após isquemia, quanto reperfusão, pois além de proteger a CNI, foi a única droga que, sozinha, protegeu a CCG. A associação com a Parawixina 11 foi menos neuroprotetora na CCG após ISQ e não foi estatisticamente significante na CCG e na CNI após ISQ/REP e na CCG após ISQ.

Considerando os efeitos das associações, pode-se inferir que a potencialização do efeito da Parawixina 11 com o do ácido nipecótico e com o do muscimol, indicam que a Parawixina 11 pode atuar, a princípio, no sistema gabaérgico. Entretanto, é importante ressaltar que, considerando os efeitos das associações com o ALX 5407 e com o riluzol, a Parawixina 11, pode não ter uma ação específica. 
Embora sozinha a Parawixina 11 não tenha sido neuroprotetora na CCG, ela contribuiu para um aumento da atividade de drogas que atuam no sistema gabaérgico nesta camada, podendo ser uma ferramenta interessante para o desenvolvimento de terapias para o glaucoma que combinem diferentes drogas. 
7. REFERÊNCIAS BIBLIOGRÁFICAS 
Abercrombie, M. Estimation of nuclear population from microtome sections. Anat Rec. 94, 239-247, 1946.

Almasieh, M.; Wilson, A. M.; Morquette, B.; Vargas, J. L. C.; Polo, A. D. The molecular basis of retinal ganglion cell death in glaucoma. Progress in Retinal and Eye Research 31 152-181, 2012.

Atkinson, B. N.; Bell, S. C.; De Vivo, M.; Kowalski, L. R.; Lechner, S. M.; Ognyanov, V. I.; Tham, C.- S.; Tsai, C.; Ashton, D.; Klitenick, M. A. ALX 5407: A potent, selective inhibitor of the hGlyT1 glycine transporter. Molecular Pharmacology 60, 1414-1420, 2001.

Azbill, R. D.; Mu, X.; Springer, J. E. Riluzole increases high-affinity glutamate uptake in rat spinal cord synaptosomes. Brain. Res. 871, 175-180, 2000.

Beleboni, R. O.; Pizzo, A. B.; Fontana, A. C. K.; Carolino, R. O. G.; Coutinho-Netto, J.; Santos, W. F. Spider and wasp neurotoxins: pharmacological and biochemical aspects. Review. Eur. J. Pharmacol.493, 1-17, 2004.

Beleboni, R. O.; Guizzo, R.; Fontana, A. C. K.; Pizzo, A. B.; Carolino, R. O. G.; Gobbo-Neto, L.; Lopes, N. P.; Coutinho-Netto, J.; Santos, W. F. Neurochemical characterization of a neuroprotective compound from Parawixia bistriata spider venom that inhibits synaptosomal uptake of GABA and glycine. Mol Pharmacol. 69, 19982006.

Blaschke, M.; Keller, B. U.; Rivosecchi, R.; Hollmann, M.;Heinemann, S.; Konnerth, A. A single amino acid determines the subunit-specific spider toxin block of a-amino-3-hydroxy-5-methylisoxazole-4-propionate/kainate receptor channels. Neurobiology. 90, 6528-6532,1993. 
Bringmann, A.; Thomas Pannicke, T.; Grosche, J.; Francke, M.; Wiedemann, P.; Skatchkov, S. N.; Osborne, N. N.; Reichenbach, A. Müller cells in the healthy and diseased retina. Progress in Retinal and Eye Research 25, 397-424, 2006.

Cairrão, M. A. R.; Ribeiro, A. M.; Pizzo, A. B.; Fontana, A. C. K.; Beleboni, R. O.; Coutinho-Netto, J.; Miranda, A.; Santos, W. F. Anticonvulsant and GABA uptake inhibition properties of venom fractions from the spiders Parawixia bistriata and Scaptocosa raptoria. Pharmaceutical Biology. 40(6), 472-477, 2002.

Candelario-Jalil, E.; Alvarez, D.; Merino, N.; León, O. S. Delayed treatment with nimesulide reduces measures of oxidativestress following global ischemic brain injury in gerbils. Neuroscience Research 47, 245-253, 2003.

Chebib, M.; Johnston, G.A.R. The 'ABC' of GABA receptors: a brief review. Clinical and Experimental Pharmacology and Physiology 26, 937-940, 1999.

Chen, B.; Tang, L. Protective effects of catalase on retinal ischemia/reperfusion injury in rats. Experimental Eye Research93(5), 599-606, 2011.

Cheung, W.; Guo, L.; Cordeiro, M. F. Neuroprotection in glaucoma: drug-based approaches. Optometry and Vision Science. 85 (6), 406-416, 2008

Chidlow, G. Wood, J. P. Sarvestani, G. Manavis, J. Casson, R. J. Evaluation of Fluoro-Jade $\mathrm{C}$ as a marker of degenerating neurons in the rat retiona and optic nerve. Exp. Eye Res. 889(3), 426-437, 2009.

Choi, D. W.; Rothman, S. M. The role of glutamate neurotoxicity in hypoxicischemic neuronal death. Annu. Rev. Neurosci. 13, 171-182, 1990.

Choi, D. W. Cellular defences destroyed. Nature. 433, 696-698, 2005.

Collingridge, G. L.; Lester, R. A. Excitatory amino acid receptors in the vertebrate central nervous system. Pharmacol. Rev. 41, 143-210, 1989. 
Costa, C.; Leone, G.; Saulle, E, Pisani, F.; Bernardi, G.; Calabresi, P.Coactivation of GABAA and GABAB Receptor Results in Neuroprotection During In Vitro Ischemia. Stroke.Stroke, 35, 596-600, 2004.

Dalby, N. O. GABA-level increasing and anticonvulsant effects of three different GABA uptake inhibitors. Neuropharmacology. 39, 2399-2407, 2000.

Dalby, N. O. Inhibition of g-aminobutyric acid uptake: anatomy, physiology and effects against epileptic seizures. European Journal of Pharmacology. 479, 127- 137, 2003.

Danbolt, N. C. Glutamate uptake. Progress in Neurobiology.65, 1-1005, 2001.

Dantas, A. M. Doenças da retina. Biblioteca Brasileira de Oftalmologia. Rio de Janeiro: Ed. Cultura Médica, p. 1-14, 1989.

Dijk, F.; Kamphuis, W. Ischemia-induced Alterations of AMPA-type glutamate receptor subunit. Expression patterns in the rat retina - an immunocytochemical study. Brain Research 997, 207- 221, 2004.

Dijk, F.; Kraal-Muller, E.; Kamphuis, W. Ischemia-induced changes of AMPAtype glutamate receptor subunit expression pattern in the rat retina:a real-time quantitative PCR study. Invest Ophthalmol Vis Sci. 45, 330-341, 2004.

Dohare, P.; Garg, P.; Sharma, U.; Jagannathan, N. R.; Ray, M., BMC Complement Altern Med. 30, 8-55 2008.

Dupere, J. R. B.; Moya, E.; Blagbrough, I. S.; Usowicz, M. M. Differential Inhibition of $\mathrm{Ca} 2+$ Channels in Mature Rat Cerebellar Purkinje Cells by FTX-3.3 and FTX-3.3. Neurophnarmacology. 35, 1, 1-11, 1996.

Ettaiche, M.; Fillacier, K.; Widmann C.; Heurteaux, C.; Lazdunski M. Riluzole improves functional recovery after ischemia in the rat retina. Invest. Ophthalmol. Vis. Set. 40, 729-736, 1999. 
Estrada, G.; Villegas, E.; Corzo, G. Spider venoms; a rich source of acylpolyamines and peptides as new leads for CNS drugs. Nat. Prod. Rep. 24,145-161, 2007.

Fachim, H. A; Cunha, A. O. S.; Pereira, A. C.; Beleboni, R. O.; Gobbo-Neto, L.; Lopes, N. P.; Coutinho-Netto, J.; Santos, W. F. Neurobiological activity of Parawixin 10, a novel anticonvulsant compound isolated from Parawixia bistriata spider venom (Araneidae: Araneae). Epilepsy \& Behavior. 22(2), 158-164, 2011.

Faria, J. L. Anatomia patológica geral. $2^{\mathrm{a}}$ ed. Rio de janeiro: Ed. Guanabara Koogan, 1977.

Filho, G. B. Bogliolo - patologia geral. $3^{\mathrm{a}} \mathrm{ed}$. Rio de janeiroo: Ed. Guanabara Koogan, 2004.

Fontana, A. C. K.; Cairrão, M. A. R.; Colusso, A. J.; Santos, W. F.; CoutinhoNetto, J. Paralizing activity of the Parawixia bistriata crude venom in termites: a new bioassay. Toxicon. 38, 133-138, 2000.

Fontana, A. C. K.; Guizzo, R.; Beleboni, R. O.; Meirelles E Silva, A. R.; Coimbra, N. C.; Amara, S. G.; Santos, W. F.; Coutinho-Netto, J. Purification of a neuroprotective component of Parawixia bistriata spider venom that enhances glutamate uptake. Br. J. Pharmacol. 139, 1297-1309, 2003.

Fontana, A. C.; Beleboni, R. O., Wojewodzie, M. W.; Dos Santos, W. F.; Coutinho-Netto, J.; Grutle, N. J.; Watts, S. D.; Danbolt, N. C.; Amara, S. G. Enhancing glutamate transport: mechanism of action of Parawixin1, a neuroprotective compound from Parawixia bistriata spider venom. Mol Pharmacol. 23, 2007.

Fumagalli, E.; Funicello, M.; Rauen, T.; Gobbi, M.; Mennini, T. Riluzole enhances the activity of glutamate transporters GLAST, GLT1 and EAAC1. European Journal of Pharmacology. 578, 171-176, 2008. 
Gelfuso, E. A.; Cunha, A. O. S.; Mortari, M. R.; Liberato, J. L.; Paraventi, K. H.; Beleboni, R. O.; Coutinho-Netto, J.; Lopes. N. P.; Santos, W. F. Neuropharmacological profile of FrPbAII, purified from the venom of the social spider Parawixia bistriata (Araneae, Araneidae), in Wistar rats. Life Sciences 80, 566-572, 2007.

Ginsberg, M. D. Neuroprotection for ischemic stroke: Past, present and future. Neuropharmacology. 55, 363-389, 2008.

Green, A. R.; Hainsworth, A. H., Jackson, D. M. GABA potentiation: a logical pharmacological approach for the treatment of acute ischaemic stroke. Neuropharmacology 39, 1483-1494, 2000.

Guizzo, R.; Rodrigues-Cairrão, M. A.; Coutinho-Netto, J.; Silva, A. R. M. E; Coimbra, N. C.; Santos, W. F. dos. Neuroprotection in acute ischemia and ischemia/reperfusion in rat retina. International Journal of Pharmacology. 1 (4), 369$375,2005$.

Hama, Y.; Katsuki, H.; Tochikawa, Y.; Suminaka, C.; Kume, T.; Akaike, A. Contribution of endogenous glycine site NMDA agonists to excitotoxic retinal damage in vivo. Neuroscience Research 56, 279-285, 2006.

He, Y.; Benz, A.; Fu, T.; Wang, M.; Covey, D.F.; Zorumski, C.F.; Mennerick, S. Neuroprotective agent riluzole potentiates postsynaptic $\mathrm{GABA}_{\mathrm{A}}$ receptor function.Neuropharmacology 42, 199-209, 2002.

Hernández, M.; Urcola, J. H.; Vecino, E. Retinal ganglion cell neuroprotection in a rat model of glaucoma following brimonidine, latanoprost or combined treatments. Exp Eye Res. 86(5), 798-806, 2008.

Honda, S.; Yamamoto, M.; Naoaki, S. Immunocytochemical localization of three subtypes of GABA transporter in rat retina. Mol. Brain Res.33, 319-325, 1995. 
Hughes, W. F. Quantitation of ischemic damage in rat retina. Exp. Eye Res. 53(5), 573-582, 1991.

Izumi, Y.; Kirby, C. O.; Benz, A. M.; Olney, J. W.; Zorumski, C. F. Müller cell swelling, glutamate uptake, and excitotoxic neurodegeneration in the isolated rat retina. Glia 25, 379-389, 1999.

Jahn, K.; Schlesinger, F.; Jin, L. J.; Dengler, R.; Bufler, J.; Krampft, K. Molecular mechanisms of interaction between the neuroprotective substance riluzole and GABA $A_{A}$-receptors. Naunyn-Schmiedeberg's Arch. Pharmacol. 63, 378:53, 2008.

Jeng Y.Y., Lin N.T., Chang P.H., Huang Y.P., Pang V.F., Liu C.H., Lin C.T. Retinal ischemic injury rescued by sodium 4- phenylbutyrate in a rat model. Exp. Eye Res. 84, 486-492, 2006.

Johnson, J.; Chen, T.K.; Rickman, D. W.; Evans, C.; Brecha, N. C. Multiple gamma-Aminobutyric acid plasma membrane transporters (GAT-1, GAT-2, GAT-3) in the rat retina. J. Comp. Neurol. 375, 212-224, 1996.

Joo, C-K.; Choi, J-S.; Ko, H. W.; Park, K-Y.; Sohn S.; Chun, M. H.; Oh, Y. J.; Gwag, B. J. Necrosis and Apoptosis after Retinal Ischemia: Involvement of NMDAMediated Excitotoxicity and p53. Invest Ophthalmol Vis Sci. 40, 713-720, 1999.

Kalesnykas, G.; Tuulos, T.; Uusitalo, H.; Jolkkonen, J. Neurodegeneration and cellular stress in the retina and optic nerve in rat cerebral ischemia and hypoperfusion models. Neuroscience. 155, 937-947, 2008.

Kalloniatis, M.; Tomisich, G. Amino acid neurochemistry of the vertebrate retina. Progress in Retinal and Eye Research. 18 (6), 811-866, 1999.

Katsuki, H.; Watanabe, Y.; Fujimoto, S.; Kume T.; Akaike, A. Contribution of endogenous glycine and D-serine to excitotoxic and ischemic cell death in rat cerebrocortical slice cultures. Life Sciences 81, 740-749, 2007. 
Kawaguchi, M.; Furuya, H.; Patel, P. M. Neuroprotective effects of anesthetic agents. J. Anesth. 19, 150-150, 2005

Kvist, T.; Christiansen, B.; Jensen, A. A.;Bräuner-Osborne, H. The four human gamma-aminobutyric acid (GABA transporters:pharmacological characterization and validation of a highly efficient screening assay. Comb Chem High Throughput Screen. 12(3), 241-9, 2009.

Levi, H. W. Spiders of the orb-weaver genus Parawixia in America (Aranea:Araneidae). Bull. Mus. Comp. Zool. 153, 1-46, 1992.

Li, Y.; Lei, Z.; Xu, Z. C. Enhancement of inhibitory synaptic transmission in large aspiny neurons after transient cerebral ischemia. Neuroscience. 159, 670-681, 2009.

Li, Y.; Blanco, G. D.; Lei, Z.; Xu, Z. C. Increased GAD expression in the striatum after transient cerebral ischemia. Molecular and Cellular Neuroscience. 45, 370-377, 2010.

Liberato, J. L.; Cunha, A. O. S.; Mortari, M. R.; Gelfuso, E. A.; Beleboni, R. O.; Coutinho-Netto, J.; Santos, W. F. Anticonvulsant and Anxiolytic activity of FrPbAII, a novel GABA uptake inhibitor isolated from the venom of the social spider Parawixia bistriata (Araneidae: Araneae). Brain Res. 1124, 19-27, 2006.

Lilley, S.; Robbins, J. The rat retinal ganglion cell in culture: an accessible CNS neurone. Journal of Pharmacological and Toxicological Methods. 51, 209-220, 2005.

Lin, Y.; Tian, G.; Roman, K.; Handy, C.; Travers, J. B.; Lin, C. G.; Stephens, R. L. S. Increased glial glutamate transporter EAAT2 expression reduces visceral nociceptive response in mice Am. J. Physiol. Gastrointest Liver Physiol. 296, G129G134, 2008. 
Lipton, P. Ischemic Cell Death in brain neurons Physiol. Rev.79, 1431-1568, 1999.

Lipton, S. A. Retinal ganglion cells, glaucomaand neuroprotection. Progress in Brain Research. 131, 713-718, 2001.

Louzada-Jr, P.; Dias, J. J.; Santos, W. F.; Lachat, J. J.; Bradford, H. F. ; Coutinho-Netto, J. Glutamate release in experimental ischemia of the retina. An approach using microdialysis. J. Neurochem. 59, 358-363, 1992.

Lyden, P. D.; Hedges, B. Protective effect of synaptic inhibition during cerebral ischemia in rats and rabbits. Stroke.23, 1463-1469, 1992.

Machado, Angelo. B. M.Neuroanatomia funcional. 2aed. São Paulo: Ed. Atheneu, 2000.

Maragakis, N. J.; Rothstein, J. D. Glutamate transporters in neurologic disease.Arch. Neurol. 58, 365- 370, 2001.

Martinez, G.; Musumeci, G.; Loreto, C.; Carnazza, M.L.Immunohistochemical changes in vulnerable rat brain regions afterreversible global brain ischaemia. J Mol Hist. 38, 295-302, 2007.

Marty, A.; Llano, I. Modulation of inhibitory synapses in the mammalian brain. Current Opinion in Neurobiology 5, 335-341, 1995.

Meldrum, B. S. Glutamate as a neurotransmitter in the brain: review of physiology and pathology. Journal of Nutrition. 130, 1007S-1015S, 2000.

Mohammadi, B.; Krampfl, K.; Moschref, H.; Dengler, R.; Bufler, J. Interaction of the neuroprotective drug riluzole with GABA and glycine receptor channels. European Journal of Pharmacology 415, 135-140, 2001. 
Mortari, M. R.; Cunha, A. O. S.; Ferreira, L. B., \& Santos, W. F. Neurotoxins from invertebrates as anticonvulsants: from basic research to therapeutic application. Pharmacol \& Ther. 114, 171-183, 2007.

Nakanishi, S. Molecular diversity of glutamate receptors and implications for brain function. Science. 258, 597-603, 1992.

Osborne, N. N.; Casson, R. J.; Wood, J. P. M.; Chidlow, G.; Graham, M.; Melena, J. Retinal ischaemia: mechanisms of damage and potential therapeutic strategies. Ret. And Eye Res. 23, 91-147, 2004.

Osborne, N. N. Recent clinical findings with memantine should not mean that the idea of neuroprotection in glaucoma is abandoned. Acta Ophthalmol. 87, 450-454, 2009.

Ozawa, S.; Kamiya, H.; Tsuzuki, K. Glutamate receptors in the mammalian central nervous system. Progress in Neurobiology. 54, 581- 618, 1998.

Pellegrini-Giampietro D.E.; Gorter, J. A.; Bennett, M.V.; Zukin, R.S. The GluR2 (GluR-B) hypothesis: $\mathrm{Ca}(2+)$-permeable AMPA receptors in neurological disorders.Trends Neurosci.20 (10):464-70, 1997.

Pereira, A. C; Cunha, A. O. S; Mortari, M. R.; Fachim, H. A.; Lopes, N. P.; dos Santos, W. F. dos. Neuropharmacological profile of Parawixin 11, purified from Parawixia bistriata spider venom (Araneae, Araneidae), in Wistar rats (artigo em preparaçãoa).

Pereira, A. C.; fachim, H. A.; Cunha, A. O. S.; Mortaria, M. R.; Rosa, M. L. M. N. Lopes, N. P. Santos, W. F. Neuroprotective, anticonvulsant and mnemonics effects of Parawixin 11, purified from Parawixia bistriata spider venom (Araneae, Araneidae), in Wistar rats submitted to status epilepticus by pilocarpina (artigo em preparação ${ }_{b}$ ). 
Pinheiro, A. C. N.; Silva, A. J.; Prado, M. A. M.; Cordeiro, M. N.; Richardson, M.; Batista, M. C.; Castro Júnior, C. J.; Massensini, A. R.; Guatimosim, C.; RomanoSilva, M. A.; Kushmerick, C.; Gomez, M. V. Phoneutria spider toxins block ischemiainduced glutamate release, neuronal death, and loss of neurotransmission in hippocampus. Hippocampus 19, 1123-1129, 2009.

Pow. D. V.; Barnett, N. L. Developmental expression of excitatory amino acid transporter 5: a photoreceptor and bipolar cell glutamate transporter in rat retina. Neuroscience Letters. 280, 21-24, 2000.

Pow, D. V. Amino acids and their transporters in the retina. Neurochem Int 39(3), 261-5, 2001.

Pratt, J.; Rataud, J.; Bardot, F.; Roux, M.; Blanchard, J. C.; Laduron A, P. M.; Stutzmann, J. M. Neuroprotective actions of riluzole in rodent models of global and focal cerebral ischaemia. Neuroscience Letters, 140, 225-230, 1992.

Rash, L. D.; Hodgson, W. C. Pharmacology and biochemistry of spider venoms. Toxicon 40, 225-254, 2002.

Rauen, T.; Taylor, W. R.; Kuhlbrodt, K.; Wiessner, M. High- affinity glutamate transporters in the rat retina: a major role of the glial glutamate transporter GLAST- 1 in transmitter clearance. Cell Tissue Research. 291, 19-31, 1998

Rodrigues, M. C. A.; Guizzo, R..; Santos, W. F.; GarciaCairasco,N.Acomparative neuroethological study of limbic seizures induced by Parawixia bistriata and kainic acid injections in rats. Brain Research Bulletin 55(1), 79-86, 2001.

Rodrigues, M. A. C.; Guizzo, R.; Gobbo-Neto, L.; Ward, R. J.; Lopes, N. P.; Santos, W. F. The biological activity in mammals and insects of the nucleosidic fraction from the spider Parawixia bistriata. Toxicon 43, 375-383, 2004. 
Schumed, L. C. Stowers, C. C. Scallet, A. C. Xu, L. Fluoro-Jade C results in ultra high resolution and contrast labeling of degenerating neurons. Brain Research. 1035 (1), 24-31, 2005.

Shepherd, G. M. The synaptic organization of the brain. Oxford University Press. 1974. Cap. 6 p. 217- 269.

Shleper, M.; Kartvelishvily, E.; Wolosker, H. D-serine is the dominant endogenous coagonist for NMDA receptor neurotoxicity in organotypic hippocampal slices. The Journal of Neuroscience 25(41), 9413-9417, 2005.

Simão, F.; Matté, A.; Matté, C.; Soares, F. M. S.; Wyse, A. T. S.; Netto, C. A.; Salbego, C. G. Resveratrol prevents oxidative stress and inhibition of Na+K+-ATPase activityinduced by transient global cerebral ischemia in rats. Journal of Nutritional Biochemistry 22, 921-928, 2011.

Soltau, J. B.; Zimmerman, T. J. Changing paradigms in the medical treatment of glaucoma. Surv. Ophthalmol. 4,. S1- S4, 2002.

Soudijn, W.; Wijngaarden, I. V. The GABA transporter and its inhibitors. Curr Med Chem. 7(10), 1063-79, 2000.

Szabadfi, K.; Mester, L.; Reglodi, D; Kiss, P; Babai, N.; Racz, Boglarka; Kovacs, K; Szabo, A.; Tamas, A.; Gabriel, R; Atlasz, T. Novel neuroprotective strategies in ischemic retinal lesions. Int. J. Mol. Sci.11, 544-561, 2010.

Tanabe,M.; Nitta, A.; Ono, H.Neuroprotection via strychnine-sensitive glycine receptors during post-ischemic recovery of excitatory synaptic transmission in the hippocampus. J. Pharmacol. Sci. 113, 378 - 386, 2010.

Tezel, G. Oxidative stress in glaucomatous neurodegeneration: mechanisms and consequences.Progress in Retinal and Eye Research. 25, 490-513, 2006. 
Torres-Salazar, D.; Fahlke, C. Parawixin1: a spider toxin opening new avenues for glutamate transporter pharmacology. Mol Pharmacol. 72(5), 1100-1102, 2007.

Tostes, J. R. Atividade neuroprotetora do composto FrPbAII isolado da peçonhadaaranha Parawixia bistriata em ratos submetidos a um modelo deglaucoma experimental agudo. Dissertação de mestrado apresentada à Faculdade de Filosofia, Ciênciase Letras de Ribeirão Preto da Universidade de São Paulo, 2009.

Tuttolomondo, A.; Di Sciacca, R.; Di Raimondo, D.; Arnao, V.; Renda C.; Pinto, A.; Licata, G. Neuron protection as a therapeutic target in acute ischemic stroke. Curr. Top. Med. Chem. 9(14), 1317-34, 2009.

Usherwood, P. N. R.; Blagbrough, I. S. Spider toxins affecting glutamate receptors: polyamines therapeutic neurochemistry. Pharmac. Ther. 52, 245-268, 1991.

Vassilevski, A. A.; Kozlov, S. A., Grishin, E. V. Molecular diversity of spider venom. Biochemistry (Moscow). 74 (13), 1505-1534, 2009.

Vasudevan, S.K.; Gupta V.; Crowston, J.G. Neuroprotection in glaucoma. Indian J Ophthalmol 59, 102-13, 2011.

Wahl, F.; Allix, M.; Plotkine, M.; Boulu, R. G. Effect of riluzole on focal cerebral ischemia in rats. European Journal of Pharmacology. 230, 209- 214, 1993.

Wang, G. H.; Jiang, Z. L.; Fan, X. J.; Zhang, L.; Li, X.; Ke, K. F. Neuroprotective effect of taurine against focal cerebral ischemia in rats possibly mediated by activation of both GABAA and glycine receptors.Neuropharmacology 52 , 1199-1209, 2007.

Ward, M. M.; Jobling, A. I.; Puthussery, T.; Foster, L. E.; Fletcher, E. L. Localization and expression of the glutamate transporter, excitatory amino acid transporter 4, with astrocytes of rat retina. Cell Tissue Research. 315, 305-310, 2004 
Wässle, H. Parallel processing in the mammalian retina. Nature reviews Neuroscience. 5, 1-11, 2004.

Wässle, H., Heinze, L.; Ivanova, E.; Majumdar, S.; Weiss, J.; Harvey, R. J.; Haverkamp, S. Glycinergic transmission in the mammalian retina.Front Mol Neurosc.6 (2), 1-12, 2009.

Weinreb R. N. Glaucoma neuroprotection: What is it? Why is it needed? Can. J. Ophthalmol. 42, 396-398, 2007.

Yang, X. L. Characterization of receptors for glutamate and GABA in retinal neurons. Progress in Neurobiology. 73, 127-150, 2004.

Yoles, E.; Schwartz, M. Potential neuroprotective therapy for glaucomatous optic Neuropathy. Surv. Ophtalmol. 42, 367-372, 1998.

Yue, L.; Xie, A.; Bruzik, K. S; Frolund, B.; Qian, H.; Pepperberg, D. R. Potentiating action of propofol at $\mathrm{GABA}_{\mathrm{A}}$ receptors of retinal bipolar cells. Invest. Ophthalmol. Vis. Sci.November 10, 2010.

Zhang, L. H.; Gong, N.; Fei, D.; Xu, L.; Xu, T. L. Glycine uptake regulates hippocampal network activity via glycine receptor-mediated tonic inhibition. Neuropsychopharmacology 33, 701-711, 2008.

Zeevalk, G. D.; Nicklas, W. J. Activity at the GAB A transporter contributes to acute cellular swelling produced by metabolic impairment in retina. Vision Res. 37 (24), 3463-3470, 1997.

Zhu, X. M.; Ong, W. Y. Changes in GABA Transporters in the rat hippocampus after kainite- induced neuronal injury: Decrease in GAT-1 and GAT-3 but upregulation of betaine/ GABA transporter BGT-1. Journal of Neuroscience Research 77, 402-409, 2004. 